\title{
Assessment of students' motivation to use computer tools in a Web -enhanced counseling course
}

\author{
Ying-Ying Kuo \\ West Virginia University
}

Follow this and additional works at: https://researchrepository.wvu.edu/etd

\section{Recommended Citation}

Kuo, Ying-Ying, "Assessment of students' motivation to use computer tools in a Web -enhanced counseling course" (2003). Graduate Theses, Dissertations, and Problem Reports. 2509.

https://researchrepository.wvu.edu/etd/2509

This Dissertation is protected by copyright and/or related rights. It has been brought to you by the The Research Repository @ WVU with permission from the rights-holder(s). You are free to use this Dissertation in any way that is permitted by the copyright and related rights legislation that applies to your use. For other uses you must obtain permission from the rights-holder(s) directly, unless additional rights are indicated by a Creative Commons license in the record and/ or on the work itself. This Dissertation has been accepted for inclusion in WVU Graduate Theses, Dissertations, and Problem Reports collection by an authorized administrator of The Research Repository @ WVU.

For more information, please contact researchrepository@mail.wvu.edu. 


\title{
Assessment of Students' Motivation to Use Computer Tools in a Web-Enhanced Counseling Course
}

\author{
Ying-Ying Kuo
}

Dissertation submitted to the College of Human Resources and Education at West Virginia University in partial fulfillment of the requirements for the degree of

\section{Doctor of Education}

in

Technology Education

\author{
John G. Wells, Ph.D., Chair \\ Shahab D. Mohaghegh, Ph.D. \\ Neal Shambaugh, Ph.D. \\ David J. Srebalus, Ph.D. \\ Jaci L. Webb-Dempsey, Ed.D. \\ Department of Technology Education
}

\section{Morgantown, West Virginia}

2003

Keywords: assessment, career development, motivation, WBI design, web-based instructional design, web-based learning 


\begin{abstract}
Assessment of Students' Motivation to use Computer Tools in a Web-Enhanced Counseling Course
\end{abstract}

Ying-Ying Kuo

Increasing numbers of professional counseling educators recognize the importance of information technology in counselor education, but the majority of members in the counseling community still lack interest in using computer tools for their professional development. How to motivate them to acquire these necessary skills is a problem in counselor education. This study provided a motivating web-based instructional (WBI) design for a web-enhanced course and examined counseling students' motivation to use computer tools in the course. It focused on four research questions that examined

(1) how students' use of computers changed;

(2) the impact of web-based instructional (WBI) features on their motivation to learn;

(3) the relationship between their motivation to learn and learning experiences; and

(4) indicators of their adoption of computer tools.

The results of this study showed that students were motivated to learn in this webenhanced environment. Most students increased their use of computer tools, became more confident using computer tools, and had more positive attitudes regarding the use of computers. WBI features that consider learners' needs and learning outcomes can motivate students to learn to use computer tools. This study concluded that motivation to learn computer skills is a complicated matter which is related to several variables, including improved computer skills, web performance, emotion regarding computer use, and learning satisfaction. Students were more likely to continue to use computer tools in the future if they had positive experiences using computer tools. All indicators of adoption supported the belief that students were likely to adopt computer tools in the future.

This study implies that students will improve their computer skills and become motivated to continue to use computer tools in the future, if they are exposed to a learning environment similar to that in Coun 620. Students will be motivated to learn to use computer tools if they have access to a course web site that includes active hyperlinks, an organized structure, intuitive navigation, and the integration of computer tools that includes at least instructors and instructional designers is required to design a course that features a motivating WBI design. Further studies should seek to understand how counseling students can be convinced to become competent computer users through the use of a WBI environment. 


\section{DEDICATION}

I would like to dedicate this dissertation to my parents, Ying-Po Kuo and Hsu-Shya Hung Kuo. They recognized the value of education and always supported my efforts. They encouraged me to study hard and to explore what interested me.

I also dedicate this dissertation to my beloved family: my husband Shih-Houng Young, Ph.D., my son Tso-Hsuan, and my daughter Pei-Chen. It would have been impossible to finish this project without their support, understanding, and love. 


\section{ACKNOWLEDGEMENTS}

The process of writing this dissertation would have been impossible without the guidance and support of my doctoral committee members, my course professors, all my friends and coworkers in the Teaching and Learning Technologies Center.

First of all, I would like to sincerely thank the members of my doctoral committee. I especially want to thank my advisor, Dr. John Wells, for his guidance, advice, support, and encouragement. With his teaching and guidance, I became a more competent researcher step by step. Despite his busy schedule, he always supported me whenever I needed his advice. He patiently guided my work and helped me organize my writing. He introduced me to a writing style that has helped me present my research without confusing and boring my readers.

All of my committee members were very helpful and contributed their knowledge and experience to my dissertation. I appreciate the help of Dr. Shahab Mohaghegh, a pioneer in web-based education, who allowed me to observe his wonderful E-2 course-a fully webbased course for engineering students at WVU. Because of his generous support, I was exposed to the culture of Internet learning and chose web-based learning research as the foundation of my dissertation. Dr. David Srebalus has kindly and unconditionally shared his course, Coun 620, with me so I was able to implement a WBI design for a course project and for my dissertation research. He was extremely supportive of my work; if he had not been willing to collaborate, if he had not been as generous and open-minded, this dissertation would not have been possible. Dr. Webb-Dempsey introduced me to the value of the qualitative method so I could investigate motivation in depth. With her warm and experienced guidance, she helped me refine my focus on Internet-based learning as the 
groundwork of my dissertation. Dr. Shambaugh is such an enthusiastic professor of instructional design! He introduced me to the importance of creating personal instructional design sequences and models and made the process of instructional design a joy.

I want to thank the professors of all the courses I have taken at West Virginia University. Dr. Edward Pytlik opened the door of technology for me. Dr. David McCrory initialized my interest in the adoption of technology in different disciplines. Dr. George Maughan gave me new perspectives on technology. In the first semester of my doctoral program he told me that, "I will be surprised if you would not change the knowledge of technology when you graduate." Dr. Andrew Katayama re-started my interest in research, which had been buried for a long time. Dr. Carol Parke systematically introduced statistics to her class, which helped refresh my knowledge of statistics that played such a crucial role in my dissertation. She also helped solidify my interest in assessment development. I am always grateful for her interest in my research and for encouraging me to publish my work. Dr. William Deaton, a professional researcher in assessment development, widened my interest in multivariate statistics. He also very patiently ensured that the data analysis of my dissertation and guided me to correct the format of my data tables. Without the guidance, support, and encouragement of these professors it would not have been possible for me to implement my dissertation research.

I would also like to show my appreciation to all my friends and professionals who have supported my work. Mr. Alex Lubman, a close friend of my family, has worked with me to improve my writing. He has taught me American idioms, answered whatever questions I had, and proofread almost all my course handouts since 2001 . He has worked patiently with me to ensure that my ideas were expressed accurately. Without his help my dissertation would not 
be as readable. Dr. Paul Pedersen, my advisor in the Counseling Program at the University of Alabama at Birmingham, has been very supportive and encouraging, so I have been able to keep the dream of integrating technology into counseling. He always provided me with valuable resources related to the application of technology in counseling and the impact of technology on society. With his help, I was able to finish the literature review of the impact of technology on society. Ms. Nancy Dorset, my conversation partner, has shared my burden, stress, and the happiness of my study. She shared philosophy of technologies with me when I could hardly understand what I was reading. The road of study was not so lonely because we could support each other via chatting or emailing.

Many more friends have generously shared their time with me during the period of my doctoral study. Ms. Carol Spiroff has helped solve my problems whenever I had questions about the program. Dr. Francis Murage and Ms. Anna Casanova were kind enough to share their experiences and knowledge with me when I was a novice in the program preparing to take my competency examination. I have been so lucky to work in the Teaching and Learning Technologies Center, which directly and indirectly contributed to my dissertation work. My director, Mr. Tim Mitchem and all my coworkers (Dr. Francis Murage, Mr. Rodolfo Argueta, Mr. Abrar Khan, Mr. Santhosh Balla, Ms. Karla Assis, Ms. Smiti Bhattacharya, and others) helped me improve my computer skills, introduced me to new technologies, and provided an opportunity to hone my skills. As a Graduate Assistant in the TLTC, I have become more confident using computer technology and communicating with and helping others. The technologies and techniques I learned there have helped me conduct my dissertation research efficiently. 
As I reflect back on my study of Technology Education at West Virginia University, I cannot imagine how I could have achieved my Educational Doctor Degree without the support and encouragement of these professors and friends. I want to tell you all that I have thoroughly enjoyed my dissertation research because of your unconditional support and guidance. I sincerely deliver my appreciation to each of you. 


\section{TABLE OF CONTENTS}

ABSTRACT

DEDICATION

iii

ACKNOWLEDGEMENTS ----10

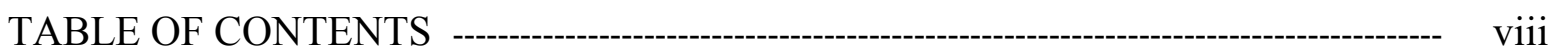

LIST OF TABLES ----_-

LIST OF FIGURES -

CHAPTER 1: INTRODUCTION- 1

Problem Statement - -

Technical Competence in Counselor Education ---on 3

Resistance to the use of computer tools ---_on 4

The adoption of technology in counselor education ------------------------------- 4

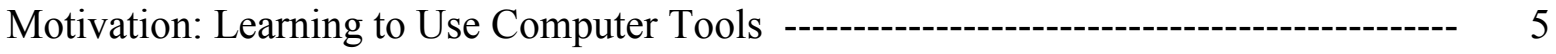

Motivation in Instructional Design --_-

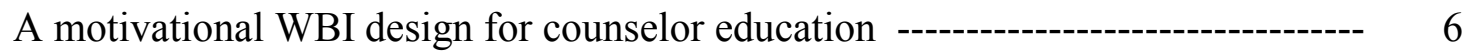

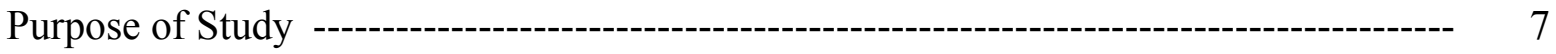

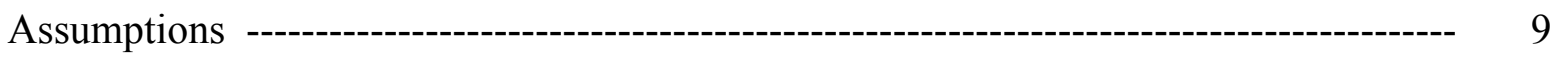

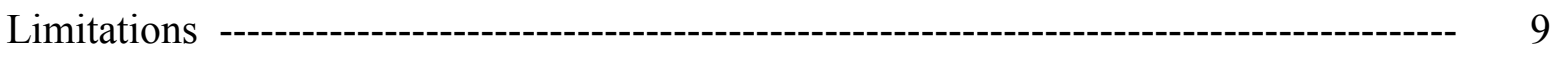

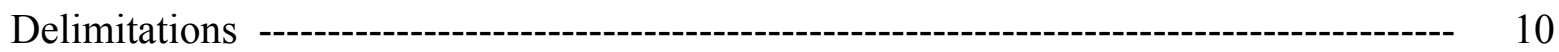

Definition of Terms ----_-_- 11

CHATPER 2: LITERATURE REVIEW -

The Changes in Society at the Information Age - 13

The Changes in Workforce ---_-_- 13 


\section{TABLE OF CONTENTS (Continued)}

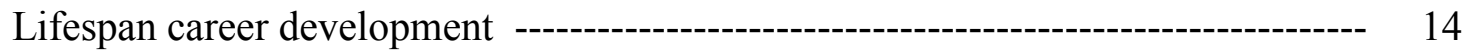

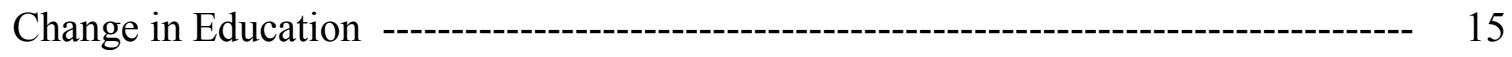

The use of Internet technology in education ------------------------------------------ 15

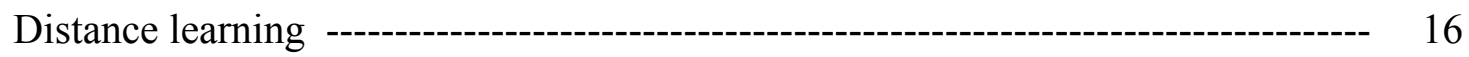

Mental Health Concerns

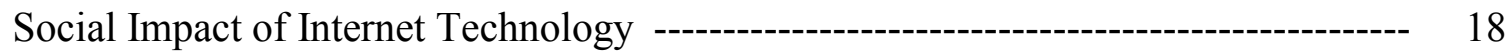

Social involvement and psychological well-being -------------------------------------- 18

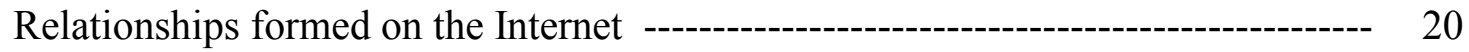

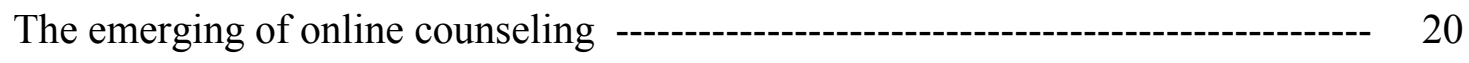

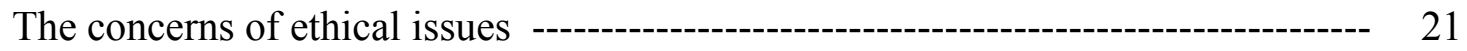

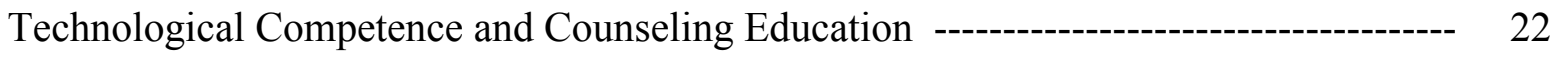

Current Status of Technological Competence in Counseling Education ---------------- 23

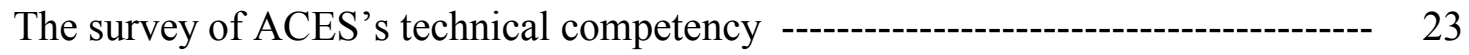

The survey of technology in CACREP counselor education programs --------------- 24

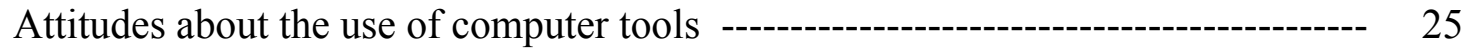

The use of Computer Technology in Counseling Education ----------------------------- 27

The integration of computer tools as a part of the curriculum ----------------------- 29

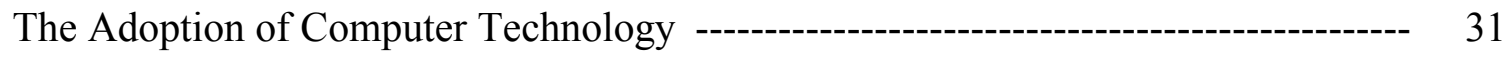

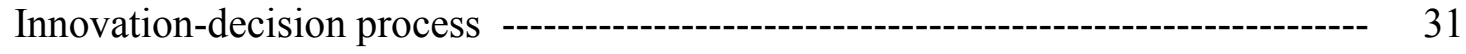

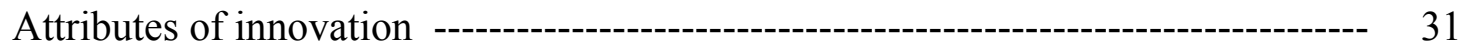

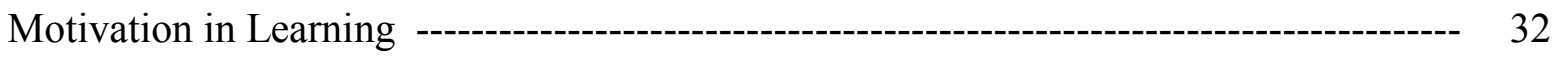

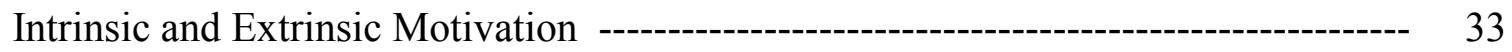




\section{TABLE OF CONTENTS (Continued)}

Motivation and Rewards - 34

Achievement and expectancy --------------------------------------------------------- 34

Confidence in skills ----_- 34

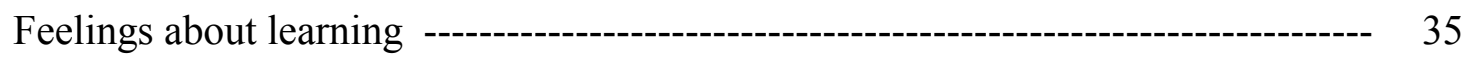

Internalization and Integration of Intrinsic Motivation ----------------------------------- 35

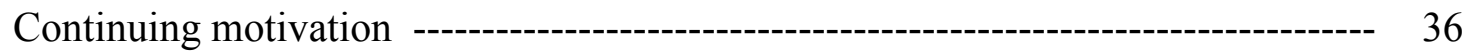

Motivation in Instruction Design --_- 37

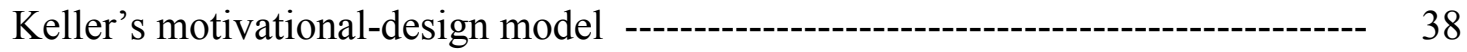

Continuing motivation to learn ---

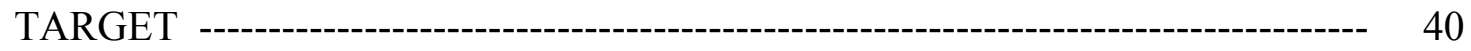

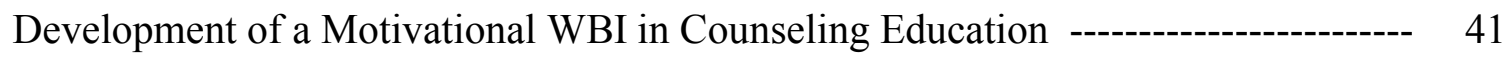

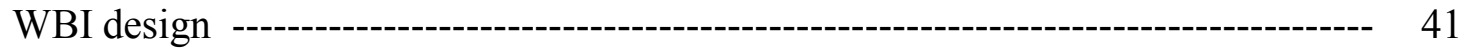

Need-related, content-related supplementary resources ------------------------------ 42

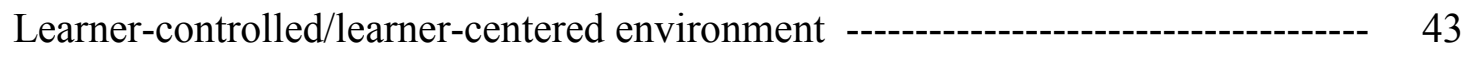

Goal-directed instructions ----------------------------------------------------------------------- 44

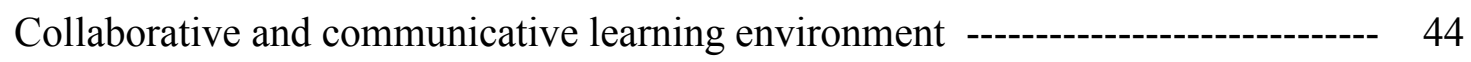

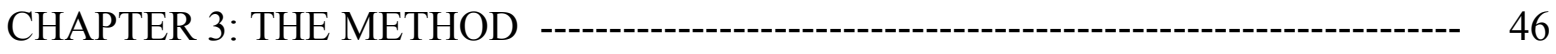

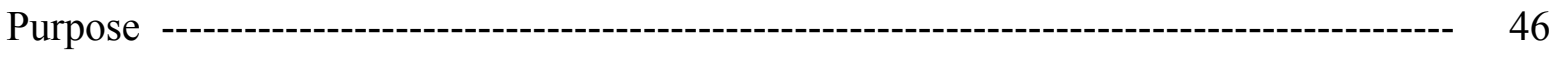

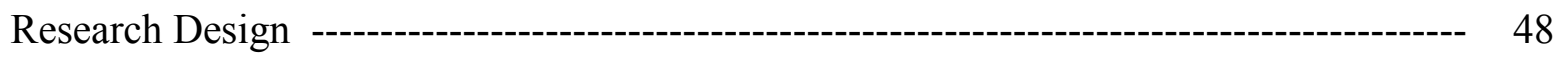

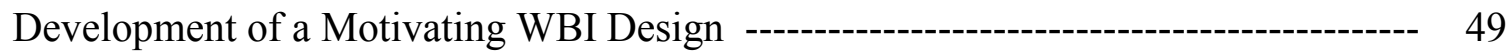

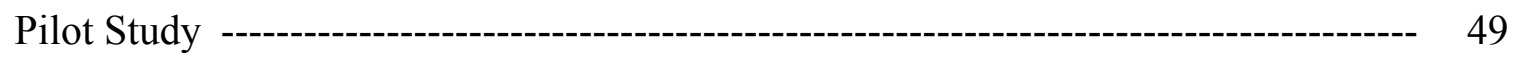

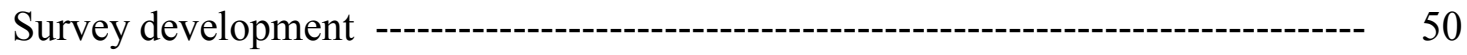




\section{TABLE OF CONTENTS (Continued)}

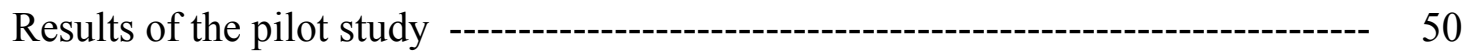

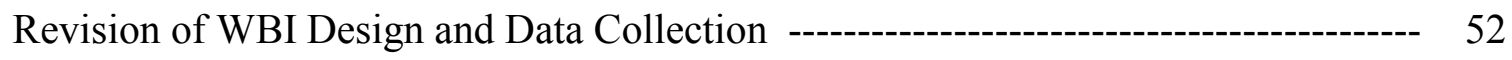

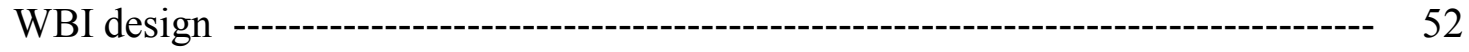

Data collection ---

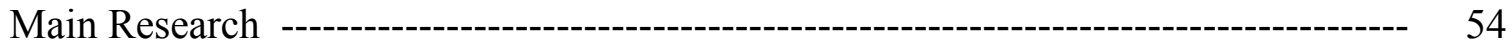

Data Collection -----

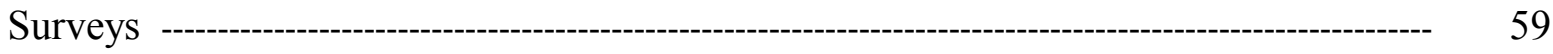

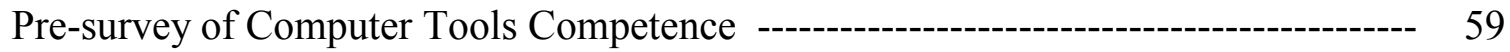

Post-survey of Computer Tools Competence -

The Survey of Emotion Level Regarding the use of Computer Tools ------------------ 62

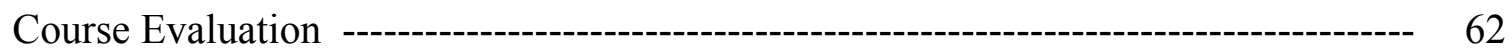

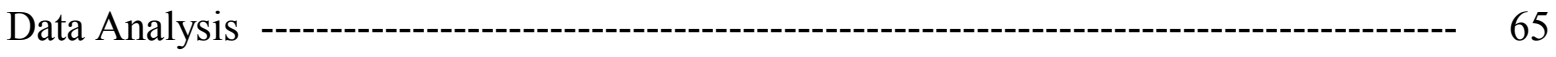

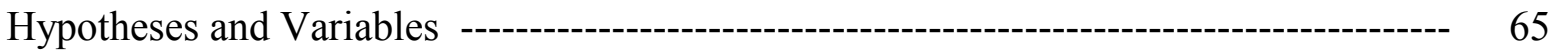

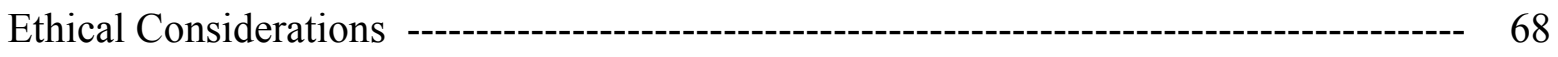

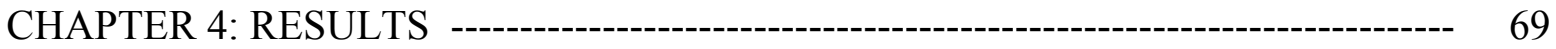

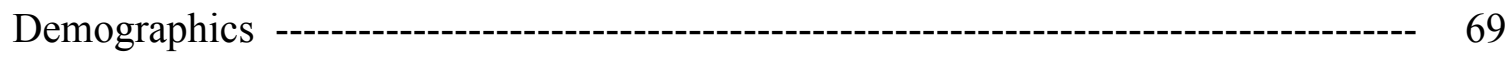

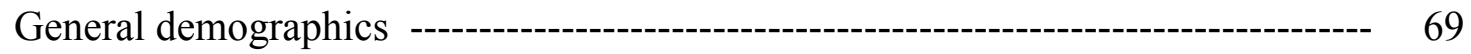

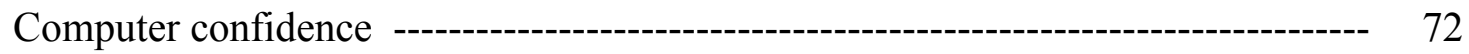

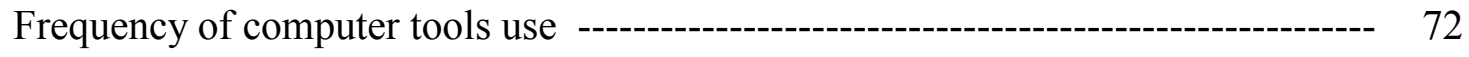

ACES's technological competencies --_-_- 73

Research Question 1: Changes in Students' Computer use ---------------------------- 73

Changes of Confidence in Computer Uses (Hypothesis 1-1) - - 


\section{TABLE OF CONTENTS (Continued)}

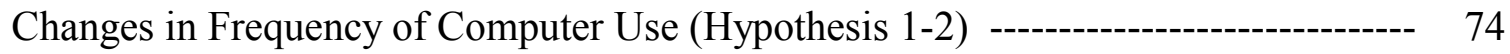

Changes in ACES's Technological Competence (Hypothesis 1-3) -------------------- 77

Changes in Emotions while using the computer (Hypothesis 1-4) ------o--o----- 79

Research Question 2: WBI Features and Motivation to Learn ------------------------------- 81

Motivation and WBI Features -----

Need-directed/content-related supplementary resources ----------------------------- 83

Learner-controlled/learner-centered environment -------------------------------------- 83

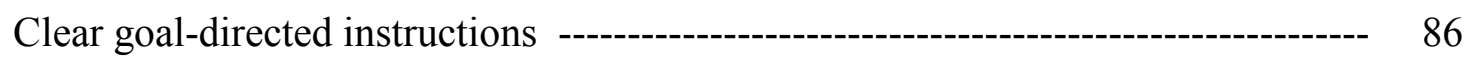

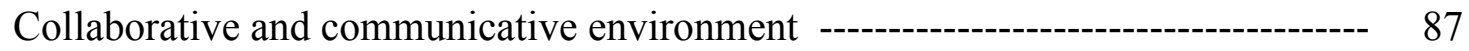

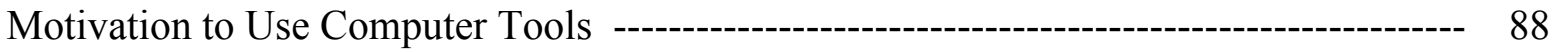

Research Question 3: Motivation and Learning Experiences ---------------------------- 91

Motivation to use computer tools --_- 91

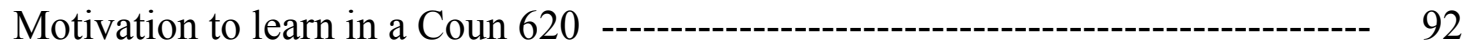

Motivation and Academic Achievement (Hypothesis 3-1) ---------------------------- 92

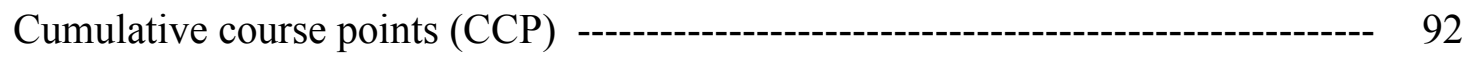

Cumulative course points for computer use (CCP_computer) --------------------- 92

Research question 3-1 ----------------------------------------------------- 93

Motivation and Computer Tools Use (Hypothesis 3-2) -------------------------------- 95

Improvement of computer skills --_-

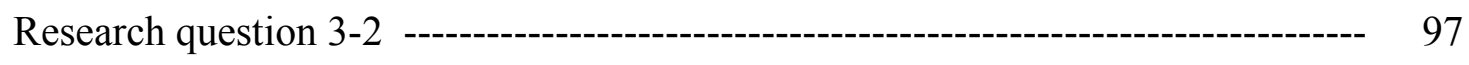

Motivation, Learning Satisfaction, and Performance of the Course Website 98

(Hypothesis 3-3) - - 


\section{TABLE OF CONTENTS (Continued)}

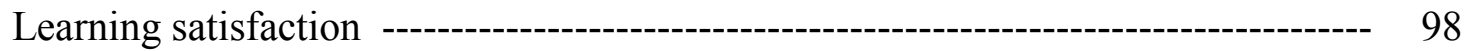

Performance of the course web site ------------------------------------------------------- 99

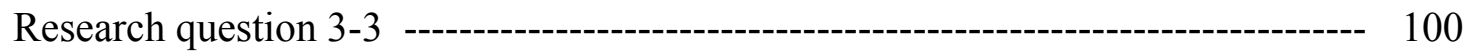

Motivation and Feelings While Using Computer Tools (Hypothesis 3-4) ------------- 101

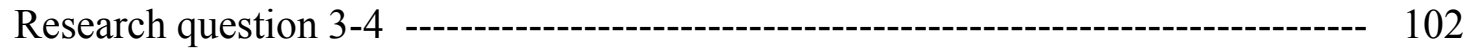

Research Question 4(RQ 4): Indicators of Changes of the Computer Use ----------------- 103

Attitude Regarding Computer Use in the Future ------------------------------------------- 103

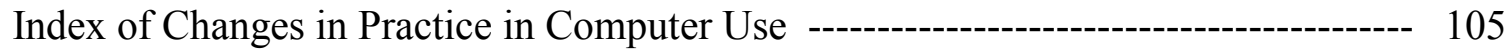

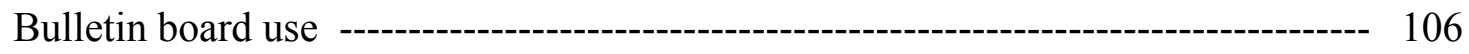

The frequency and purposes of computer use - -

CHAPTER 5: DISCUSSION AND CONCLUSION

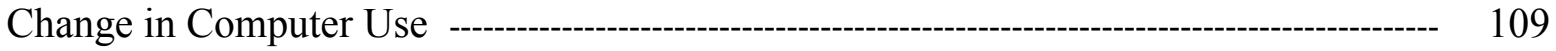

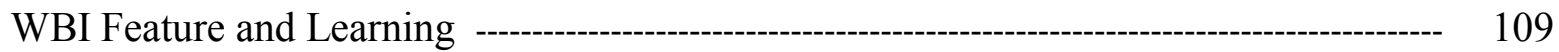

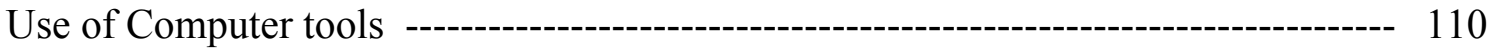

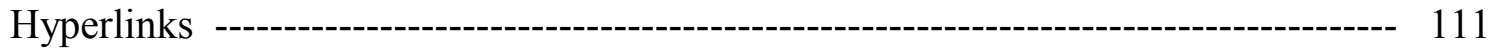

Structure and Navigation ----------------------------------------------------------------------- 111

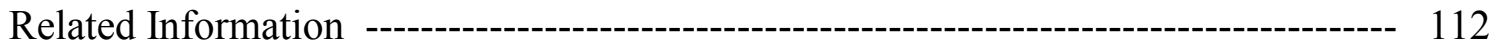

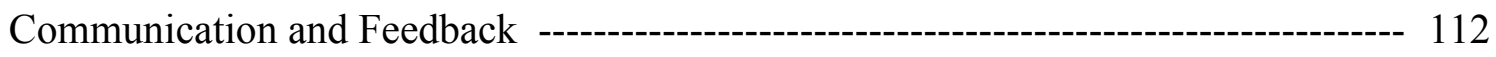

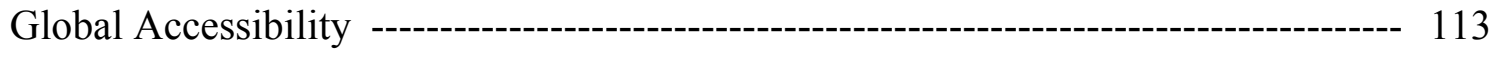

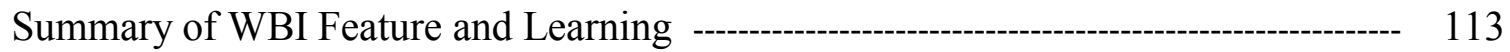

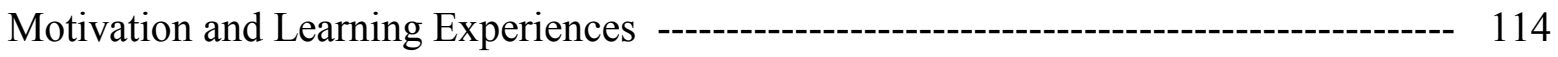

Summary of Motivation and Learning Experiences ----------------------------------------- 116 


\section{TABLE OF CONTENTS (Continued)}

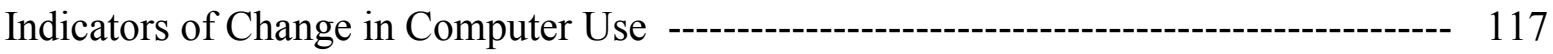

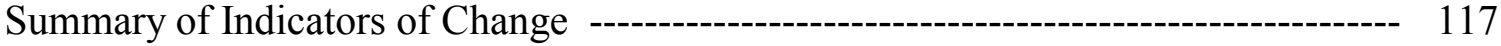

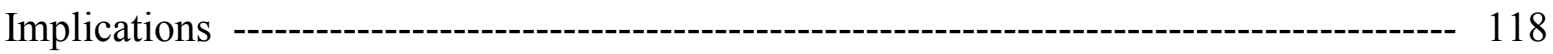

Motivation in WBI Design --_on

Team Work in WBI Design -

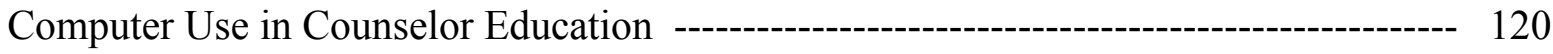

Recommendations for Further Study

Summary of the Study - -ב-_-ar

REFERENCES - -

APPENDIXES -.-_- 132

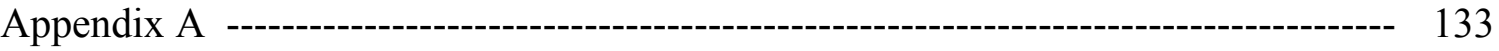

Appendix B -

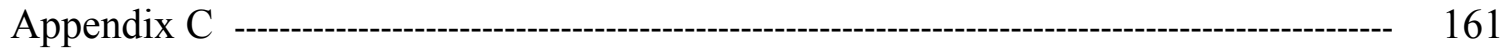

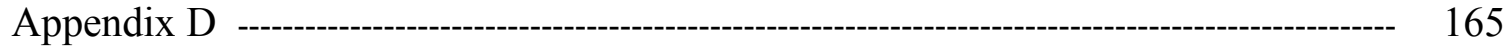

Appendix E ----on

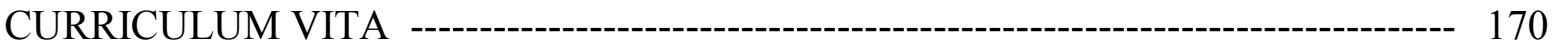




\section{LIST OF TABLES}

\section{TABLE}

2-1 Types of motivation in the self-determination continuum of the Organismic

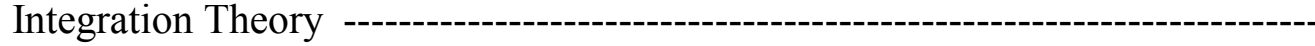

3-1 The Data Sources, Methods, and Expected Outcomes for Research Questions in this Study

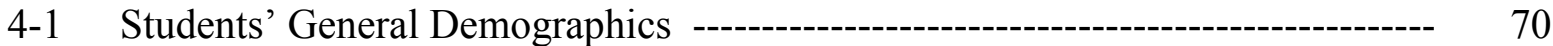

4-2 Students' Confidence Using Computer Tools - -

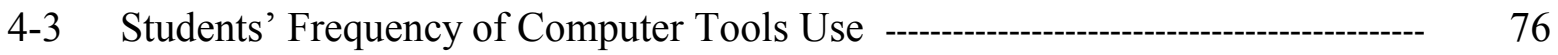

4-4 Comparison of ACES's Technological Competencies -

4-5 Change in Computer Tools use During the Semester ----------------------------- 77

4-6 Comparison of Students' Emotional Response to Computer Tools Use ---------- 81

4-7 The Computer Tools use in Assignments of Coun 620

4-8 The Relationships of Motivation and Academic Achievements ------------------ 95

4-9 Comparison of Learning Outcome Between Students who had Skill

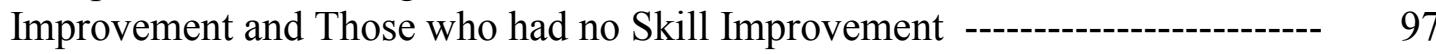

4-10 Students' Learning Satisfaction in Classroom and Web Settings ------------------ 99

4-11 Evaluation of the Performance of the Course Web Site ---:- 100

4-12 The Relationships of Motivation, Learning Satisfaction, and the Performance of Course Web Site

4-13 Differences in Motivation to Learn, Learning Satisfaction, and the Performance of Web Site Between Students who had Positive and Negative Feelings While Using Computer Tools (at the End of the Course)

4-14 Responses of the Question 5 in Students Who Had Positive and Negative Feelings about Using Computer Tools

4-15 Motivation to use Computer Tools 


\section{LIST OF TABLES (Continued)}

\section{TABLE}

A-1 Two Phases and six Stages of a web-based Instructional Design Model ----------- 


\section{LIST OF FIGURES}

\section{FIGURE}

1. Web-based Instructional Design Model: Building a house ----------------------- 134

2. The Site Structure for the Revision of Coun 620

3. The Site Map of Coun 620 ------------------------------------------------------------- 140

4. The Web Page of Syllabus in Coun 620

5. The Activity Page -

6. The Downloading Links Provided on the "Before You Start" Page ------------ 143

7. Web-based Practice Quiz for Guided Study ------------------------------------------- 144

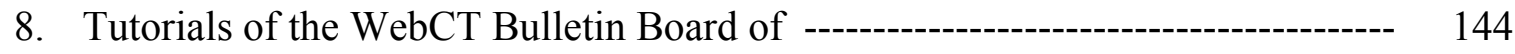

9. The Web Page of Resources in Coun 620 ------------------------------------------- 145

10. The Resources Web Page for Career Exploration ------------------------------ 146

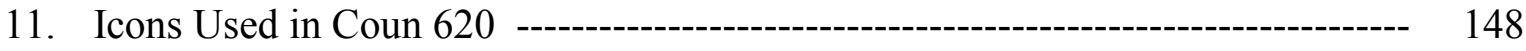

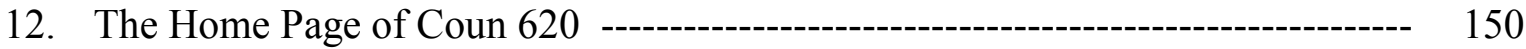

13. An Example of the Page Layout (Syllabus Page) of the Coun 620 Website ----- 150

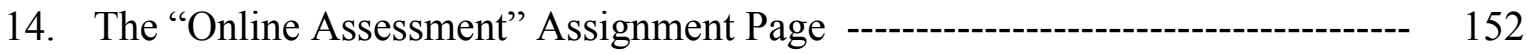




\section{Chapter 1: Introduction}

The use of the Internet and the World Wide Web are widespread, adopted increasingly by governments, businesses, and individuals since 1980 (NSF, 2000). Many new technological advances have changed society immeasurably throughout the $20^{\text {th }}$ century; the impact of the Internet on society in this past two decades is surely among the most significant. Like it or not, people have had to accept that rapid, unpredictable changes are part of life in the Information Age.

Americans can no longer expect to stay in one job forever (NCDA, 2000). As jobs that do not require technical skills become obsolete and are replaced with jobs requiring highly technical skills, people expect more training and education to keep up with the development

of technology (NCDA, 2000). In the $20^{\text {th }}$ century, the needs of education have extended from K-12, higher education (DOL, 2001), to even continuing education. The impact of Internet technology on education has significantly changed from the traditional teacher-centered, localized learning environment, to an open, global, user-centered, network-based learning environment. Schools have increased Internet connections and the use of computer tools (NCES, 2001). With the use of Internet technology distance education has expanded, which encourages people to pursue lifelong learning (NSF, 2000).

However, this powerful new technology has also created new sources of stress. Even though technological advances have extended the lifespan and lead to fewer and less severe illnesses, people have dealt with the changes in their lives. Faced with the changes of society in the last four decades, increasing numbers of Americans reported that they felt they were going to have a "nervous breakdown" (Swindle, Heller, Pescosolido, \& Kikuzawa, 2000). 
Many studies have reported about the social impact of the Internet on interpersonal communication among friends, family, and community members, and the influence on people's behaviors and psychological statuses (Kraut, Lundmark, Patterson, Kiesler, Mukopadhyay, \& Scherlis, 1998; Kraut, Kiesler, Boneva, Cummings, Helgeson, \& Crawford, 2002; McKenna, Green, \& Gleason, 2002). However, the overall impact of Internet technology still is not clear yet.

The impact of the Internet on the areas of health care and counseling has been reported. The attraction of easy access and the low cost of mental health information and online counseling services have resulted in a proliferation of counseling services on the Internet (Powell, 1998; Sussman, 1998). As a result of the rapid spread of online counseling and mental health services, professional associations (e.g. the National Board for Certified Counselors, NBCC; the American Counseling Association, ACA; American Psychology Association, APA) have defined and revised the standards for counseling practice on the Internet (NBCC, 2001; ACA, 1999; APA, 1997). Likewise, the National Career Development Association (NCDA) has adopted guidelines for career counseling on the Internet. In addition, professional counseling educators have paid more attention to the ethical concerns of the use of technology on counseling services, such as confidentiality, the validity of online assessments, the authenticity of the online counseling relationship, the quality and effectiveness of counseling delivery, and the credentials of counselors (Sampson, Kolodinsky, \& Greeno, 1997).

\section{Problem Statement}

Professional counseling educators recognize the importance of information technology (computer software, Internet-based software) in counseling preparation and professional 
development (McFadden, 2000; Sampson, Kolodinsky, \& Greeno, 1997), but the majority of counselors-in-training and professional counselors do not take advantage of new technologies (Berry, 2002; Mayers \& Gibson, 1999; Owen \& Dean, 1999; Quinn, Hohenshil, \& Fortune, 2002). There is a gap between their recognition of the importance of computer tools in counseling and their implementation of these tools (Cabaniss, 2002; Quinn, Hohenshil, \& Fortune, 2002). Since counselors-in-training and professional counselors lack interest in using computer tools, how they can be motivated to acquire the necessary skills is a problem currently facing the field of counselor education.

\section{Technical Competence in Counselor Education}

The Association for Counselor Education and Supervision (ACES) has recognized the importance of competence in using computer tools in counseling. It has identified 12 technical competencies as recommended guidelines for program development in counselor education (ACES, 1999a). The Council for Accreditation of Counseling and Related Educational Programs (CACREP) has determined that technological competence and computer literacy for counseling students and counselors should be integral parts of counseling programs in the 2001 standards of CACREP (CACREP, 2001). A survey

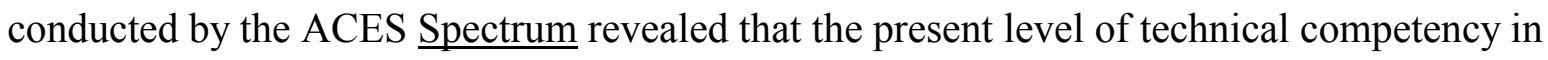
counseling students and counselors is not uniform across the 12 competencies (Mayers \& Gibson, 1999). Quinn, Hohenshil, and Fortune (2002) report that computer technology is slowly being integrated into the curriculum of CACREP counselor education programs, though counselor educators were not convinced of the effectiveness of computer tools in course delivery (Quinn, Hohenshil, \& Fortune, 2002). 
Resistance to the use of computer tools. Traditional counseling services depend on personal contact and communication, not the use of technology. In fact, increased use of computer technology in counseling areas did not occur until the 1990s (Lunberg, 2000). An increasing number of college courses have incorporated e-mail, Internet resources, Webbased teaching, and so forth since 1994 (NCES, 2001); unfortunately, there is little specific information regarding the use of information technology in counselor education. Since it has not traditionally been an important feature of the counseling curriculum, counseling students and professors have not put effort toward enhancing the technological competencies in counselor education. In addition, the concerns of the ethical issues of using these new tools in counseling services make counselor educators, counselors-in-training and professional counselors not want to adopt computer tools in a rush (ACA, 1999; ACES, 1999a; APA, 1997; NBCC, 1998; Sampson, Kolodinsky, \& Greeno, 1997).

The adoption of technology in counselor education. According to Rogers' theory of innovation-decision process (1995), to become technically competent counselors-in-training and professional counselors have to experience the process of adoption. The American Counseling Association has applied some Internet technologies (email, e-publishing) for counselor education, such as ACA eNews (http://www.counseling.org/enews) and CTOnline (http://www.counseling.org/ctonline). Many counselor educators and researchers advocate to adopt computer tools throughout counseling education to help counseling students learn the value of using computer technology (Hines, 2002; McFadden, 2000; Quinn, Hohenshil, \& Fortune, 2002). A new online journal, the Journal of Technology in Counseling (http://jtc.colstate.edu/), appeared in 1999, which provides counselor educators, counselors- 
in-training, and professional counselors with information regarding the integration of technology in the teaching and practice of counseling.

Counselor educators have started to integrate computer technology into teaching and learning; however, progress has been slow and the situation has not significantly changed (Chandras, 2000; McFadden, 2000; Quinn, Hohenshil, \& Fortune, 2002). As more individual counseling professors have advocated integrating computer technology into counselor education, they have focused on their own purposes, such as teaching at a distance (Jones \& Karper, 2000; Woodford, Rokutani, Gressard, \& Berg, 2000), off-site supervision (Getz \& Schnuman-Crook, 2000), or cultural competency (Ancis, 1998). To become technological competent, counselors-in-training and professional counselors have to learn to use computer technology during their counselor education and training. For example, the Indiana State University (ISU) School Counselor Program has started to require counseling students to develop technology competence during their two-year masters degree program (Hines, 2002). It requires students to build up basic technology skills and defines 10 competencies resulting in the School Counseling Program Technology Proficiencies. Hines (2002) reports that students became ambitious computer use and understood the importance of technology proficiency in this program. McFadden (2000) advocates that counselor educators have to examine computer use in both instructional design and counseling services.

\section{Motivation: Learning to Use Computer Tools}

Counselors-in-training and counselors realize that computer tools are essential for their learning and practice. They can use computer tools to learn at a distance, to have continuing education and training for certification, and to provide effective counseling services at a distance. However, it has been difficult to persuade them to use computer tools (Cabaniss, 
2002). Their ability to use technology is limited to a few areas (Berry, 2002; Mayers \& Gibson, 1999;). The motivation for counselors-in-training and professional counselors to use computer tools has to begin with counselor education (Hines, 2002; McFadden, 2000; Quinn, Hohenshil, \& Fortune, 2002). They need to be encouraged to use computer tools via a motivational environment—-by using an appropriate instructional design integrating computer tools into counselor education.

\section{Motivation in Instructional Design}

Instructional design is the process that arranges methods of instruction for achieving specific teaching purposes for a specific population of students (Reigeluth, 1983). Instructional design is concerned with optimizing the process of needs analysis, task/user analysis, structure design, implementation, evaluation, and feedback (Brown, 1997; Driscoll, 2002). According to motivation theories, people are motivated to learn in order to achieve their goals, either for extrinsic reward (e.g. earning credits, getting good grades or gaining abilities) or for their own sake (e.g. interests, curiosity) (Bandura, 1977; Deci, 1975; Maehr, 1976; Pintrich \& Schunk, 2002; Ryan \& Deci, 2000). The motivation to learn can be enhanced in an appropriate environment (Maehr \& Midgley, 1991). Since an instructional design does not automatically motivate people to learn, it has to be developed by adding motivating features (Keller, 1983; Kinzie, 1986; Maehr \& Midgley, 1991).

A motivational WBI design for counselor education. In order to encourage counseling students to use computer tools, a web-enhanced course with motivational features is necessary. A web-based instructional (WBI) design provides a learning environment, which uses the Web as the medium to facilitate learning (Khan, 1997). A motivational WBI design allows counseling students to learn to use computer tools and practice their computer skills 
so they may become self-sufficient in the use of computer tools. It can provide a positive experience with computer tools that help them reach their learning goals, feel satisfied with their learning, and increase their ability to use computer tools (Bandura, 1977; Csikszentmihalyi, 1988; Keller, 1983). As their ability to use computer tools increase and they feel positive about their learning, they may be persuaded to adopt computer tools and continuously motivated to use them (Maehr, 1976; Rogers, 1995).

The features of a web-based instructional design with the integration of computer tools, such as learner-centered (learner-controlled) (Jonassen, 1993; Lundberg, 2000; Maehr \& Midgley, 1991; McCombs, 1996), clear goal-directed instruction (Archer \& Scevak, 1998; Kinzie, 1986; Maehr \& Midgley, 1991), related-resources provided (Sampson, et. al., 2002; Brown, 1997), collaborative learning activities (Dewey, 1938; Visser, Plomp, \& Kuiper, 1999; Woodford, et. al., 2000) and technological support (Ancis, 1998; McFadden, 2000) may facilitate students to develop and enhance their motivation to use computer tools.

\section{Purpose of Study}

The purpose of this study is to investigate counseling students' motivation to use computer tools via a web-enhanced counseling course. This study was conducted in a webenhanced counseling course to investigate the relationships of students' motivation to use computer tools and the features of the motivational WBI design, by exploring four main questions:

I. What changes in computer tools use occurred in students at the end of the course?

(1) How did students' confidence about using computer tools change?

(2) How did students change using the computer tools in frequency?

(3) How did students become aware of the ACES technology competencies? 
(4) How did students' feelings about using computers change?

II. What were the relationships between the features of web-based instructional design and students' motivation to use computer tools?

(1) What features of web-based instructional design motivated students to use computer tools?

(2) What features of web-based instructional design discouraged students from using computer tools?

III. How were a students' learning experiences in a web-enhanced course related to his/her motivation to use computer tools?

(1) What was the relationship between motivation and academic achievement?

(2) What was the relationship between motivation and computer tools use (in terms of confidence, improved skills, and increased computer use)?

(3) What was the relationship between motivation, learning satisfaction, and the performance of course web site?

(4) What was the relationship between motivation and feelings regarding using computer tools?

IV. How did students change computer use when they were motivated to use computer tools?

(1) What were students' attitudes about computer use in the future?

(2) What indicators of changes in practice occurred in students during the course?

The sequence of this research included:

(1) defining the problems of computer competence in counselor education,

(2) reviewing literature, 
(3) constructing and implementing a motivational WBI design in a counseling course,

(4) conducting a pilot study to test the WBI design,

(5) revising the motivational WBI design and the methods of data collection,

(6) conducting a main research to investigate the relationships of students' motivation to learn computer tools and the features of a motivational WBI design via a webenhanced counseling course.

\section{Assumptions}

This study was designed with the following assumptions:

1. It assumed that WBI design has an impact on students' motivation. The WBI design was applied as an extrinsic reward for students.

2. It assumed that students' learning would be influenced by at least four main WBI features: learner-central/learner-controlled environment, need-directed supplementary resources, collaborative and communicative environment, and goal-directed instructions.

3. It assumed that there were no interrelationships among learning variables. It examined bivariate relations between one learning variable (academic grades, confidence in the ability to use a computer, learning satisfaction, emotions, etc.) and motivation.

4. It assumed that individuals would respond the same to a web-based environment. It did not consider the impact of individuals' learning traits (ability, interest, prior experience, learning strategies, etc.) on motivation in a web-based environment.

\section{Limitations}

This study investigated instructional design elements purposefully incorporated to encourage the use of computer tools in a web-enhanced counseling course. Not all counseling courses are appropriate for web-based learning. Coun 620, Lifespane Career Counseling, was 
chosen because the impact of computer use on career guidance and counseling has been obvious. Six ACES technical competencies were integrated into the web-enhanced Coun 620 because these technical competencies are important for providing career guidance and counseling services in the Information Age. The six competencies include the use of presentation software (part of ACES \#1), the use of email (ACES \#5), the search for Internet information (ACES \#8), legal and ethical codes related to Internet counseling service (ACES \#9), understanding strengths and weakness of Internet counseling services (ACES \#10), continuing education via the Internet (ACES \#11).

Evaluation of technology competency is therefore limited to the array of computer tools chosen for this study: PowerPoint, Microsoft Word (ACES \#1), email, chat room (ACES \#8, 10, 11), bulletin board (ACES \#8, 10, 11), PowerPoint, Internet search tools, web browsers, Adobe Reader (ACES \# 8, 9, 11), and audio/video software (ACES \# 8, 9, 11). Among them some tools are required to use for implementing assignments (e.g. PowerPoint, Microsoft Word, search tools, web browsers, bulletin board) and some tools just recommended to use (e.g. Adobe Reader, audio/video software, chat room).

\section{Delimitations}

In this study, the web-enhanced course is the product of a team, which includes the instructor, an instructional designer, Internet technicians, and administrators. The instructor is able to define learning goals and develop activities that use $\mathrm{CMC}$ tools; the instructional designer has developed web-based modules for providing easy navigation, learning-centered environments, technical support tutorials, and rich resources with valid hyperlinks. The technical and administrative persons will provide support in maintaining the server and the 
stability of CMC tools. All the efforts of developing this web-based enhanced course strive for the goal of enhancing students' technology competency.

\section{Definition of Terms}

Computer tools: a wide definition of information technologies, which include computer software and CMC technology.

$\mathrm{CMC}$ technology: CMC technology allows learners to interact with one another or access information over time and distance. Two modes of communication-asynchronous and synchronous - are differentiated. Asynchronous CMC tools allow people to interact with information or others, but not necessarily at the same time. Synchronous CMC tools require that participants be online at the same time.

Counselor education: According to CACREP, a qualified counselor must complete an accredited program and periodically renew certification through continuing education. CACREP programs include career counseling, college counseling, community counseling, gerontological counseling, family counseling, mental health counseling, school counseling, student affairs, and counselor education and supervision.

Information technology: according to the National Science Foundation (NSF), "information technology reflects the combination of three key technologies: digital computing, data storage, and the ability to transmit digital signals through telecommunications networks" (p.9-5).

Intrinsic motivation: Intrinsic motivation is a personal quest for competence and selfdetermination (Deci, 1975).

Intrinsic reward: Internal rewards are related to fulfilling experiences, the desire for competence, enjoyment of learning, personal interests, and curiosity. 
Extrinsic rewards: Extrinsic rewards involve incentives or rewards offered from outside of the activity itself, such as salary, promotion, money or praise, tokens, etc.

Reliability: Reliability of a survey refers to the consistency of a group of items, which intend to measure a specific characteristic, in the survey. When the measurements of a survey are consistent, accurate, and predictable, the survey is reliable.

Self-efficacy: One's convictions to perform successfully at designated levels.

Web-based instruction (WBI): A hypermedia-based instructional design using the Web as the medium to deliver information and activities to remote learners for the purposes of attaining their attention and facilitating their learning for specific learning goals.

WebCT (a Web-based set of Course Tools) was developed by the University of British Columbia. WebCT allows instructors to design their web-based activities or courses based on their needs. 
Chapter 2: Literature Review

The Changes in Society at the Information Age

The impact of information technology (e.g. telephone, television, computers) on society has been rapid and far-reaching. Since the Industrial Age, significant changes have occurred in occupational markets, economics, education, and in fact almost every aspect of life that relies on technology.

The Changes in Workforce

According to the Report on the American Workforce 2001 (DOL, 2001), the registered U.S. workforce increased from 24 million (including persons 10 years and older) to 139 million (including persons 16 years and older) between 1900 and 1999. Female participation in the labor market has grown dramatically from only $19 \%$ in 1900 to about $60 \%$ in 1999 (DOL, 2001). Occupations have also changed a great deal. At the beginning of the $20^{\text {th }}$ century, $38 \%$ of the labor market was employed in agriculture; only $3 \%$ of the labor force was involved in agriculture at the end of century. Also, goods-producing industries decreased from $31 \%$ to $19 \%$, while services industries have jumped from $31 \%$ in 1900 to $78 \%$ in 1999 .

Since the development of the Internet, the growth of the information technology industry has exploded, contributing about 29 percent of growth in the real Gross Domestic Income of the U.S. in 1998 (NSF, 2000). In 1998 Internet-based transactions amounted up to $\$ 100$ billion, and it is estimated that it will reach $\$ 1$ trillion by 2003 (NSF, 2000). The job market has an increasing demand for high-skilled computer-related jobs, such as computer scientists, computer engineers, system analysts, and computer programmers. 
Lifespan career development. People no longer expect to remain in one job for their entire life. The National Career Development Association (NCDA) conducted a national survey from June 19 to July 24, 1999. This survey asked questions about current employment status, the need for career help, sources of help in selecting, changing, or getting a job, job satisfaction, the use of career counseling, etc. The sample of 1,003 adults aged 18 or older, ( $47 \%$ male, $53 \%$ female), represented a total population of 185.2 million adults in the USA. In all, 1001 participants had been employed at some time in their lives, $659(65 \%)$ were currently employed, including 568 employed full-time and 91 part-time. Of the remainder, $3 \%$ could not find work; $9 \%$ were unemployed by choice, $2 \%$ unemployed outside home (e.g. homemaker), and 19\% were retired. This survey revealed several important facts about career development:

(1) only $10 \%$ of employed participants reported that their current job was their first job. The reasons that they gave for changing or leaving jobs included: personal choice; job elimination or reduction; their job was moved to new location; they were fired or retired.

(2) $61 \%$ of employed respondents did not expect to change jobs in the next three years; $3 \%$ of them expected to be forced to change jobs; $17 \%$ will choose to change jobs, 6 $\%$ will retire completely; $6 \%$ will retire but work part-time; $3 \%$ will be temporarily unemployed.

(3) The Internet (12\%) and computer-based career information systems (5\%) have become important career resources, though the major career resources remain newspapers/magazines/television (42\%) and friends/relatives/associates (35\%). 
(4) About 1/5 (21\%) of participants have visited a counselor or career specialist to explore their career choices. Of these, $83 \%$ felt that the counselor was helpful or somewhat helpful, while $16 \%$ said the counselor was not helpful.

(5) Over half (53\%) of ever-employed participants said they needed more training and education. Among them, younger adults were more interested in getting training and education than older adults.

This survey demonstrates the impact of Information technology on career development in the USA. People realize that they will seldom stay in the same job for their whole life so they need to get more career help and continuing education. They are aware of the need to use technology for getting more useful career information and training or education for their new career.

\section{Changes in Education}

People have taken advantage of increased educational opportunities available in the $20^{\text {th }}$ century. In 1900 less than 14\% of Americans had graduated from high school; but by 1999, $83 \%$ of Americans had at least a high school education. Also, 25\% of Americana had graduated from higher education by 1999, while less than 3\% in 1910 (DOL, 2001).

The use of Internet technology in education. Information technology has profoundly changed the ways of teaching and learning. As the World Wide Web (WWW) rapidly expanded throughout the world, $\mathrm{K}-12$ schools started to adopt it as an important teaching resource. In 1994, 35\% of public schools were connected to the Internet. By 1998, only four years later, $89 \%$ were connected (NCES, 1999) and continuously increased to $95 \%$ were connected by 1999 (NCES, 2001). The Internet connections in public schools were also upgrading. The use of dial-up connections has dropped from 74\% of public schools in 1996 
to $22 \%$ in 1998 , while increasing numbers of schools used higher-speed Internet connections, from 39\% in 1996 to $65 \%$ in 1998 (NSF, 2000).

Likewise, the percentage of college courses using email, course web sites and other Internet resources has increased rapidly. In 1998 an average of $96.7 \%$ of full-time postsecondary instructional faculty and staff accessed the Internet. Among them 69.0\% reported that they used email and $40.2 \%$ of them used web sites for teaching courses (NCES, 2001).

Distance learning. Distance education, which supports continuing education, has existed for centuries (Verduin \& Clark, 1991). More and more people take advantage of continuing education opportunities to help them meet the challenge of the changing job market. Distance education has been significantly influenced by technology. The initial form of distance learning was correspondence study, which used mailed materials (e.g. printed text, photos, audio/video). Later, via electronic media, such as radio, television, telephone, and audio/video were used for distance education. As computer technology has evolved in last few decades, information technology has been greatly integrated into distance education and it is replacing the old way in distance education (Verduin \& Clark, 1991). For example, One-way prerecorded video was used by $52 \%$ of schools in 1995 , but decreased to $48 \%$ in 1997/1998. Two-way interactive video was the most widely used by $57 \%$ of schools in 1995 , but it decreased slightly to $56 \%$ in $1997 / 1998$ (NSF, 2000).

As the needs for continuing education have increased for adult learners, the number of higher education institutions offering distance-learning courses has significantly increased. Only 33\% of 2-year and 4-year colleges offered distance education in 1995 and increased to 44\% by 1997/1998 (NSF, 2000). Also, the number of distance courses offered in 2-year and 
4-year higher education doubled from 25,730 in 1994/95 to 52,270 in 1997/98 (NSF, 2000). According to the 2001 National Survey of Information Technology in Higher Education (Campus computing project, 2001), full online course offerings increased from about $45 \%$ in 1998 to $56 \%$ in 2001 . The use of CMC tools has increased with the increase of Internet courses. In 1997/98, 60\% of institutions offered online courses integrating asynchronous CMC tools, and 19\% offered synchronous CMC tools. However, there are no comparable statistics for the use of synchronous and asynchronous CMC tools in 1995 (NCES, 1999). Mental Health Concerns.

Increasing numbers of Americans reported that they felt they were about to have a "nervous breakdown," according to a study conducted by Swindle, Heller, Pescosolido and Kikuzawa (2000) in 1996. This study was compared with other surveys administered in 1957 and 1976 to investigate the profile of the public's view of Americans' mental health. It explored whether Americans ever felt they were going to have a nervous breakdown and how they responded to the feeling. The General Social Survey was administered to 1,444 adults in 1996 and compared with two Americans View Their Mental Health surveys, which were administered in 1957 (2,460 adults) and 1976 (2,264 adults). It was found that in 1996 more Americans admitted that they had feelings about having a "nervous breakdown" than people did in 1976 and 1957 . It reported that $26 \%$ of the participants felt like they were going to have a nervous breakdown in 1996, while $21 \%$ reported an impending nervous breakdown in 1976 and $19 \%$ in 1957 . Faced with increasing feelings about having a "nervous breakdown", more participants reported that they preferred to use informal support from friends and family, combined with non-medical professionals. The percentage of people who choose to get help from non-medical professionals (e.g. psychologists, counselors, social 
workers) rose from $0.6 \%$ in 1957 to $18 \%$ in 1996 . Also, shown was a decline in seeking physician's assistance from $44 \%$ in 1957 to $18 \%$ in 1996 . Major events related to an impending nervous breakdown included divorce, marital strains and separation, and troubles with members of the opposite sex. According to this study, work and educational problems were generally stable during 1957 to 1996 , which were related to tension in work place and course load. In this study, the definition of "nervous breakdown" corresponds to neurotic and mood disorders. The definition of mental illness corresponds to more serious psychotic disorders, along with socially deviant and violent behavior, which was not explored in the earlier surveys in 1957 and 1976.

\section{Social Impact of Internet Technology}

The Internet has had a greater impact on society than television or telephone. The Internet is used for accessing information sources and communicating with others. Kraut et. al. (2002) identified four types of Internet use: “(a) for communication with friends and family; (b) for acquiring information for school, work, news, and other instrumental purposes such as shopping; (c) for entertainment, such as playing games, downloading music, and escape; (d) for meeting new people and socializing in chat rooms" (p. 64)

Through email, discussion groups, chat rooms, instant messaging, newsgroups, and online polls and surveys, people are able to share aspects of their daily lives and interests, communicate with family, friends, or group members, and request information from experts or databases. Many researches have reported the positive and negative impacts of Internet use. However, the overall impact of Internet technology is still far from clear.

Social involvement and psychological well-being. Kraut, et. al. (1998) directed a longitudinal study of Internet use by tracking 169 participants' Internet use over their first 
one or two years. Subjects were recruited from 73 households in four school or neighborhood groups in Pittsburgh, Pennsylvania. The data were collected from a field trial of Internet use. When participants began using a computer and the Internet at home, they were tracked for either during 104 weeks of use starting in March 1995 or 52 weeks of use from March 1996. The data gathered included hours on-line in a week, the volume of email sent and received, and Web sites visited per week. Measures of social involvement and psychological wellbeing were collected twice via a pre- and post- self-reported questionnaire. It was found that participants gained computer skills with more Internet use. The researchers concluded that subjects who used the Internet more heavily became less socially involved with friends and family members and showed symptoms of increasing loneliness and depression. However, a follow-up study in February 1998 showed different results (Kraut, et. al., 2002). The followup study revealed Internet use had different effects early and late in respondents' Internet experience. Depressive symptoms increased significantly with Internet use during the first study but declined significantly with the Internet use during the follow-up study. Loneliness increased significantly with Internet use during the first study but was not associated with Internet use during the follow-up study (Kraut, et. al. 2002).

Kraut et. al. (2002) also conducted one longitudinal study to examine the differential effects of Internet use on individual differences (extroversion vs. introversion) or perceived social support (gets more support or lacks social support). They reported that Internet use with community involvement was positively correlated with extroverts and negatively correlated with introverts. Different positive effects on Internet use interacted with adults and teens were found, which meant both adults and teens has increased their face-to-face interaction with family and friends with more Internet use. For the effects of Internet use on 
psychological well-being, extroverts who used the Internet more showed decreased levels of loneliness and time pressure, and increased self-esteem. Introverts who used the Internet more reported that they were lonelier than those who rarely used it.

Relationships formed on the Internet. The Internet has become a new place for social communication and interaction. Researchers have reported different perspectives of the impact of the Internet on the formation of relationships. McKenna, Green, and Gleason (2002) reported that the effects of the Internet depended on how people disclose themselves. They stated that people who were able to express their true selves better over the Internet were able to form close and stable online relationships and built these friendships on a faceto-face basis. People who felt socially anxious and lonely could express their true selves to others better than face-to-face. The close online relationships tend to become part of nonInternet social life. The Pew Internet \& American Life Project (2000) has found that email and the Internet are perceived as a valuable way of communication. According the results of their survey, Internet users reported that the use of email has improved their connection to family members $(62 \%)$ and friends (72\%). Women participants reported higher percentages than man. In addition, the use of email has increased as a substitute for the telephone.

However, Parks and Roberts (1998) found that online social relationships are weaker than off-line relationships. Cole (2000) reported that people who use the Internet heavily spend less time communicating with their families.

The emerging of online counseling. As Internet use grows, people increasingly use it for information seeking, such as news, self-help and/or mental health information, and contacting to experts or professionals. Online counseling services (Cybertherapy or Net Counseling) are increasingly attractive to people because of the flexibility of service delivery 
and much cheaper service charges. This kind of new mental health service provides information via web sites and "advise giving" via CMC tools (e.g. email, chat rooms), which offer access to mental health professionals. These methods are especially helpful to clients who live in remote areas or are disabled (Powell, 1998; Sussman, 1998). The service fees vary. Some may be free, or service may be charged as monthly basis, by the minute, or per occurrence (Powell, 1998).

The concerns of ethical issues. Professional ethical standards are statements of principle which provide definitions and boundaries of counseling and mental-health services and are used as guidelines. While the use of Internet counseling services has been growing, professional mental health related associations have addressed the ethical concerns of online health-care information and service delivery. These include confidentiality, privacy, legal issues, and credentialing. Consequently, the National Board for Certified Counselors has made an effort to define the practice of Internet counseling (NBCC, 1998); the American Counseling Association approved the Ethical Standards for Internet Online Counseling in 1999, the American Psychology Association defines codes of ethics on services by telephone, teleconferencing, and Internet (APA, 1997).

It is difficult to assure the confidentiality of clients' digital records when they are transmitted via the Internet (Sampson, Kolodinsky, \& Green, 1997). A breach of confidentiality may happen when client information is transmitted via the network. There may be unauthorized access to client digital files, inappropriate data collection, storage, retrieval, and dissemination. Counseling via the Internet technology raises the concerns of confidentiality, which requires more regulations and policies to protect clients (Powell, 1998; Sussman, 1998). Privacy is critical during counseling sessions, because it is provided to 
facilitate clients self-disclosure and ensure confidentiality (Sampson, Kolodinsky, \& Green, 1997; Powell, 1998). Online communication might be intercepted by others and is difficult to detect due to the limitations of Internet technology. Credentialing problems may arise because it is difficult to determine whether online mental health counselors have adequate training, experience, and supervision (ACA, 1999; APA, 1997).

\section{Technological Competence and Counseling Education}

The purpose of counselor education is to train students to become competent counselors who can help people deal with their problems in one or more areas of cognition, emotion, or behavior (NBCC, 1997). The process of becoming a qualified counselor entails completing an accredited program and, subsequently, continually renewing certification through continuing education. All of this is defined and monitored by the Council for the Accreditation of Counseling and Related Educational Programs (CACREP). Today's counselors are faced with the effects of technology on counseling services. The goal of including computer competence in counseling education is not to replace traditional counseling services, but to provide an effective array of counseling options. Since counseling students have to become competent in the use of computer tools during counselor preparation and professional development, ACES has identified 12 technical competencies for counselor education (ACES, 1990a), including:

1. Be able to use productivity software to develop web pages, presentations, letters, reports, etc.;

2. Be able to use audiovisual equipment such as video recorders, audio recorders, projection equipment, and playback units;

3. Be able to subscribe, participate in, and sign off counseling-related listservs; 
4. Be able to access and use counseling-related CD-ROM data base;

5. Be able to use email;

6. Be able to use computerized statistical packages;

7. Be able to use computerized testing, diagnostic, and career-decision-making programs with clients;

8. Be able to help clients search for various types of counseling-related information about careers, employment opportunities, education and training opportunities, financial assistance/scholarships, treatment procedures, and social and personal information;

9. Be aware of the legal and ethical codes which relate to counseling services via the Internet;

10. Understand the strengths and weaknesses of counseling services provided via the Internet;

11. Be able to use the internet for finding and using continuing education opportunities in counseling;

12. Be able to evaluate the quality of Internet information.

\section{Current Status of Technological Competence in Counseling Education}

The majority of counseling students and counselors do not have enough technology competence (Mayers \& Gibson, 1999). They are starting but slowly to integrate technology into the curriculum of counselor education (Quinn, Hohenshil, \& Fortune, 2002).

The survey of ACES's technical competency. A survey delivered by the ACES

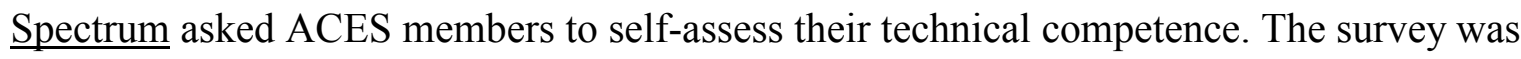
also posted on a counseling profession listserv, Counselor Education and Supervision 
Network-List (CESNET) in the spring of 1999. The survey showed that counseling students and professionals were not equally competent in the use of computer technologies. This survey required participants to respond using a 5-point Likert scale, from no competency (1 point) to very competent (5 point). It also included some open-ended questions regarding technical competence in counselor education and supervision. A total of 92 individuals responded to the survey, including 62 counselor educators, 22 students, 13 professional counselors, and 7 supervisors. The survey could not differentiate the participants from members of CESNET or ACES; however, the estimated response rate was 4\%, based on 2,492 ACES members. Since only 4\% of ACES members returned this survey, the result could not be considered a valid representation of the whole population of ACES. Mayers and Gibson (1999) reported that the levels of the 12 technical competencies in this survey were just represented by respondents who had the greatest interest in technology.

Among the 12 competencies the highest levels of competence included the use of email, listserves, and audiovisual equipment; the lowest levels were in the areas of using computerized tests, knowledge of web counseling, and use of computerized statistical packages. The means of the 12 competencies ranged from 2.95 to 4.55 on the 5-point scale (Mayers \& Gibson, 1999). There were no significant differences in technology competence among assistant, associate, and full professors. Only three significant differences were found in knowledge of ethical codes and knowledge of Internet counseling for counselor educators. Students showed higher ability in the use of audiovisual equipment.

The survey of technology in CACREP counselor education programs. Quinn, Hohenshil, and Fortune (2002) reported that counselor educators are not convinced of the effectiveness of the use of technology in counseling programs, even though they are 
increasingly aware of the use of technology. They conducted research via an online survey to investigate what types of technologies were in use and how they were utilized in CACREP counselor education programs in the USA. The technologies utilized in this survey included audio, video, interactive satellite, PowerPoint, CD-ROMs, laserdiscs, scanners, fax machines, modems, digital cameras, and overhead projectors. Data were collected via a web-based survey, which included a mix of open-ended questions, checklists, and yes/no questions.

Out of 146 CACREP counselor education programs, 44 responded to the survey $(30 \%$ response rate). Survey results show that these programs use both traditional and new technologies, $93 \%$ of them used video, $66 \%$ used audio, $50 \%$ used CD ROM, and 75\% faculty use PowerPoint for teaching while $70 \%$ of students used it for presenting in class. There was a wide range of technology use, some programs showed more advanced use of technology while others were just beginning. For a question regarding whether they followed the ACES Competency Guidelines (1999a) of technology requirements, 39\% respondents replied that they did it while $20 \%$ did not, $36 \%$ were considering, and $4 \%$ did not answer it. For the use of Internet technology, $86 \%$ of faculty used email to communicate with peers and students, $70 \%$ used online research, $66 \%$ used the Internet for posting class information, 54\% required students to read electronic journals, and 34\% required students to participate in chat rooms.

This study concluded that counselor educators have started to integrate technology into curriculum but slowly. They were not widely accepting online or satellite courses.

Attitudes about the use of computer tools. Traditionally, counseling services are performed face-to-face. Counseling students and counselors who do not have prior experience in the use of technology do not consider using computer technology for their 
learning and counseling services. They are not motivated to learn to use computer tools (Myrick \& Sabella, 1995). They lack experience with computer technologies and seemingly have little interest in using them (Owen \& Dean, 1999).

Hayes and Robinson (2000) administered a survey to explore counseling students' attitudes toward computers- assisted instruction (CAI). The sample consisted of 44 graduate students who enrolled in an introductory graduate counseling technique class. Only the instructors used the computers, not the students. An Attitude Survey developed by Misfeldt and Stahl was applied in this study. It contained 30 questions based on a 5-point Likert scale to determine students' attitudes toward computerization. Students responded that they did not feel pressure in this class.

Another nationwide computer use survey, designed by Berry (2002), found that none of the respondents preferred online instruction. This study randomly selected 12 CACREPAccredited counselor training programs, from six CACREP-accredited universities. Berry got agreements from instructors with classes of 10 students or more. The surveys were mailed to the instructors and instructors delivered the surveys to students in classes. Student participants completed the surveys and turned them into their instructor in class; then, the instructors mailed the completed instruments back to the researcher. In all, 102 students participated this study, $16 \%$ male and $84 \%$ female with an average age of 30 years old. The computer use survey asked participants to rate their experience in the use 10 different types of computer software, with 6-point Likert scale between 0 (little experience) to 5 (high level of experience). Berry reported that participants had more experiences in the use of wordprocessing, web-browsing and email software, and the least experience in the use of authoring and programming software. Berry (2002) also surveyed about participants' 
preferred modes of instruction from six modes of instruction: lecture, discussion, small group, online instruction, role playing, and programmed instruction. It was found that most of participants chose "Discussion" (52\%), "Lecture" (36\%), and "Small Group" (34\%) as their favorite. However, no participants chose "Online instruction."

The Use of Computer Technology in Counselor Education

Many features of the Internet, including bulletin board systems, listservs, email, file transfer protocols (FTPs), the World Wide Web (WWW), web browser, search engines, and chat rooms, show great potential for having an impact on counseling services and counselor education. Many counseling educators have recognized the importance of integrating computer technology into counseling education. Sampson, Kolodinsky, and Greeno (1997) pointed out the advantages of applying computer tools into counseling services, which include assistance with career choice and job placement, the increase of information delivery, professional discussion and sharing at a distance, access to self-help psychoeducational resources and assessment, more cost-effective research and data collection, and the arrangement of counseling services at a distance. However, they also reported potential problems that accompany the use of technology, including ethical concerns and the issues of relationship development.

Increasing numbers of counseling educators have devoted themselves to integrating Internet technology into counseling education. Most of them have adopted computer tools to present learning materials or teach/supervise at a distance. Their reason for using computer tools is to provide flexibility, to enable students to learn at a distance (Jones \& Karper, 2000; Woodford, et. al., 2000), to supervise at a distance (Getz \& Schnuman-Crook, 2000) or to enhance cultural competence (Ancis, 1998). Although counselor educators have integrated 
computer technology into the teaching, they have not included technology competence as a goal in the instructional design.

Woodford, Rokutani, Gressard, and Berg (2000) held a distance-learning course that used interactive television (ITV), monitors, and Polycom SoundStations via satellite. This course shared a main site with 16 students and a satellite site with 11 students. Students experienced collaborative learning at a distance with the support of technology, but the intention was not to enhance their ability to use technology.

Getz and Schnuman-Crook (2000) provided mixed CMC tools for off-site supervision, using email, streaming audio/video, downloading, and hyperlinks. They advised students by using email for communication, and using streaming video clips to demonstrate clinical supervision. Students used hyperlinks for accessing online resources, downloaded necessary forms, and watched streaming video clip at a distance. Even though this course might indirectly help counseling students increase their ability to use computer tools, the teachers were more concerned about efficiency and convenience of supervision at a distance.

Jones and Karper (2000) used WebCT to develop a web-based course for teaching counseling techniques (http://jtc.colstate.edu/vol1 2/online.htm). In this course, the instructor provided a web site with email, a chat room, and a streaming demonstration to teach counseling skills. This course offered four face-to-face classroom session; with the remaining 11 sessions conducted online. The online portion included 9 modules, 2 streaming video clips, chat rooms, and instructions. The video clips demonstrated interviewing skills on the web site. However, no specific activities were designed to improve students' ability to use computer tools. The only assignments required students to hand in four videotapes demonstrating their counseling skills. 
Ancis (1998) used interactive televised instruction with an integrated system of video monitor, computer, and an audio system to teach students about multicultural counseling training at multiple classrooms remotely. Using closed circuit or satellite television, with video monitors and audio systems, students could verbally communicate and interact with each other. In order to enhance the learning of cultural diversity, Anics suggested some strategies to help students become more culturally competent with the integration of technology. For example, videotape assignments can provide skills practice and practice assessment of cultural competence; the use of email, listservs, web sites, and access to Internet resources can promote students' cultural competencies. The intention of this course was to use technology to increase multicultural knowledge at a distance.

The integration of computer tools as a part of the curriculum. The integration of computer technology into counselor education may enrich teaching and learning activities, but it may not enable students to become technologically competent without appropriate design in curriculum. McFadden (2000) points out that instructional processes in counselor education have evolved to the point that students can take advantage of technologies. He states that in order to help counselors-in-training and professional counselors gain technology competencies defined by ACES, counselor educators have to examine computer technology applications and the ethical implications of each application in both instructional and service delivery settings. Chandras (2000) states that although technology has had an impact on counseling services, the work of counselors appears largely unchanged. It is necessary for counseling students to be educated appropriately to enhance technology competencies in counseling programs. Quinn, Hohenshil, \& Fortune (2002) suggested integrating the requirements of technology skills into licensure and certification programs. 
To become technologically competent is to have the knowledge and skills to use technology efficiently, to use technology effectively to help others, to understand the impacts of technology, to provide useful resources, and more (ACES, 1999a; Hines, 2002). Hines (2002) introduced the enhancement of technology skills in Indiana State University (ISU) School Counselor Program. The ISU School Counselor Program has tried to help students to acquire technology skills during their two-year masters degree program with defining the School Counseling Program of Technology Proficiencies and the developing the Basic Technology Competencies (Hines, 2002). In this program, if students cannot demonstrate their ability in the use of 10 competencies they have to take one to three credit hours from a course in Technology for School Counselors. According to the requirements of the Basic Technology Competencies, students have to demonstrate their ability to use computer tools by means of implementing a series of assignments. The 10 competencies require students to be knowledgeable, skilled, and efficient users of computer technology, who demonstrate the use of technology and resources, understand the ethical and legal implications of technology, develop and evaluate counseling and guidance program with appropriate technology use, etc. The Basic Technology Competencies require students to be able to submit documents using Word processing/desktop publishing tools, use database and spreadsheet, use multimedia presentation software, and search/use/evaluate electronic and Internet resources. It is expected that students will at least understand the relationship of technological competencies with the functions and responsibilities of a school counselor, effectively provide school counseling services integrating the use of technology skills, and be able to continue to enhance their use of technology skills in their professional development in the future. 


\section{The Adoption of Computer Technology}

Traditionally, counseling services have been performed face-to-face. Counseling students and counselors who do not have prior experience in the use of technology do not consider using computer technology for their learning and counseling services. They lack experience with computer technologies and seem to have little interest in using them (Berry, 2002;Myrick \& Sabella, 1995; Owen \& Dean, 1999).

Innovation-decision process. According to the theory of innovation-decision process (Rogers, 1995), there are five stages leading to adoption of an innovation: Knowledge, Persuasion, Decision, Implementation, and Confirmation. The Knowledge stage is to deliver the information of the innovation to people so they can learn about it. Persuasion is the stage when people start to learn about the value of the innovation, they may consider knowing more about it if they are interested. Decision is the stage that people will initially make the decision to use it. The stage of implementation happens when people try to change or modify the use of the innovation for their own purposes. The Confirmation stage appears when people decide whether to reaffirm or reject the innovation.

Attributes of innovation. The rate of adoption of innovations is related to the attributes of innovations, which includes related advantage, compatibility, complexity, trialability, and observability (Rogers, 1995). People adopt an innovation at different rates, which are dependent on their understanding of the attributes of the innovation. For the adoption of computer tools, people decide whether to adopt computer tools when they are aware of their attributes. They will judge them by their advantage over other related tools; their compatibility with the circumstances, their complexity to see how difficult or easy to use; 
their trialability by checking its outcomes following a trial run; and their observability if they can notice observable outcomes.

Based on Rogers' theories (1995), the process of adoption is related to the learning process in the use of innovation. The process of integrating computer tools into the curriculum of counselor education is to help students learn to adopt computer tools. When counselor educators develop activities with the integration of computer tools, the activities provide students an opportunity to know about and use computer tools. As students' abilities to use computer tools increase, they will be persuaded to continue to use the tools. As they decide to adopt it, students will try to use computer tools for their own purposes and decide to continue or to stop using them. As counseling students use computer tools, they evaluate their attributes, which makes the rate of adoption individually different.

Appropriately using instructional design to develop activities with the integration of computer tools allows students to learn about the attributes of computer tools throughout their innovation-decision process. An appropriate instructional design will help students have a positive learning experience, increase their ability to use computer tools, and recognize the attributes of computer tools, while an inappropriate instructional design will discourage students' learning about computer tools and impede their adoption of them.

\section{Motivation in Learning}

It has been noted that motivation plays an important role in learning. The amount of research on motivation is vast; however, the term itself does not conform to a single definition. Because educational researchers have different perspectives, a definition of motivation in one study may not fit the circumstance in another study. Motivation is contextual and time dependent: the conclusions of two studies that examine the effects of 
motivation on learning and performance may vary depending on the different environments in which they are conducted.

Pintrich and Schunk (2002) define motivation as "the process whereby goal-directed activity is instigated and sustained" (p.5). These goal-directed activities involve the expectation of achievement; they may be either short-term or long-term, and are usually related to consequences (e.g. success, failure, enjoyment, skill improvement). When an individual engages in a goal-directed activity, he or she is usually either intrinsically or extrinsically motivated to persistently work toward goal and attain rewards for achievement.

\section{Intrinsic and Extrinsic Motivation}

An individual's motivation is affected by personal (intrinsic) or environmental (extrinsic) factors. Deci (1975) stated that "intrinsically motivated behavior is behavior which is motivated by a need for competence and self-determination" (p. 116). Competence implies that people are capable of effectively dealing with their surroundings, and seek appropriate challenges; self-determination means that people make decisions to overcome challenging situations or reduce incongruity (Deci, 1975). As people become highly intrinsically motivated, they work on tasks for their own sake and derive enjoyment and satisfaction from their work.

Extrinsic motivation, on the other hand, occurs when an individual participates in an activity for the sake of external rewards or incentives rather than the activity itself (Deci \& Ryan, 1985). Extrinsically motivated behaviors are usually initially performed to satisfy external demands or for rewards. When the motivation to learn is derived from receiving external rewards for implementing an activity, an individual may attain outcomes but does 
not experience inherent joy from his or her learning. Extrinsic motivation will decline or disappear when the external reward is withheld.

\section{Motivation and Rewards}

During the learning process, an individual's motivation fluctuates, influenced by circumstances - rewards (external or internal) or reinforcements from the learner, teachers, etc. There are complicated relationships between rewards and motivations.

Many educators use rewards and punishments in order to help students reach a desired outcome. Motivation will increase when people receive rewards, and will decline or disappear when the external reward is withheld. Rewards may come from internal and external environments, such as academic achievement (final grade, credits, etc.), increased confidence, improved skills, enjoyment in learning, etc.

Achievement and expectancy. Atkinson (1964) describes achievement motivation as "when an individual knows that his performance will be evaluated (by himself or by others) in terms of some standard of excellence and that the consequence of his action will be either a favorable evaluation (success) or an unfavorable evaluation (failure)" (p.240-241). He applied the Expectancy x Value theory, which involves "an individual's expectations concerning the consequences of his actions and/or the incentive value of the consequences (or goals) produced by action" (Atkinson \& Raynor, 1978, p.12). If students are motivated by the goals of academic achievement, they will achieve the expected goals to reach rewards and try to avoid punishment.

Confidence in skills. Bandura (1977) emphasizes that people are not motivated to complete work if they do not have the ability/skills to be successful. Perceiving oneself as competent at an activity will increase one's motivation to perform the activity; conversely, 
perceiving oneself as incompetent will decrease one's motivation (Bandura, 1977; Deci \& Ryan, 1985). When people are motivated, they believe their abilities, set goals, anticipate achievements and guide their actions to pursue their plans.

Feelings about learning. According to Csikszentmihalyi (1978), one's motivation is derived through a process of engagement or interaction with an optional experience that they experience positive feelings, such as happy, satisfied, and concentrated. People, who had optional experience intensively involve with an activity, are internally rewarded by positive feelings about themselves, regardless of external rewards. They exhibit happiness, concentration, excitement, satisfaction, and creativity as they were motivated.

Deci \& Ryan (1985) emphasizes that rewards do not always enhance peoples' motivation. They state that extrinsic rewards might decrease intrinsic motivation if people have decreased feelings of competence and self-determination or if the rewards are more control-directed than information-directed. Eisenberger and Cameron (1996) emphasize that rewards may result in reduced motivation if they are not tied to performance; however, rewards can have a positive effect on intrinsic motivation if they are dependent on performance quality.

\section{Internalization and Integration of Intrinsic Motivation}

The Organismic Integration Theory (OIT) (Ryan \& Deci, 2000) explains the internalization and integration of intrinsic motivation. Internalization refers to "taking in a value or regulation" and integration refers to "the further transformation of that regulation into their own." According to OIT, a self-determination continuum describes change in the nature of motivation, which differs in the value and regulation of behavior. People implement tasks with different degrees of motivation, ranging from unwillingness 
(amotivation) to highly personal commitment (intrinsic motivation). Between these extremes, four extrinsic motivational behaviors are identified: external, introjected, identified, and integrated. Each level of motivation shows different levels of autonomous and self-regulated behavior, which correspond with regulatory behavior in a social context. Table 2-1 explains types of motivation in OIT.

Intrinsic and extrinsic motivation do not have to be opposites on a continuum. While working on a task, an individual's motivation level might occur at any point of the selfdetermination continuum, which displays a combination of intrinsic and extrinsic motivation in different degrees, depending on his or her prior experiences and current environmental factors. Internalization and integration of intrinsic motivation occur when an individual become intrinsically motivated, more self-regulated and takes greater controls over his/her environment during the process of learning (Ryan \& Deci, 2000).

Continuing motivation. Continuing motivation emerges when people become intrinsically motivated, which means they are able to take control of their own learning and are willing to work for the satisfaction they get form doing the job. Maehr's continuing motivation theory (1976) defines motivation as "the tendency to return to and continue working on tasks away from the instructional context in which they were initially confronted" (p. 443). By his definition, continuous motivation is created when people continue learning outside the classroom. It reflects an individual's willingness to continue to learn, and implies the internalization and integration of intrinsic motivation (Maehr, 1976; Ryan \& Deci, 2000). 
Table 2-1

Types of Motivation in the Self-determination Continuum of the Organismic Integration Theory (Ryan \& Deci, 2000)

\begin{tabular}{|c|c|c|}
\hline Motivation & Regulation styles & Definition \\
\hline Amotivation & Non-regulation & $\begin{array}{l}\text { The state of lacking the intention to act, resulting } \\
\text { from not valuing an activity or not feeling } \\
\text { competent to do it, or not expecting desirable } \\
\text { outcomes. }\end{array}$ \\
\hline \multirow{4}{*}{$\begin{array}{l}\text { Extrinsic } \\
\text { Motivation }\end{array}$} & $\begin{array}{l}\text { External regulation } \\
\text { (at least autonomous) }\end{array}$ & $\begin{array}{l}\text { Actions are performed to satisfy an external } \\
\text { demand or reward contingency }\end{array}$ \\
\hline & Introjected regulation & $\begin{array}{l}\text { An individual takes an action involving a } \\
\text { regulatory process but does not fully accept it as } \\
\text { his/ her own. }\end{array}$ \\
\hline & Identified regulation & $\begin{array}{l}\text { An individual who consciously works on a task } \\
\text { accepts it or views it as personally important. } \\
\text { The individual values the task as a behavioral } \\
\text { goal or regulation. }\end{array}$ \\
\hline & $\begin{array}{l}\text { Integrated regulation } \\
\text { (most autonomous) }\end{array}$ & $\begin{array}{l}\text { When identified regulations are fully assimilated, } \\
\text { the individual values the task for attaining } \\
\text { outcomes rather than for his/her inherent } \\
\text { enjoyment. }\end{array}$ \\
\hline $\begin{array}{l}\text { Intrinsic } \\
\text { motivation }\end{array}$ & Intrinsic regulation & $\begin{array}{l}\text { An individual internalizes and assimilates } \\
\text { motivation. He or she experiences interest, } \\
\text { enjoyment, and satisfaction when working on the } \\
\text { task. }\end{array}$ \\
\hline
\end{tabular}

\section{Motivation in Instructional Design}

When individuals face the task of learning a new skill, they encounter challenges. In order to support and encourage students' learning, professional educators can apply instructional design to external rewards or incentives to support learning. Examples include the grade system (points, credits, grades), and the support system (tutorials, resources, feedback), etc. Instructional design is the process that arranges methods of instruction for 
achieving specific teaching purposes for a specific population of students. It is "a body of knowledge that prescribes instructional actions to optimize desired instructional outcomes, such as achievement and affect" (Reigeluth, 1983, p. 5).

Instructional design may reinforce teaching and learning; it can include rules or an instructor's expectations (learning goals, learning outcomes), to help produce the expected behavior and consequence. Instructional design can promote students' motivation by encouraging learners to excel, instilling the desire for competence, and promoting their enjoyment of learning, their interests, and their curiosity. It is concerned with optimizing the process of developing, implementing, and evaluating instruction (Driscoll, 2002).

Keller (1983) argued that it is not totally true that "if instruction is of good quality, motivation will take care of itself' (p. 388). Maehr and Midgley (1991) emphasize that motivation can be enhanced in a learning environment. A motivational instructional design can directly or indirectly promote motivation that encourages people to learn, fosters creativity, leads them to seek challenges, and to become confident. Adding motivation to the process of instructional design also helps learners achieve the goals of the instructional design (Keller, 1983). When a learning environment fails to encourage people and to sustain spontaneous motivation to learn, less learning will occur. When people become intrinsically motivated and sustain the motivation, they will be able to set up their own learning plans and goals in the future. A motivational instructional design incorporates motivating features into a course/activity design to encourage learners to approach their learning goals and to become capable and knowledgeable throughout the course/activity.

Keller's motivational-design model. Keller (1983) argued that motivation has been neglected in instructional design. He believes that it is not totally true that "if instruction is 
of good quality, motivation will take care of itself" (p. 388). He describes motivation in instructional design as "the choices people make to what experiences or goals they will approach or avoid, and the degree of effort they will exert in that respect" (p.389).

In Keller's motivational-design model, four categories of variables-interest, relevance, expectancy, and outcomes (satisfaction) - facilitate the synthesis of the concerns of motivation (1983). Interest refers to the methods that increase learners' curiosity and sustain it over time. Relevance refers to learners' perceptions of needs and goals that are related to the instructional design. Expectancy refers to the perception of success and the extent to which success is under a learner's control. Outcomes include several factors that influence the satisfaction of accomplishment. Satisfaction implies that the learners' anticipation of the combination of extrinsic rewards and intrinsic motivation will be met.

Continuing motivation to learn. Kinzie (1986) noted that the purpose of instructional design is to increase students' continuing motivation to learn. Four components must be integrated into instructional design: competence, control, relevance, and curiosity.

(1) Competence: it refers to learners' ability to implement activities. Providing the student with opportunities to succeed in moderately challenging instructional situations can promote feelings of self-efficacy and encourage continuing motivation.

(2) Control: Giving learners significant amounts of control in situations that are responsive to their choices, such as an interactive system, will encourage their motivation to learn.

(3) Relevance: providing related instructions and contents will support students' desire to learn. 
(4) Curiosity: The stimulation of curiosity can support students' motivation to learn.

Kinzie (1986) reported that if the instructional system is well-designed and the learner is adequately prepared, learners will be able to exercise control and effectively regulate their own learning in a flexible learning system and will be motivated enough to explore.

TARGET. Maehr and Midgley (1991) propose six facets of motivation enhancement from a schoolwide approach. TARGET, an acronym for "task, authority, recognition, grouping, evaluation, and time", provides a task-focused instructional design, which aims to enhance students' motivational through task-oriented goals. They stated that students' perceptions of goals influence their motivation and learning. TARGET provides a motivational learning environment, which allows students to be involved in choice and decision making, to interact and cooperate with others, to learn from group work, to experience success in terms of effort, progress, and improvement (Maehr \& Midgley, 1991). TARGET elements are summarized below:

(1) Task: the focus is on the intrinsic value of learning. The reliance on extrinsic incentives is reduced.

(2) Authority: Authority provides opportunities to develop self-regulation skills. It gives optimal choice in instructional settings and teaches meta-cognitive strategies for self-regulation.

(3) Recognition refers to recognizing progress in goal attainment and efforts in learning activities.

(4) Grouping provides opportunities for group learning, problem solving, and decision making. 
(5) Evaluation increases students' sense of competence and self-efficacy and the awareness of progress in developing skills and understanding, while reducing social comparison of achievement.

(6) Time involves improvement in self-management ability and skills in planning and organization. It allows students to progress at their own pace.

\section{Development of a Motivational WBI in Counselor Education}

The inclusion of motivating factors into instructional design is a cost effective way to encourage counseling students to use computer tools. The goal is to increase students' computer competence, so they can use the technology to provide counseling services in the future.

WBI design. A WBI design involves the process of developing instruction for achieving teaching and learning through the use of the World Wide Web. A WBI design creates an environment that supports learning via the Internet (Driscoll, 2002; Khan, 1997). The procedure used to develop a WBI design consists of performing a needs analysis and a task/user analysis, determining a structure, implementation, evaluation, and feedback (Brown, 1997; Driscoll, 2002). WBI design provides activities with information and resources. It can include text, graphics, videos, audios, animations, and simulations, which can be accessed via hyperlinks. A WBI design depends on synchronous or asynchronous information which are available throughout networks.

Schrum \& Berenfeld (1996) note three levels of instructional design with the develop CMC modules as curricular enhancement, and fully integrate $\mathrm{CMC}$ tools into curricula. Due to the limitations of contemporary information technology, a fully web-based 
learning environment currently cannot meet the guidelines of ACES to provide quality and effective learning that is equivalent to that provided by the traditional course setting (ACES, 1999b). To enhance students' technological competencies, either integrating computer tools as an extracurricular activity or developing a web-based curriculum enhancement will offer a practical solution.

In order to encourage counseling students to use computer tools, a motivational WBI design involves need-related resources (Brown, 1997; Sampson, et. al., 2002), learnercentered/learner-controlled environment (Jonassen, 1993; McComb, 1996; Lundberg, 2000), clear goal-directed instruction (Archer \& Scevak, 1998; Maehr \& Midgley, 1991), collaborative/communicative learning context (Dewey, 1938; Woodford, et. al., 2000; Visser, Plomp, \& Kuiper, 1999), and infrastructure support (Ancis, 1998; McFadden, 2000). The features for a motivational WBI design have to consider the integration of computer tools, navigation and interaction, the structure of a web site, and the support of the infrastructure.

Need-related, content-related supplementary resources. Duchastel (1997) states that providing richness of information with a task-driven instructional strategy will encourage students to learn. Providing need-related supplementary resources in web pages can motivate people to learn, which relies on hyperlinks, infrastructure, and related computer tools. Without the support of resources, counseling students will be discouraged to use computer tools, because most of them are not familiar with learning in a web-based environment so it would require a long period of practice and training to become capable of accessing and assessing appropriate web resources.

Sampson, et. al. (2002) advocate a need-based Internet web design for counseling and career services. A need-based instructional design categorizes relevant resources for users to 
get technical support or access to web resources. Since counseling students are more novice users who need more navigation using the web resources and more help in technical support. Instructional designs need to provide guidance for different levels of learners. Provide abundant resources, based on learners' needs can help them get used to web-based environment. As they gain confidence in their ability to use computer tools, they will not need as much help as before.

Learner-controlled/Learner-centered environment. A motivating web-based learning circumstance allows learners to flexibly and dynamically interact with people and information. A learner-centered environment, which includes the consideration of learners' needs, beliefs, experiences, and preferences, is a critical factor to motivate people to learn. (McCombs, 1996). Learners can decide their learning strategies and choices, which needs the support of learning activities, synchronous/asynchronous computer-mediated communication (CMC) tools, organized web structure, and infrastructure support. Jonassen (1993) emphasizes the importance of learner control in computer-supported learning systems. He states that a learner-controlled system has to provide more constructivistic process of knowledge, which assumes that learning is a process of knowledge construction rather than reproduction.

Lundberg (2000) emphasized humanistic factors that allow students to self-directed their learning, while integrating computer technology into counseling. Lundberg integrated computer tools (e.g. email, browsers, Internet search tools) into several exercises in an introductory graduate counseling course: Human Development. His humanistic WBI design allowed individuals to access the Internet for their own purpose, at a convenient time, and at their own pace so they will perceive the values of using computer technologies. 
Goals-directed instructions. A motivational WBI design encourages people to achieve learning goals. Defining learning goals is important in instructional design, which includes the expectations of purposes of learning, procedures, and outcomes. Maehr and Midgley (1991) identified two kinds of achievement goals, task-focused and ability-focused, contribute to students' motivation to learn. For task-focused learners, the goals of learning are "to gain understanding, insight, or skill and to accomplish something that is challenging" (p.403); for ability-focused learners, "they are concerned with being judged able (or avoiding being judged not able)" (p. 402-403).

Archer and Scevak (1998) reported that the way that lectures approach the goals of teaching and display the expectations of learning attitudes and behavior was related to students' motivation to learn. They applied the theory of achievement goals, providing the nature of the task, evaluation procedures, and options of work, into an Education course in a university. They reported that students' perceived the lecture as an encouraging mastery goal. There were significant correlations between their perceived ability and perceptions of the master goal. Students showed increasing willingness to take difficult tasks in two times of measurement.

Collaborative and communicative learning environment. Collaborative learning and communication (e.g. feedback, questions, discussion) between teachers and students can motivate students' learning, which rely on the support of CMC tools. Collaborative learning involves building knowledge structures, creating new concepts of information, and being able to enrich students' ability to differentiate various ideas (Cecez-Kecmanovic \& Webb, 2000). Dewey (1938) states that effective learning requires interaction and the continuity of interaction. Effective communication can support and increase students motivation in 
learning (Visser, Plomp, \& Kuiper, 1999). Timely feedback from instructors and on-site support are factors that motivate students to learn.

Visser, Plomp, and Kuiper (1999) emphasize that communication has motivated students as the Motivational Messages Support System (MMSS). They studied how motivational messages between student and tutor are effectively motivated in distance learning. In their study, two groups of students received personalized and collective motivational messages, with a control group without motivational messages in MMSS. They reported that the motivational messages helped students to stay and complete the distance course. The group receiving motivational messages showed significantly higher completion rates than the completion rates in control group. They concluded that using motivational messages was rewarding to students' learning. However, no significant difference was found in the effectiveness of enhancing motivation between the use of collective and personalized messages. 


\section{Chapter 3: The Method}

This study investigated and evaluated counselors-in-training and counselors' motivation to use computer tools in a web-based learning environment used as part of a counseling course. The design of this study included development of a web-enhanced counseling course, a pilot study and the main research. In order to provide a motivating webbased environment to encourage students to learn, a pilot study was conducted to examine the features of the WBI design. Data collection from the pilot study has helped to guide revisions to the features of WBI design and the method of data collection. The main research was conducted later to fully investigate the relationships of the features of WBI and students' motivation to use computer tools.

\section{Purpose}

Computer technology has had a powerful impact on society. Professional counselors have to be aware of the effects of technology on people and societies and must learn how to use computer tools in order to provide better service. However, counselor education has not changed its curriculum to include the integration of computer tools. The current problem in counselor education is that it has been difficult to persuade counselors-in-training and professional counselors to use computer tools.

The purpose of this study is to investigate how students in a counseling course with a WBI design can be motivated to become computer competent. Four main research questions guided this study. The first investigated what changes occurred in students' computer use after they took this course. Four areas - confidence in computer use, frequency of computer use, emotions regarding using computer tools, and awareness of the ACES (Association for Counselor Education and Supervision) technology competencies-were examined to 
understand these changes. The second main question explored the relationships between the features of WBI and students' motivation to use computer tools. Two sub-questions were asked to help understand the impact of WBI features on students' motivation to use computer tools. The third main question aimed at understanding how students' motivation to use computers related to their learning experiences, (i.e. academic achievement, learning satisfaction, skills improvement in computer use, confidence in computer use, increase in computer use, and feelings regarding computer tools use.) The fourth main question identified changes in practice among students who were motivated to use computer tools. This question examined students' attitudes regarding computer use in the future and indicators of changes in computer use. The main questions and related sub-questions are:

I. What changes in computer tools use occurred in students at the end of the course?

(1) How did students' confidence about using computer tools change?

(2) How did students change using the computer tools in frequency?

(3) How did students become aware of the ACES technology competencies?

(4) How did students' feelings about using computers change?

II. What were the relationships between the features of web-based instructional design and students' motivation to use computer tools?

(1) What features of web-based instructional design motivated students to use computer tools?

(2) What features of web-based instructional design discouraged students from using computer tools? 
III. How were students' learning experiences in a web-enhanced course related to their motivation to use computer tools?

(1) What was the relationship between motivation and academic achievement?

(2) What was the relationship between motivation and computer tools use (in terms of confidence, improved skills, and increased computer use)?

(3) What was the relationship between motivation, learning satisfaction, and the performance of course web site?

(4) What was the relationship between motivation and feelings regarding using computer tools?

IV. How did students change computer use when they were motivated to use computer tools?

(1) What were students' attitudes about computer use in the future?

(2) What indicators of changes in practice occurred in students during the course?

\section{Research Design}

The research design of this study included four phases. The first phase began in September 2001, at the beginning of West Virginia University's fall semester. This phase involved developing a motivating WBI design that integrated the use of computer tools in a counseling course: Coun 620, Lifespan Career Development. The second phase occurred in April, 2002. At this time a pilot study was conducted to assess Coun620 students' motivation to use computer tools. The third phase took place between May and August, 2002. This phase involved revision of the WBI design based on data collection from the pilot study. The fourth phase, in which the main study took place, occurred during fall semester of 2002. The main study investigated students' motivation to use computer tools in Coun 620 . 
The significant components in each phase are discussed below to provide a better understanding of this research:

\section{Development of a Motivating WBI Design}

Coun 620, Lifespan Career Development, is a required masters' level course in the counseling program in the College of Human Resources and Education at West Virginia University. The course focuses on career guidance and development in the Information Age. In order to develop and improve students' ability to use computer tools, it was designed as a web-enhanced course that includes both a face-to-face classroom setting and a web-based environment featuring the integration of computer tools.

The features of the WBI design in Coun 620 consisted of need-directed supplementary resources, a learner-centered/learner-controlled environment, goal-directed instruction, and a collaborative and communicative environment. Certain activities required the use of computer tools, such as Microsoft Word, PowerPoint, a bulletin board in WebCT, a web browser, e-mail (electronic mail), and web-based search tools. Some additional computer tools (Adobe Reader, and a chat room in WebCT) were integrated into this course to facilitate students' learning, but students' were not required to use them. For a detailed description of the WBI design used for Coun 620 see Appendix A.

\section{Pilot Study}

A pilot study was conducted in Coun 620 from April 19 to May 18, 2002. At this time, the course was offered as an intensive weekend course in a cohort program of the Master's Degree in Counseling Program. The purpose of the pilot study was to understand students' motivation to use computer tools when they were exposed to them in a course that included a WBI design. In order to understand students' motivation to use computer tools, the pilot 
study collected data concerning students' use of computer tools, feelings regarding computer use, and learning experiences in Coun 620. These data were collected via surveys, an analysis of bulletin board messages, and students' final grades. The data provided feedback for guiding revisions to the WBI design in Coun 620 and the method of data collection.

Survey development. In order to evaluate students' motivation to use computer tools, several variables were considered: academic achievement (final grades), confidence using computer tools, feelings about using computer tools, course performance, and learning satisfaction. Three surveys were developed, (Pre- and Post- surveys of Computer Tools Competence and the Course Evaluation), to assess students' motivation to use computer tools. The Pre-survey of Computer Tools Competence was used to collect students' demographic information and their confidence using 10 computer tools before taking this course. The Post-survey of Computer Tools Competence collected information regarding students' confidence using computer tools at the end of the course. It contained some openended questions to explore the impact of computer use on their learning, their motivation, and whether their use of computer tools had changed. The Course Evaluation mainly collected information about course performance, learning satisfaction, feelings about using computer tools, and learning experiences.

Results of the pilot study. The pilot study consisted of eight sessions in the classroom and four sessions on the Internet. A total of 26 students took this course and participated in this study. Students did not live near campus and had to commute to school for face-to-face class meetings. They had to use their own PC with an Internet connection to access the course web site in order to download the supplementary materials, work on assignments and activities, and use a bulletin board and chat room on the WebCT server. 
Both qualitative and quantitative data were collected via surveys, bulletin board use, and instructor's observation. Students' progress in academic achievement was indicated by their cumulative course points. The pre- and post- Surveys of Computer Competence indicated that there was significant progress in the students' confidence using computer tools. In open-ended questions on surveys and in bulletin board messages, some students reported that their motivation to use computer tools came from the course requirements, their own interests, increasing ability in using computer tools, and the WBI design. The instructor observed that students improved their ability to use computer tools and that some of them planned to buy new computers and had changed to faster Internet connections.

The relationships between the features of WBI design and student motivation to use computer tools were found in their answers to "the most helpful and disliked features" question in the Course Evaluation and related open-ended questions on surveys. Participants indicated that the most helpful features of the WBI design, including user-friendly WBI design, clear goal-oriented instructions, and abundant supplementary materials and resources, helped them learn and use computer tools. However, students were discouraged by the extra time and work needed to use the computer tools and because the quality of communication was not as good as in a face-to-face setting. Significant relationships were found between emotion level when using the computer and several areas-learning satisfaction, confidence of computer use, and plans to continue to use computer tools. Participants who had stronger negative emotions while using computer tools showed lower learning satisfaction, less confidence in their computer use, and less intention to use computer tools in the future.

Some students became more motivated to use the bulletin board as the course progressed. The indicators of bulletin board adoption were derived from the purposes for 
use, communication targets, and the numbers of bulletin board responses. The purposes of the bulletin board use changed from meeting course requirements to personal needs; communication targets changed from generalized (addressed to all classmates) to more individualized (addressed to specific classmates). In addition, the number of responding messages increased, indicating that the frequency of interaction among students via the bulletin board increased as the course progressed.

Revision of WBI Design and Data Collection

Based on the data collected and analyzed in the pilot study, some revisions were made to the WBI design and the data collection method.

WBI design. The revision of the web design included assuring consistency between web-based content and classroom hand-outs, providing more technical support (tutorials and web sites), providing more supplementary resources and quizzes, and having more reasonable workload expectations. The goal-directed feature of course guidance and instruction was modified to account for the variety of student backgrounds and needs. The due date of each assignment was clearly stated in the syllabus and on the web site in order to help students set up their study plans. In addition, better maintenance of hyperlinks between web pages may decrease students' frustration when using the course web site.

Data collection. The methods of collecting data were revised in several ways. Misprinted words on surveys were corrected, and some minor changes were made to the collection of participants' demographic information. In order to collect more data, the following revisions were implemented:

1. The Survey of Emotion Level Regarding Computer Tools Use. The section that addressed emotion level while using computer tools was removed from the Course 
Evaluation and become an individual survey. The administration of the emotion level survey increased from once (at the end of course) to twice (at the middle and the end of the course) in order to examine changes in students' emotion level while using computer tools, and how these changes related to their motivation to use computer tools.

2. The revision of Pre- and Post-surveys of Computer Tools Competence. There were three major revisions to the pre- and post- surveys. First, the "Frequency and Purposes of Computer Use" section was added in order to investigate the use of computer tools in depth. A comparison of the pre- and post-surveys revealed the indicators of the adoption of computer tools. Second, the section of ACES's technological competencies was removed from the Course Evaluation and added to the pre- and post-surveys. A comparison of the pre- and post- surveys indicated the improvement in students' performance of ACES's technological competencies. Third, a new section, "Learning Goals of Computer Tools Use," was added in order to understand the changes in students' attitude toward using computer tools.

3. The revision of the Course Evaluation. Several sections were moved from the Course Evaluation into the Pre- and Post-surveys of Computer Tools Competence. Two sections devoted to motivation were added. One section asked students to evaluate 23 webbased items. The students were asked to rate these items on a scale ranging from very discouraging to very motivating. The second section measured students' motivation to use computer tools in this course. This section included two parts. In the first part students were asked to state whether they were motivated or discouraged from using specific computer tools, or if there had been no change in their attitude. In the second part they were asked to select statements that described their reasons for using computer tools. This section was 
based on a section in the Course Evaluation of the pilot study ("Most Helpful and Disliked Features"). Students could choose any and all statements that were true to them. Their answers were used to understand the reasons that students were motivated or discouraged by the WBI features and learning context of the web-based environment. In addition, some open-ended questions were revised to understand students' learning and their intentions regarding using computer tools in the future.

\section{Main Research}

The purpose of this research was to investigate students' motivation to use computer tools in a web-based learning environment, which was delivered in a web-enhanced course, Coun 620. The main research was conducted in the fall semester of 2002. Coun 620 was offered as a 14-week course in a Master's level counseling program at West Virginia University in Morgantown, West Virginia. The course was held in one three-hour class each week, including 3 weeks on the Internet and 11 weeks in a classroom setting.

Most of the students who took this course were counseling graduate students who did not have experience in counseling services. They lived on or near the main campus of West Virginia University. They had easy access to computers in the computer labs on campus or could use their own computers. Computers in computer labs had T1 Internet connections and had all the necessary software, such as Windows Office, Web browsers, Adobe, etc.

\section{Data Collection}

The examination of students' motivation in this study included three perspectives: motivation to use computer tools, motivation to learn in the web-enhanced environment, and desire to learn in the future (continuing motivation). Both qualitative and quantitative data 
were collected via surveys, instructor's observation, students' final grades, and records of the use of CMC tools.

The evaluation of students' learning involved four areas: academic achievement, competence, emotion level, and learning satisfaction. Data were collected from students' final grades (cumulative course points (CCP) and letter grades), surveys (confidence in computer use, frequency of computer use, emotional level, learning satisfaction, web site performance), open-ended survey questions, the course instructor's observations and CMC tools communication. The instructor was interviewed at the end of the course to help understand students' learning in web-enhanced Coun620. CMC tools used for communication in this course included a bulletin board, chat rooms, and email. Records of bulletin board and chat room use were collected through the WebCT server. Information about messages posted on the bulletin board, including the post time (month, date, time), senders (first and last name), subject, content, and targeted person, were collected. To analyze the use of the bulletin board, qualitative data were converted into quantitative information, including the number of words in the messages, the purpose of the message (academic, social, or both), targets (general, personal, or both), and the numbers of respondents. In addition, quantitative data regarding WebCT use included the number of hits, and the number of messages read and posted to the bulletin board by students.

Hypotheses for each research question and its sub-questions were set up to examine how students computer use changed during this course, the relationships between their motivation and learning experiences, and the indicators of adoption of computer tools. The changes in students' ability to use computer tools as well as the frequency and purposes of computer use were derived from the questionnaires in the pre- and post- Surveys of 
Computer Tools Competence. The relationships of students' motivation and learning experiences were examined via data from the Post-survey of Computer Tools Competence, the $2^{\text {nd }}$ evaluation of Emotion Level when Using Computer Tools, and the Course Evaluation. The test for indicators of adoption of computer tools involved students' continuing motivation to use computer tools and changes in bulletin board use. Table 3-1 lists the information gleaned from these data sources. Methods and expected outcomes for research questions are explained in more detail in the following sections. 
Table 3-1

The Data Sources, Methods, and Expected Outcomes for Research Questions in This Study

\begin{tabular}{|c|c|c|c|c|}
\hline & Subquestions & Data Sources: & Methods: & Expected outcomes: \\
\hline RQ 1 & $\begin{array}{l}\text { (1) confidence using } \\
\text { computer tools } \\
\text { (2) frequency of computer } \\
\text { tools use } \\
\text { (3) awareness of ACES } \\
\text { technological } \\
\text { competencies } \\
\text { (4) emotions regarding } \\
\text { using computers }\end{array}$ & $\begin{array}{l}\text {-- computer tools } \\
\text { competence (Pre survey), } \\
\text { Sections I, II, IV } \\
\text {-- computer tools } \\
\text { competence (Post } \\
\text { survey), Sections I, III } \\
\text { \& IV } \\
\text {-- survey of emotional } \\
\text { level }\end{array}$ & $\begin{array}{l}\text { Quantitative: } \\
\text { Hypothesis 1-1 } \\
\text { Hypothesis 1-2 } \\
\text { Hypothesis 1-3 } \\
\text { Hypothesis 1-4 } \\
\text { Dependent T test at } \alpha= \\
.05\end{array}$ & $\begin{array}{l}\text { Statistically significant } \\
\text { differences in students' } \\
\text { computer use after taking this } \\
\text { course. }\end{array}$ \\
\hline RQ 2 & $\begin{array}{l}\text { (1) WBI design } \\
\text { motivated } \\
\text { students' learning } \\
\text { (2) WBI design } \\
\text { discouraged } \\
\text { students' learning }\end{array}$ & $\begin{array}{l}\text {-- Instructor's observation } \\
\text { collected via interview } \\
\text {-- survey of course } \\
\text { evaluation, Sections IV } \\
\text { 1a \& 1b. } \\
\text {-- computer tools } \\
\text { competence (Post } \\
\text { survey), Section V }\end{array}$ & $\begin{array}{l}\text { Qualitative: } \\
\text { Interview the instructor } \\
\text { Students' statements in } \\
\text { the survey } \\
\text { Quantitative: } \\
\text { Descriptive data (N, } \\
\text { percent) }\end{array}$ & $\begin{array}{l}\text { Explore the relationships } \\
\text { between students' learning and } \\
\text { WBI features, with a description } \\
\text { of quantitative data (number, } \\
\text { percentage) and qualitative } \\
\text { information of their use of WBI } \\
\text { features. }\end{array}$ \\
\hline
\end{tabular}


Table 3-1 (continued)

The Data Sources, Methods, and Expected Outcomes for Research Questions in This Study

\begin{tabular}{|c|c|c|c|c|}
\hline & Subquestions & Data Sources: & Methods: & Expected outcomes: \\
\hline RQ 3 & $\begin{array}{l}\text { (1) Motivation \& } \\
\text { academic } \\
\text { achievement } \\
\text { (2) Motivation \& } \\
\text { computer tools use } \\
\text { (3) Motivation \& } \\
\text { learning } \\
\text { satisfaction } \\
\text { (4) Motivation \& } \\
\text { feeling }\end{array}$ & $\begin{array}{l}\text {-- course evaluation, } \\
\text { Sections I, II \& III } \\
\text {-- computer tools } \\
\text { competence (Post } \\
\text { survey), Sections I \& II } \\
\text {-- survey of emotional } \\
\text { level }\end{array}$ & $\begin{array}{l}\text { Quantitative: } \\
\text { Hypothesis 3-1 } \\
\text { Hypothesis 3-2 } \\
\text { Hypothesis 3-3 } \\
\text { Hypothesis 3-4 } \\
\text { Pearson/ Spearman } \\
\text { correlation test at } \alpha=.05\end{array}$ & $\begin{array}{l}\text { Statistically significant } \\
\text { correlation (SSR) between } \\
\text { motivation and the learning } \\
\text { experience. }\end{array}$ \\
\hline RQ 4 & $\begin{array}{l}\text { (1) Attitude toward } \\
\text { computer use in } \\
\text { the future } \\
\text { (2) Indicators of } \\
\text { changes in } \\
\text { practice }\end{array}$ & $\begin{array}{l}\text {-- computer tools } \\
\text { competence (Pre } \\
\text { survey), Section IV. } \\
\text {-- computer tools } \\
\text { competence (Post } \\
\text { survey), Section II. } \\
\text {-- course evaluation, } \\
\text { Sections IV, 4a \& 4b } \\
\text {-- WebCT bulletin board } \\
\text { messages } \\
\text {-- The Instructor's } \\
\text { observation (interview) }\end{array}$ & $\begin{array}{l}\text { Qualitative: } \\
\text { Interview the instructor } \\
\text { Students' statements in } \\
\text { surveys } \\
\text { Quantitative: } \\
\text { Descriptive data (N, } \\
\text { percent) } \\
\text { Hypothesis } 4-1 \\
\text { Hypothesis } 4-2 \\
\text { Hypothesis } 4-3 \\
\text { Pearson chi-square test at } \\
\alpha=.05\end{array}$ & $\begin{array}{l}\text { Explore students' attitudes } \\
\text { toward computer use in the } \\
\text { future (continuing motivation) } \\
\text { and how their computer use } \\
\text { changed after taking the course. } \\
\text { Statistically significant changes } \\
\text { in bulletin board use during the } \\
\text { course. }\end{array}$ \\
\hline
\end{tabular}




\section{Surveys}

Four surveys were designed to collect information regarding students' learning in Coun 620. Students were asked to identify themselves by using the last 4 digits of their Social Security Number on their surveys to facilitate matching their responses. Pre-survey of Computer Tools Competence (See Appendix B)

This survey collected students' background information and their ability to use computer tools. The survey was divided into five sections: demographics, a self-evaluation of computer tools competence, frequency and purposes of computer use, goals for using computer tools, and technical competence in the ACES standards. The survey was administered at the first class meeting to students who had agreed to participate in the study. All quantitative data were based on either a 5-point or 7-point scale. The choice of 5-point or 7-point was made based on the need for discrimination. A more delicate, 7-point scale was chosen to discriminate students' ability to use computers. A 5-point scale was sufficient to clarify frequency of computer use.

Section I: Demographics. There were seven demographic questions to collect students' personal information, including gender, age, ethnicity (Caucasian, African American, Asian, Hispanic, and other), main interest in counseling service (career development, parenting, relationship, marriage, mental health, school, drug \& alcohol, undecided, and other), years employed in a counseling-related field, level of computer use (no experience, beginner, intermediate, and advance), and experience with web-based courses (none, once, and more than once).

Section II: Computer tools competence. Ten computer tools, including CMC tools, were mentioned: Microsoft Word, PowerPoint, web browser, electronic mail, Internet search 
tools, bulletin board, chat room, multimedia, Adobe Reader, and listserv. Students evaluated their ability to use these computer tools on a 7-point of Likert scale-from No experience (1) to Very Confident (7). This represented their ability to use computer tools before taking this course.

Section III: The frequency and purposes of computer tools use. In this section, participants identify the frequency and purposes for using the same ten computer tools. Participants determined how much they used computer tools and marked their responses on “frequency of use" in a 7-point scale - from (1) None (implied 'no use') to (7) Always (implied 'most of time a day'). Intermediate scale points were seldom (2), monthly (3), weekly (4), daily (5), and frequently (6). An explanation of frequency of use was provided to guide participants. They were required to provide their "purposes of computer tool use" that involved four categories: Academic (any work related to getting grades), Socialized (communications with others), Shopping, and Other. If participants had no use for a computer tool, they did not need to answer its purpose of use; otherwise, they were given multiple choices to describe their use for each computer tool. This represented their computer use before they started this course.

Section IV: The goals of computer use. Five questions explored students' goals regarding the use of computer tools in this course. The questions explored (1) the use of Internet related software in professional development, (2) the use of computer software in study, (3) the plan of developing the ability to use computer tools, (4) the expectation of using computer tools in counseling services, (5) the application of computer tools in counseling services. A 5-point scale was chosen to describe their goals regarding computer 
tool use, from No interest (1) to Very positive (5). This indicated their goals regarding computer use before taking this course.

Section V: Technical competencies of the ACES. Twelve items of technological competence defined by the Association for Counselor Education and Supervision, were provided to inquire about participants' technological competence. Students indicated their competence on a 5-point scale from Very poor (1) to Excellent (5), before taking this course. Post-survey of Computer Tools Competence (See Appendix C)

The post- survey was delivered at the last class meeting. It consisted of five sections; four were repeated from the Pre-survey of Computer Tools Competence, including computer tools competence, the frequency and purposes of computer tools use, the goal of computer use, and the technical competence of the ACES. The survey also included open-ended questions regarding experiences using computer tools. Responses in this survey indicate computer tools competence, frequency and purpose of use, the goal of computer use, and the ACES technical competence at the end of this course.

Section I: Computer tools competence. The same as the Pre-survey of Computer Competence, in Section II.

Section II: The goals of computer use. The same as the Pre-survey of Computer Competence, in Section IV.

Section III: The frequency and purposes of computer tools use. The same as the Presurvey of Computer Competence, in Section III. 
Section IV: the technical competencies of the ACES. The same as the Pre-survey of Computer Competence, in Section V.

Section V. The experience of using computer tools in this course. Four open-ended questions explored participants' experience using computer tools during this course. These questions asked the respondents to (1) describe the impact of using computer tools in the course, (2) describe the motivation to use computer tools, (3) compare their ability to use computer tools before and after the course, and (4) make comments or suggestions about the course.

The Survey of Emotion Level Regarding the Use of Computer Tools (See Appendix D)

The Survey of Emotion Level was delivered twice during the semester (at the middle and the end of the semester). Students were asked to evaluate their feelings regarding the use of computer tools during their learning period. They were given 14 responses, 7 negative (stressed, worried, anxious, alone, confused, bored, and uncertain) and 7 positive (satisfied, happy, creative, concentrated, pleased, confident, and interested), and asked to use a 7-point scale, ranging from Not at all (1) to All the time (7), to rate their level of response to each. Participants were then asked to summarize their feelings by completing one sentence: “Overall, I felt when I used them."

The 7-point scale was chosen in this questionnaire because emotion level regarding the use of computer tools can be differentiated better in a 7-point than a 5-point scale. Course Evaluation (see Appendix E)

A Course Evaluation was delivered at the end of the course in order to understand students' experiences. The Course Evaluation Survey was divided into four sections: the performance of the course web site, learning satisfaction, factors that affected the learning 
experience, and feedback. The feedback section included an additional set of statements designed to determine what features motivated students to use computer tools, which discouraged them, and five open-ended questions. It also collected demographic information, including student status (part time, full time) and job status (part time, full time, or neither).

Section I: Performance of the course web site. The performance of the web site was evaluated by asking students to consider accessibility, speed, reliability, maintenance, use, availability of links, navigation, and overall quality. A 5-point scale, ranging from Very Poor (1) to Excellent (5), was used to assess these aspects of the web site's performance. A score for the performance of the course web site was calculated based on the average of all items.

Section II: Learning satisfaction. Learning satisfaction with both web-based and classroom sessions was measured. Students were asked to evaluate (1) richness of lecture notes, (2) supplementary materials, (3) assignments, (4) activities, (5) technical support, (6) communication on the Web, (7) accessibility of instructors and (8) overall learning. Once again, a 5-point scale, ranging from Very Poor (1) to Excellent (5), was used to assess learning satisfaction. Separate scores were calculated for learning satisfaction in web-based settings and in classroom settings. Items related to web-based settings included 1a, 2a, 3a, 4a, 5, 6, and 8a. Items related to classroom settings included $1 \mathrm{~b}, 2 \mathrm{~b}, 3 \mathrm{~b}, 4 \mathrm{~b}, 7$, and $8 \mathrm{~b}$.

Section III: Factors that affected the learning experience. Students were asked to use a 7-point scale (from Very Discouraging (1) to Very Motivating (7)) to rate 23 items that affected their learning experience. These items included:

- the course web site (appearance, performance, navigation), its features (tutorials, technical support, web-based activities, learner-centered design, instructions, web-based resources, collaborative activities, grades check, web-based quizzes, contents); 
- $\quad \mathrm{CMC}$ tools (bulletin board, chat room);

- computers (access, performance, Internet connection);

- communication (with instructor, with classmates);

- course features (optional assignment choices, flexibility of learning schedule);

- audio/video clips. (Even though audio/video clips were not part of features in this course, they were added for some students who had experiences using them.

If a student could not answer a question, he/she could select 'No Opinion.'

Section IV: Feedback. This section included six questions. The first question included two sub-questions, each of which included a set of statements. First, participants were asked to describe their motivation to use computer tools using the same 10 items as had been used on the surveys of computer competence. Respondents could indicate they were either 'motivated', 'discouraged', or had 'no opinion.' They were also asked to respond to more specific questions regarding how WBI design and the learning environment motivated them to use computer tools, or discouraged their use. Participants were encouraged to add additional comments to explain why they were motivated or discouraged.

The second question included a yes-no question that asked students whether the course web site enhanced their learning, and an open-ended question that asked them to discuss their reasons.

The third question asked participants to remember how many times they used the course web site and WebCT site per week. This question used a 'fill-in-the-blank' format. An open-ended question asked what they used the sites for. 
The fourth question used a simple yes/no format to explore how students thought they might use computer tools in the future. An open-ended question asked them to go into more detail regarding their future use of computer tools.

The fifth question was another yes/no that asked students whether they spent more time in this course compared to other courses. An open-ended question then asked them to explain their answer.

The sixth question requested their feedback on the WBI design of this course.

\section{Data Analysis}

Data analysis was conducted via a statistical software program-Advanced Statistical Package for the Social Sciences (SPSS) Windows version 9.0. Descriptive analyses consisted of frequency, percent, range, mean, and/or standard deviation. Inferential methods for hypotheses included the Pearson, Spearman, and point biserial correlations, which were applied to understand the relationship between students' performance, emotions, learning satisfaction, ability to use computer tools, continuity in using computer tools, etc. A Pearson Chi-square contingency table was applied to identify the uses of the bulletin board by weeks. A dependent T-test was applied to examine individual differences in the ability to use computer tools. A parameter of .05 was used in all hypotheses tests.

\section{Hypotheses and Variables}

Null hypothesis 1-1. There was no statistically significant change in students' confidence about using computer tools before and after the course. The independent variable was the time (at the beginning, at the end); the dependent variable was the confidence in using computer tools. A dependent T-test was chosen at $\alpha=.05$. 
Null hypothesis 1-2. There was no statistically significant difference in the frequency of computer use before and after the course. The independent variable was the time of the course (at the beginning, at the end); the dependent variable was the frequency of computer use. A dependent T-test was chosen at $\alpha=.05$.

Null hypothesis 1-3. There was no statistically significant change in students' awareness of ACES's technological competence before and after the course. The independent variable was the time of the course (at the beginning, at the end); the dependent variable was the sub-scale of each ACES technological competence. A dependent T-test was chosen at $\alpha=.05$.

Null hypothesis 1-4. There was no statistically significant change in students' feelings while using computer tools at the middle and at the end of the course. The independent variable was the time of the course (at the middle, at the end); the dependent variable was students' feelings while using computer tools. A dependent T-test was chosen at $\alpha=.05$.

Null Hypothesis 3-1. There were no statistically significant correlations between students' motivation and their academic achievement (cumulative course points, cumulative course points requiring computer tools use). The independent variable was students' motivation to use computer tools. The dependent variables were the cumulative course points (CCP) for all assignments and the cumulative course points requiring computer tools use (CCP_computer). Appropriate correlation tests were chosen at $\alpha=.05$.

Null Hypothesis 3-2. There were no statistically significant correlations between students' motivation and computer tools use (confidence in use, computer skills improved). The independent variable was students' motivation to use computer tools. The dependent 
variables were confidence in using computer tools and improvement in computer skills. Appropriate correlation tests were chosen at $\alpha=.05$.

Null Hypothesis 3-3. There were no statistically significant correlations between students' motivation and learning satisfaction and the course site performance. The independent variable was students' motivation; the dependent variables were their learning satisfaction and the course site performance. Appropriate correlation tests were chosen at $\alpha$ $=.05$.

Null Hypothesis 3-4. There were no statistically significant correlations between students' motivation and their feelings regarding using computer tools. The independent variable was students' motivation; the dependent variable was the emotion while using computer tools. Appropriate correlation tests were chosen at $\alpha=.05$.

Null hypotheses 4-1. (Research question IV, subquestion (2)) There was no statistically significant relationship between the purposes for using the bulletin board and the time period (weekly, biweekly, or monthly). The independent variables were the purposes for using the bulletin board (academic, social, or both) and the time period during the course. The dependent variable was the number of messages posted on the bulletin board. A Pearson Chisquare test was chosen at $\alpha=.05$.

Null hypotheses 4-2. (Research question IV, subquestion (2)) There was no statistically significant relationship between the communication targets of posted messages and the time period. The independent variables were the communication targets of posted messages (general, personal, or both) and the time period (weekly, every two weeks, or monthly). The dependent variable was the numbers of messages posted to the bulletin board. A Pearson Chi-square test was chosen at $\alpha=.05$. 
Null hypotheses 4-3. (Research question IV, subquestion (2)) There was no statistically significant relationship between the numbers of responses for messages and time periods (weekly, every two weeks, or monthly). The independent variables were the time period and the categories of the numbers of responding messages. The dependent variable was the ratio of responses in a time period, which were converted from the number of messages posted on the bulletin board. A Pearson Chi-square test was chosen at $\alpha=.05$.

\section{Ethical Considerations}

An approval by the Institutional Review Board (IRB) for the protection of human research participants was received before starting this research. A consent and information form was sent to students at the beginning of the course. All students realized that there were no known or expected risks from participating in this study and that their participation was voluntary. They understood that they would be free to withdraw anytime. Their refusal to join this study would not affect their grades or work opportunities, and that all information in this study would remain confidential. No personal information would be identified in this study. 


\section{Chapter 4: Results}

This study assumed that counseling students would be motivated to use computer tools in a web-enhanced learning environment. Four research questions in this study investigated if and how students were motivated to learn to use computer tools in a web-enhanced counseling course. Research question 1 (RQ1) was concerned with what changes in computer tool use occurred in students. Four areas were examined: confidence in computer use, frequency of computer tools use, the awareness of ACES's technological competence criteria, and feelings regarding computer use. Research question 2 (RQ2) explored what features of WBI design would motivate or discourage students' learning. Research question 3 (RQ3) examined students' motivation to learn. Four sub-questions investigated the relationships between motivation and academic achievement, confidence and skills, learning satisfaction, and emotions. Research question 4 (RQ4) explored what indicators of changes in practice (adoption) occurred in students. Two sub-questions explored students' attitudes toward computer use in the future and how they may use them differently.

\section{Demographics}

To collect students' demographic information, a pre-survey of computer tools competence was administrated during the first week of the course. It collected information regarding students' backgrounds, confidence and frequency in using computer tools, and their awareness of the 12 ACES's technological competences.

General demographics. Thirty-two West Virginia University students who took Coun 620 in the fall semester of 2002 participated in the study. Among them, eight were male $(25 \%)$ and 24 were female (75\%). Most were traditional students. Nineteen students (59\%) 
were between 18 and 25 years old, and $11(34 \%)$ were between the ages of 26 and 35 . Most students described themselves as Caucasian (91\%). Students were interested in different counseling services, such as in relationships (19\%), school counseling (44\%), and mental health (19\%). Six students $(19 \%)$ had no specific career plans. Among students who took the course, only ten $(31 \%)$ had previous counseling-related experiences. Seven students $(22 \%)$ reported that they were employed full-time, 19 (59\%) had part-time jobs, and four were not working. Most of them (84\%) were full-time students. Table 4-1 provides detailed demographics on students who participated in this study.

\section{Table 4-1.}

Students' General Demographics $(N=32)$

\begin{tabular}{llc}
\hline & Demographic: & $n$ \\
\hline Gender: & Male: & 8 \\
& Female: & 24 \\
\hline Age: & $18-25:$ & 19 \\
& $26-35:$ & 11 \\
& $>45:$ & 2 \\
\hline Ethnicity: & Caucasian: & 29 \\
& African American: & 2 \\
& Asian: & 1 \\
& &
\end{tabular}


Table 4-1.

Students' General Demographics $(N=32)$ (Continued)

\begin{tabular}{|c|c|c|}
\hline \multicolumn{2}{|c|}{ Demographic: } & \multirow{2}{*}{$\frac{n}{1}$} \\
\hline Main interest in & Career development: & \\
\hline $\begin{array}{l}\text { counseling } \\
\text { services. }\end{array}$ & Relationship: & 6 \\
\hline & Mental health: & 4 \\
\hline & School: & 14 \\
\hline & Undecided: & 6 \\
\hline & Other: & 1 \\
\hline \multirow{3}{*}{$\begin{array}{l}\text { Level of } \\
\text { Computer use: }\end{array}$} & Beginner: & 7 \\
\hline & Intermediate: & 23 \\
\hline & Advanced: & 1 \\
\hline \multirow{4}{*}{$\begin{array}{l}\text { Work years in } \\
\text { counseling } \\
\text { related }\end{array}$} & None: & 22 \\
\hline & $1-5$ & 9 \\
\hline & $6-21$ & 0 \\
\hline & $>21:$ & 1 \\
\hline \multirow{3}{*}{$\begin{array}{l}\text { Prior online } \\
\text { learning: }\end{array}$} & None: & 24 \\
\hline & Once: & 6 \\
\hline & More than once: & 1 \\
\hline \multirow[t]{3}{*}{ Job status: } & Full time: & 7 \\
\hline & Part time: & 19 \\
\hline & None: & 4 \\
\hline \multirow[t]{3}{*}{ Student status: } & Full-time student: & 27 \\
\hline & Part-time student: & 4 \\
\hline & No response: & 1 \\
\hline
\end{tabular}


Computer confidence. All students reported that they had had some experience using computers. Most students (23) reported that they were intermediate computer users; seven students reported that they were beginners and one considered him/herself an advanced user. In the survey of computer tools competence (see appendix B) taken at the beginning of the course, students were asked to describe their confidence in the use of 10 computer tools (section II), including Microsoft Word, a web browser, PowerPoint, Email, search tools, bulletin board, chat room, multimedia, Adobe Reader, and listserv. A 7 point scale, ranging from No experience (1) to Very confident (7) was used to measure computer tools confidence. Seven students $(22 \%)$ reported that they were not confident in the use of computer tools, $10(31 \%)$ were moderately confident, $16(50 \%)$ were confident, and $6(19 \%)$ reported they were very confident in computer use ${ }^{1}$. Students in this study reported a higher level of confidence in computer use than had students in the pilot study. Detailed information regarding students' confidence using computer tools before taking this course can be found in the Pre-Survey column of Table 4-2 (p. 72). Table 4-2, in the section of RQ1, provides statistics regarding students' confidence in computer use in this course.

Frequency of computer tools use. A 7-point scale (1 indicated 'No Use' and 7 indicated 'Always') was used to rate the frequency of computer tools use (see Appendix B, section III). Intermediate scale points were seldom (2), monthly (3), weekly (4), daily (5), and frequently (6). Prior to taking this course, the average student used email on a daily base $(M=5.45)$, and used Microsoft Word $(M=4.66)$, a web browser $(M=4.59)$, and search tools $(M=4.09)$ on a weekly base. A Bulletin Board $(M=1.71)$ and chat room $(M=1.53)$ were

\footnotetext{
${ }^{1}$ These four scales were converted from the 7-point scale. "Not confident" was equivalent to point 1 on the scale; "Moderately confident" was equivalent to points 2 and 3 on the scale; "Confident" was equivalent to points 4 and 5, and "Very confident" was equivalent to points 6 and 7.
} 
used the least. Detailed information on the frequency of using computer tools before taking this course can be found in the 'Pre-survey' column of Table 4-3 (p.73). Table 4-3 provides statistics related to frequency of computer use in this course.

ACES' technological competencies. Students were also asked to use a 5-point scale, from Very Poor (1) to Excellent (5), to indicate their levels of awareness of the 12 ACES technological competencies (Appendix B, section V). Only six competencies (Items 1, 5, 8, $9,10,11)$ are reported here, because the others were not relevant to this web-enhanced course. Students felt most competent using email (ACES \#5), followed by the ability to perform an Internet search (ACES \#11 and \#8). The ability to use presentation software (ACES \#1) ranked lower than fair. Detailed information on students' awareness of ACES's technological competencies before taking this course can be found in the 'Prior' column of Table 4-4 (p. 75). Table 4-4 provides the comparison of awareness of ACES's technological competencies before and after the course.

Most participants in this study were between 18 and 35 years old. They had experience using computer tools and some of them reported that they had advanced skills; however, most of them were not familiar with some CMC tools (e.g. bulletin board, chat room). Most of students did not have experience in a counseling related field. They had busy schedules in their jobs and study. Only three were full-time students who were not employed.

\section{Research Question 1 (RQ1): Changes in Students' Computer Use}

The instructor of Coun 620 provided a web-enhanced environment to help students improve their technological competence. To understand students' technological competence, pre- and post-surveys were administered to determine changes in students' computer tools use before and after the course. The question focused on three areas: (1) confidence, (2) 
frequency, and (3) the awareness of six ACES's technological competencies. To understand the changes in students' emotions while using computers, a survey of emotional level was administrated twice (at the middle and the end of the semester).

Changes of Confidence in Computer Uses (Hypothesis 1-1)

Analysis of pre- and post-surveys of computer competence indicated that students showed statistically significant differences in their confidence using computer tools before and after the course $(t=5.25, p=.0001, d f=31)$. Students showed significant differences in the use of all 10 computer tools, even though they were not required to use some tools (i.e. chat room, multimedia, and listserv) in Coun 620. Reliability estimates, as measured by Cronbach's alpha, of confidence using computer in pre- and post- survey were 0.95 and 0.91 . For detailed information regarding changes in students' confidence using computer tools, see Table 4-2.

\section{Changes in Frequency of Computer Use (Hypothesis 1-2)}

Students significantly increased the frequency with which they used computer tools. They used Microsoft Word, web browsers, email, and search tools on a daily basis throughout the course. They used the bulletin board and Adobe Reader more frequently than before. Students showed the greatest difference in how frequently they used web browsers $(t$ $=4.00, p=.0001, d f=31)$, the bulletin board, $(t=7.48, p=.0001, d f=31)$, and Adobe Reader $(t=4.47, p=.0001, d f=31)$. However, there were no significant differences in the changes in use of email, the chat room, or the listserv. Students still used email daily, as they had at the start of the class. Their use of the chatroom increased slightly, although its use was not required in this course. There was no increase seen in the frequency of listserv use because it was not associated with this course. The reliabilities for frequency of computer use 
in pre- and post- surveys, measured by Cronbach's alpha, were 0.81 and 0.80 . Table $4-3$ presents statistics related to frequency of computer use, based on the answers from the preand post-survey of computer competence.

Table 4-2

Students' Confidence Using Computer Tools $(N=32)$

\begin{tabular}{|c|c|c|c|c|c|c|}
\hline \multirow[b]{2}{*}{ Computer Tool } & \multicolumn{2}{|c|}{ Pre-survey } & \multicolumn{2}{|c|}{ Post-survey } & \multirow[b]{2}{*}{$t$} & \multirow[b]{2}{*}{$\begin{array}{c}p \\
\text { (2-tailed) }\end{array}$} \\
\hline & $M$ & SD & $\bar{M}$ & $S D$ & & \\
\hline Microsoft Word & 6.03 & 1.43 & 6.47 & 0.92 & 2.44 & .021 \\
\hline Web Browser & 5.00 & 1.61 & 5.62 & 1.29 & 3.40 & .002 \\
\hline PowerPoint & 3.97 & 2.18 & 4.72 & 2.00 & 3.48 & .002 \\
\hline Email & 6.00 & 1.41 & 6.34 & 1.04 & 2.08 & .046 \\
\hline Search tools & 5.47 & 1.59 & 6.00 & 1.19 & 2.13 & .042 \\
\hline Bulletin Board & 3.72 & 1.67 & 5.41 & 1.43 & 6.14 & .000 \\
\hline Chat room & 3.68 & 1.85 & 4.48 & 1.73 & 2.84 & .008 \\
\hline Multimedia & 4.13 & 1.77 & 4.84 & 1.50 & 3.40 & .002 \\
\hline Adobe Reader & 4.69 & 1.94 & 5.66 & 1.40 & 4.11 & .000 \\
\hline Listserv & 3.50 & 1.97 & 4.19 & 1.86 & 2.27 & .030 \\
\hline Overall & 4.62 & 1.45 & 5.37 & 1.10 & 5.25 & .000 \\
\hline
\end{tabular}


Table 4-3

Students' Frequency of Computer Tools Use $(N=32)$

\begin{tabular}{|c|c|c|c|c|c|c|}
\hline \multirow[b]{2}{*}{ Computer Tool } & \multicolumn{2}{|c|}{ Pre-survey } & \multicolumn{2}{|c|}{ Post-survey } & \multirow[b]{2}{*}{$t$} & \multirow{2}{*}{$\begin{array}{c}p \\
\text { (2-tailed) }\end{array}$} \\
\hline & $M$ & $S D$ & $M$ & SD & & \\
\hline Microsoft Word & 4.67 & 1.07 & 5.25 & 1.16 & 2.38 & .024 \\
\hline Web Browser & 4.59 & 1.13 & 5.44 & 0.91 & 4.00 & .000 \\
\hline PowerPoint & 2.09 & 0.82 & 2.53 & 1.11 & 2.37 & .024 \\
\hline Email & 5.45 & 0.81 & 5.42 & 0.99 & 0.18 & .861 \\
\hline Search tools & 4.10 & 1.25 & 4.97 & 1.26 & 3.40 & .002 \\
\hline Bulletin Board & 1.71 & 0.53 & 3.55 & 1.34 & 7.48 & .000 \\
\hline Chat room & 1.53 & 0.57 & 2.09 & 1.28 & 2.56 & .016 \\
\hline Multimedia & 2.80 & 1.27 & 3.17 & 1.32 & 1.43 & .163 \\
\hline Adobe Reader & 3.03 & 1.20 & 3.94 & 1.16 & 4.47 & .000 \\
\hline Listserv & 2.06 & 1.10 & 2.31 & 1.42 & 0.86 & .397 \\
\hline Overall & 3.20 & 0.62 & 3.87 & 0.71 & 5.39 & .000 \\
\hline
\end{tabular}

Some students also increased the purposes for which they used computer tools. In addition to using them for academic purposes, students also used them to communicate with others, go shopping, for their work, etc. The evaluation of the changes in computer tools use considered both frequency and purpose of use during the course ${ }^{2}$. More than half of the students increased computer tools use, which included Microsoft Word (53.1\%), web

\footnotetext{
${ }^{2}$ In determining whether the use of a computer tool increased, both frequency and purpose were considered. The frequency with which a computer tool was used was considered to have in creased if (1) a student used the tool more often, or (2) a student found new uses for the computer tool. The use of a computer tool was not counted as increasing, if (1) a student maintained the same or decreased its frequency of use, or (2) the frequency of use did not increase and the student did not use the tool for a new purpose.
} 
browser (68.8\%), PowerPoint (34.4\%), Email (28.1\%), search tools (75\%), bulletin board (78.1\%), and Adobe Reader (59.4\%). This information is in Table 4-5.

Table 4-5:

Change in Computer Tools Use During the Semester $(N=32)$

\begin{tabular}{lll}
\hline & \multicolumn{2}{c}{ Increase in use } \\
\cline { 2 - 3 } Computer Tool & $\mathrm{n}$ & $P(\%)$ \\
\hline Microsoft Word & 17 & 53.1 \\
Web Browser & 22 & 68.8 \\
PowerPoint & 11 & 34.4 \\
Email & 9 & 28.1 \\
Search tools & 24 & 75.0 \\
Bulletin Board & 25 & 78.1 \\
Chat room & 15 & 46.9 \\
Multimedia & 15 & 46.9 \\
Adobe Reader & 19 & 59.4 \\
Listserv & 8 & 25.0 \\
\hline
\end{tabular}

Changes in ACES's Technological Competence (Hypothesis 1-3)

Students exhibited statistically significant increases on ACES \#1, ACES \#8, ACES $\# 10$, and ACES \#11. Students were very competent in email use $(M=4.78)$, though there was no significant difference found when comparing the use of email before and after taking the course. However, students did not show change in their awareness of the legal and ethical concerns of Internet counseling services. This may be attributed to the fact that the course put more emphasis on accessing career information than on the legal and ethical issues of 
career guidance and counseling. For detailed descriptions of ACES technological

competencies and results refer to Table 4-4.

Table 4-4:

Comparison of ACES’ Technological Competencies $(N=32)$

\begin{tabular}{|c|c|c|c|c|c|}
\hline \multirow{2}{*}{$\begin{array}{c}\text { Description of } \\
\text { the ACES' technological competence }\end{array}$} & \multicolumn{2}{|c|}{ prior } & \multicolumn{2}{|c|}{ post } & \multirow[b]{2}{*}{$t$} \\
\hline & $M$ & $S D$ & $M$ & $S D$ & \\
\hline $\begin{array}{l}\text { 1. Be able to use productivity software to } \\
\text { develop web pages, presentations, letters, } \\
\text { reports, etc. }\end{array}$ & 2.91 & 0.96 & 3.47 & 0.98 & $3.36^{* *}$ \\
\hline 5. Be able to use email. & 4.72 & 0.68 & 4.78 & 0.42 & 0.63 \\
\hline $\begin{array}{l}\text { 8. Be able to help clients search for various } \\
\text { types of counseling-related information } \\
\text { about careers, employment opportunities, } \\
\text { education and training opportunities, } \\
\text { financial assistance/scholarships, treatment } \\
\text { procedures, and social and personal } \\
\text { information. }\end{array}$ & 3.78 & 1.13 & 4.19 & 0.82 & $2.35^{*}$ \\
\hline $\begin{array}{l}\text { 9. Be aware of the legal and ethical codes } \\
\text { which relate to counseling services via the } \\
\text { Internet. }\end{array}$ & 3.75 & 1.14 & 3.91 & 0.96 & 0.63 \\
\hline $\begin{array}{l}\text { 10. Understand the strengths and weaknesses of } \\
\text { counseling services provided via the } \\
\text { Internet. }\end{array}$ & 3.41 & 1.19 & 3.97 & 1.02 & $2.74 * *$ \\
\hline $\begin{array}{l}\text { 11. Be able to use the internet for finding and } \\
\text { using continuing education opportunities in } \\
\text { counseling. }\end{array}$ & 3.84 & 1.02 & 4.22 & 0.79 & $2.68^{*}$ \\
\hline
\end{tabular}




\section{Changes in Emotions while Using the Computer (Hypothesis 1-4)}

Emotional response to using computer tools ${ }^{3}$. Students' emotional response to using computer tools was collected via the survey of emotional level (appendix D). A 7-point scale ranging from Not at all (1) to All the time (7) was used to measure students' feelings while using computer tools. The scale was designed to discover how frequently and intensely students experienced specific positive or negative reactions while using computer tools. In order to have a consistent scale for all statements, students' responses were recoded using the following two rules:

1. Negative statements, such as "I felt anxious using them," were given a score from -6, "All the time" to 0 , "Not at all".

2. Positive statements, such as "I felt satisfied with them," were given a score from +6 , "All the time", to 0, "Not at all".

The average of all 14 statements was calculated, and assumed to represent an individual student's emotional level while using computer tools. A higher positive score indicated that students had a more positive emotional response to using computer tools (e.g. happiness, satisfaction, pleasure, confidence, interest, etc.) than a lower positive score. A lower negative score indicated that students had a more negative response to using computer tools (e.g. anxiety, stress, worry, confusion, uncertainty, etc.) than a score near zero. Students were also asked to complete a sentence, "Overall, I felt when I used them," which was to summarize their feelings about their experiences using computer tools in the course.

\footnotetext{
${ }^{3}$ In this study, the terms "emotions" and "feelings" are inter changeable in the discussion of computer use. The use of emotions while using computer tools, emotional response to computer tools use, and feelings regarding computer tools use have the same meanings.
} 
In all, 31 of 32 students took the survey at the middle of the semester. 28 students filled in the sentence regarding their emotions when using computer tools. About 50 percent of students had positive feelings and 50 percent had negative feelings about using computer tools. Detailed statistics are given in Table 4-6.

The second survey of emotional response to computer use was delivered at the final session of the course. Among the 31 students who completed this survey, more had positive feelings about computer use than they had reported in the first survey. Analysis of this survey indicated that 18 students had positive feelings about computer use, while 9 students had negative feelings while using computer tools. There was a significant difference in the results of two surveys $(t=2.22, p=.035, d f=29)$, indicating that students became significantly more positive toward using computer tools during this course. Reliability of the first and second survey of emotional level were both 0.87 as measured by Cronbach's alpha.

No statistically significant relationships were found between students' feelings about computer use and how their use of computers changed, their confidence when using computers, their skill improvement, etc. The data cannot fully explain the changes in their feelings about computer use. In addition, the emotional response to computer tools use indicated that positive levels declined in the second survey $(-.79 \sim 2.0)$, compared with the first survey $(0.0 \sim 2.36)$. This showed that although some students had positive feelings toward computer use, the degree of their positive feelings weakened by the end of the course. The results of students' pre- and post survey emotional levels are shown in Table 4- 6. 
Table 4-6:

Comparison of Students' Emotional Response to Computer Tools Use $(N=31)$

\begin{tabular}{llccccc}
\hline $\begin{array}{c}\text { Survey } \\
\text { administration }\end{array}$ & Emotional level & Range & $M$ & $S D$ & $t$ & $p$ \\
\hline $\begin{array}{llllll}\text { 1st } \\
\text { (mid-semester) }\end{array}$ & 14 positive & $0.0 \sim 2.36$ & .35 & .95 & 2.22 & .035 \\
\hline 2nd (end- & 14 negative & $-1.50 \sim 0.43$ & & & & \\
semester) & 9 negative & $-0.86 \sim 0.50$ & & & & \\
& & & & & & \\
\hline
\end{tabular}

Research Question 2 (RQ2): WBI Features and Motivation to Learn

Coun 620 focused on career guidance and counseling in the Information Age. It provided a web-enhanced environment to motivate students to learn to use computer tools to access career information and knowledge via the Internet and demonstrated how to use computer tools for career guidance and counseling services. RQ 2 explored the relationships between WBI features and students' motivation to learn.

\section{Motivation and WBI Features}

Data concerning students' motivation to learn in Coun 620 were collected on the post survey of computer tools use (the open-ended questions in Section V) and the course evaluation (Question 1b in Section IV). In the course evaluation, students were given a list of 10 statements about being motivated and 10 statements about being discouraged, and were asked to check all statements that explained what influenced them to use computer tools. Those chosen most frequently in motivation to use computer tools were:

1. It will be helpful for my professional development (75\%)

2. The course provided plenty of supplementary materials $(59.4 \%)$

3. I felt confident using them (59.4\%) 
4. I practiced using them via web-based activities $(56.3 \%)$

5. It was convenient to communicate with others $(50 \%)$

6. I was in charge of my learning $(50 \%)$.

According to their responses, at least half of the students were encouraged by support from the WBI design of the course web site (supplementary materials, the design of webbased activities, ability to communicate with others, and learner-controlled environment). In addition, the need for professional development and confidence in computer use also played important roles in motivating students to use computer tools.

Students reported that they were discouraged by infrastructure problems and some WBI features. The most common problems that discouraged students from using computer tools, were:

1. Using the Internet is too time-consuming $(28.1 \%)$

2. The course workload was too heavy $(28.1 \%)$

3. The Internet connection was slow (25\%)

4. The quality of electronic communication is not as good as face-to-face $(21.9 \%)$ The WBI features that discouraged students included difficulty navigating the site, poorly organized structure, inconsistent information, and broken links.

The WBI design of this course featured need-directed supplementary resources, a learner-centered/learner-controlled environment, a communicative and collaborative environment, and goal-directed instructions. Activities and assignments were developed to exploit these features, with the support of integration of computer tools, intuitive navigation, non-linear structure, related content, and hyperlinks. The relationships between students' motivation and the WBI features are discussed below. 
Need-directed/content-related supplementary resources. Learning in Coun 620 students were supported by the supplementary resources with hyperlinks. Over 140 web-resources with hyperlinks were categorized into seven types of resources: Organizations, Selfawareness, Interviewing, Career exploration, Job readiness, Information center, Research, and Help. With the support of these resources, students did not have to search the Internet in order to implement their activities or assignments, which would have been stressful and time consuming for novice learners. Most students were motivated to learn with this feature. One student responded, "I enjoyed the activities instead of class. Some good resources.”

However, this feature could also lead to frustration when hyperlinks were broken, which occurred in a few cases. Most resources were linked to external web sites over which the instructor had no control. Most links were checked before the course started, but some were broken during the semester.

Learner-controlled/learner-centered environment. Learner-centered environments encourage students to take charge of their learning. To incorporate this feature, the WBI design had to include intuitive navigation, an organized structure, and related contents. It is important to have an organized structure and clear navigation; otherwise students can easily become confused and get lost in a web-based environment. Since learning on the Internet relies on technology much more than traditional learning in a classroom setting, technological problems can easily discourage students from taking-control of their learning. And of course, having ready access to a computer is critical.

A. Intuitive navigation and related content. The Coun 620 web site built in intuitive navigation that allowed students to interact with all pages from each page. For a detailed design of this feature, please refer to appendix A. With intuitive navigation and active 
hyperlinks, students could make their own choices based on their own learning strategies. They did not have to take the same paths to work on their activities or assignments. The course web site also provided different resources or tutorials for students, based on their computer skills. A "Before you start" page, for example, was available for novice students who could visit any page (activities, quiz, or tutorial pages) as often as they needed. One student said, "It made me take charge and not just depend on my professor to tell me what to do."

B. Infrastructure. Effective web-based learning relies heavily on the technological infrastructure used to deliver the course, including the Internet service provider (ISP), networks, the web sever, and the capability of the hardware and software of computer. Students' responses showed that infrastructure was a crucial issue, and one which had a significant impact on their learning. Students could be motivated by the web site when the infrastructure worked well, could be discouraged when it failed.

A few students were discouraged because they did not have computers at home or their computers were not compatible with the course requirements. One student said: "I was extremely frustrated with my limited access, by the requirement to use the computer to complete assignments."

One student was not able to access the home page of Coun 620 site at first because his/her computer at home had a conflict with the design of the home page. This student said, I'm on my home computer now. I've tried 3 times to access the web page, and each time I'm told "a connection error has occurred." This is very frustrating to me. 
The WebCT site in Coun 620 encountered a conflict with the ISP, America on Line (AOL). For unknown reasons, AOL subscribers had troubles accessing the WebCT site. One AOL user who was not able to access the course web site expressd his/her frustration about the problem:

I have been having extraordinary difficulty accessing the website for the past 3 days. After about 20 - 30 minutes of repeatedly trying to sign in I can occasionally get in. I then get kicked off the site after about 5 minutes. Additionally, I could not get into webCT. I'm certain I have the right name and password.....I have visited the website many times before as well as webCT. Any suggestions? I really need to access the site and get some work done. I have tried getting in from 3 different computers.

C. Disorganized structure. The structure of web site also affected the students-centered feature. Where the structure was disorganized, it impeded students' ability to control their learning. Some students reported that the instructions and navigation were not clear enough. Students reported that they had to hunt for assignments and activities because they were scattered among 10 Course Unit pages and the Activities page. One student said: "We had to go to many places on the website to figure out our assignment." Another said, "Some info was on web syllabus, other info on 'course units', hard to navigate."

In addition, Coun 620 included one course web site (which posted most course materials and resources) and a WebCT site (which provided a bulletin board, a chat room, and the ability to check grades). A few students reported that the multiple websites confused them. One student suggested: "These need to be in one central location for each assignment 
per instructional unit. I was constantly going from place to place trying to make sure I didn't miss anything."

The disorganized structure confused students so they were not able to work independently. One student said: "I feel that using computer tools is a great way to enhance our learning. However, if the course is disorganized it can make things more confusing."

Clear goal-directed instructions. Clear instructions (e.g. a sitemap, syllabus, detailed schedule, graphic notions) can help students to learn. Detailed information that explains activities and assignments (the purpose of the lesson, learning expectations, procedure, time expectation, computer tools, evaluation, etc.) can guide students. However, inconsistent and unclear information can be very discouraging.

Even though the WBI design of Coun 620 emphasized goal-directed instructions, only four students $(12.5 \%)$ reported that this feature motivated them to use the computer. One student noted that, "The web based structure helped to keep me organized."

Several students reported their confusion about what assignments/activities they had to work on. They felt the instructions were not clear enough because information was inconsistent and there was not enough guidance to help them access related assignments and activities.

Students who were confused by inconsistent information were frustrated. One important example concerns the information supplied by the course schedule available on the web site and that distributed in class. The syllabus on the web site was designed to provide detailed information regarding weekly assignments, including in-class activities (e.g. lecture, discussion, Internet use) and assignments they had to work on outside of class. The intent of the design was to enable students to prepare for class on their own. However, it was difficult 
to coordinate with the progress of the course. Since there was no updated information provided to students before class, students were confused about what assignments were supposed to be done. Other inconsistencies between web site information and that handed out in class involved credit points available for certain activities, and the due dates of assignments.

These inconsistencies led to increased stress and wasted time because students had to contact others for clarification. As a result, most students felt the workload was too heavy. 25 students (78\%) felt that they spent more time on this course than most other courses, while only 6 students (19\%) felt they spent about the same amount of time and one (3\%) was undecided. Students who spent more time reported that they took a large amount of time to find and do assignments.

Collaborative and communicative environment. The availability of CMC tools in Coun 620 encouraged students to discuss, communicate and work together as well as get support from the instructor. However, some students were discouraged because they did not feel the instructor was accessible enough.

A. Support from CMC tools. Coun 620 provided the WebCT bulletin board and chat room as communication tools. It also required students to use email to contact the instructor and hand in assignments. The bulletin board was used more than the chat room. The instructor posted announcements on the bulletin board, and students posted messages to ask questions, share their learning, and to react with each other. Students could work with their group members with the support of CMC tools. One student said, "The bulletin board was helpful when I had questions or seeing what my classmates questions were." 
However, not all students used the bulletin board. Only 64 messages were posted during the 14 weeks the course was in session. Of these 64 messages, 15 were posted by the instructor to provide guidance for assignments and make announcements. Only 49 messages were posted by 23 students, including 11 students (48\%) who posted a single message, 4 students (17\%) posted two messages, 4 students (17\%) posted 3 messages, two students (9\%) posted 4 messages, and two students (9\%) posted five messages. One student did not use the bulletin board at all, while another read all posted messages. The mean number of messages read was 42.3 with a standard deviation of 20.2. Most students read bulletin board messages weekly, but a few students didn't use the bulletin board very much.

The chat room had a similar status: it was available for students to use, but there was no required activity or assignment associated with its use. Therefore, students did not show a significant change in their use of the chat room.

B. Accessibility of the instructor. Some students needed more support from the instructor than others. They reported that they were discouraged by lack of contact with the instructor. One student stated that “... the feedback from the instructor was not always answered in a reasonable amount of time."

Another student said, "I felt the web postings would be more helpful if the instructor replied to questions more often." However, in an interview, the instructor explained that his level of feedback was reasonable, and that it is impossible to meet the expectations of all students.

\section{Motivation to Use Computer Tools}

In general, students were motivated to use computer tools. Data were collected from the post-survey regarding computer tools competence, open-ended Questions 1 \& 2 in Section V, 
and the course evaluation (Section IV, $1 \mathrm{a}$ and $1 \mathrm{~b}$ ). Both qualitative and quantitative data were collected to help understand students' motivation to use computer tools.

Post survey question 2, ("If you were motivated to use computer tools in this course, please explain why. If you were not motivated to use them, please explain why not."), asked students what motivated them to use computer tools. The data were converted into a dichotomous variable (motivated or not motivated), based on responses to qualitative statements ${ }^{4}$. Twenty-two students $(72 \%)$ reported that they were motivated to use computer tools. Among these 22 students, 14 (64\%) said because they were required to do so for assignments, while two (9\%) enjoyed using them, two (9\%) were motivated by both reasons, and four (18\%) gave no explanation. One student who was motivated by the course requirements said: "I was motivated to use computer tools because I was required to do so, in order to correctly complete the assignments."

One student felt differently

Sometimes I was motivated to use computer tools, because I learned about new counseling tools \& websites like ONet \& Sigi. Sometimes I was not motivated because links did not work and things did not correlate with the print material.

\footnotetext{
${ }^{4}$ Students identified as motivated to use computer tools included: (1) those who clearly stated that "I was motivated to use .." in their answers, (2) those who stated that "they were not very motivating, but helpful., " and (3) those who explained what motivated them to use computer tools. Students were identified as notmotivated to use computer tools included: (1) those who clearly stated that "I was not motivated." in their answers, and (2) those who showed a strong negative response to computer use in answers. Student responses were identified as unknown if (1) their answers were not related to the question, (2) their answers indicated that they were extrinsically required to use computers, but they didn't want to evaluate their motivation, or (3) they did not respond to the question.
} 
Some students were motivated by intrinsic motivational factors (enjoyment, personal goals) more than by than external demands (assignments). They said, "I was motivated to use computer tools because I enjoy the computer and the capabilities it allows you" and "I was motivated for two reasons. First, many of our assignments required use of the computer. Secondly, I knew developing my computer skills would be good."

Two students firmly stated that they were not motivated to use computer tools. One student said, "Some of the computer tools (class website) were difficult to navigate." Another student was counted as 'not motivated' because his or her answer showed a strong negative response to computer use.

Could often not access site, had trouble opening files; often information on website did not match one another or the information from the class itself. It caused unnecessary hassles, trips to the library, fees for parking $\&$ printing and many other problems.

The remaining seven did not offer clear information regarding their motivation. They showed various attitudes toward the use of computer tools. One described stress associated with computer use. Four students appreciated the opportunity to use computer tools, but did not indicate whether they were motivated to use them. One student skipped this question and another strongly criticized the requirement to use computer tools. This student wrote, "I used the computer only because it was necessary to satisfy the course requirements. I took the course only because it was necessary to satisfy my degree requirement. I'm motivated to do counseling." 


\section{Research Question 3 (RQ3): Motivation and Learning Experiences}

RQ 3 examined students' motivation to learn in this web-enhanced environment. Four sub-questions were included to investigate the relationships between their motivation and their academic achievement, computer use, learning satisfaction, and emotions. All information was collected via surveys, including the course evaluation (sections I, II, and III), the post survey of computer tools competence (section I \& II), and the survey of emotional level.

The ways in which these questions were phrased allowed separating information to be gathered: motivation to learn the course material and motivation to use computer tools. Student responses to surveys and their achievements indicated that their motivation to use computer tools did not represent their motivation to learn in this course. Some students were motivated to learn, but were not motivated to use computer tools. Some WBI features motivated them to learn the course material, but were not related to their motivation to use computer tools.

Motivation to use computer tools. As with the discussion of RQ 2, only 25 students provided valid responses to identify their motivation to use computer tools. Of students responding, 22 described themselves as being motivated to use computer tools, and three were not motivated ${ }^{5}$.

\footnotetext{
5 Because seven students didn't clearly respond to the question in the post survey of computer tools competence (question 2 in section V), they were excluded from the analysis of research question 3, which addressed the relationship between their motivation to use computer tools and their learning experience in Coun 620. An analysis of research question 2 indicated that some students were motivated to use computer tools but were not motivated to learn in this web-enhanced course, while some students were motivated to learn in Coun 620 , but refused to use computer tools. The researcher decided to treat those seven students' data as missing data, instead of associating them with either group studied in research question 3.
} 
Motivation to learn in Coun620. Students' motivation to learn in this web-enhanced environment was evaluated via the course evaluation, Section III. Students were asked to use a 7-point scale, ranging from "Very Discouraging" (1) to "Very Motivating" (7) to rate 23 items that affected their learning experience in this web-enhanced environment. Students could also choose "No opinion" if they could not rate the effect of a specific item on their learning. A student's motivation to learn in the web-enhanced environment was represented by the average score of all of his/her valid items. The scores of students' motivation to learn were significantly different than their motivation to use computer tools $(r=.54, p=.006, d f$ $=24$, using the point biserial correlation at the .05 level of significance). This implies that if students were motivated to use computer tools, they were more likely motivated to learn in the web-enhanced environment. Therefore, both motivation indicators (motivation to use computer tools and motivation to learn in Coun 620) were examined to determine the relationships of students' motivation and their learning experiences in this course. Motivation and Academic Achievement (Hypothesis 3-1)

Cumulative course points (CCP). Academic achievement was represented by students' final grades, which were determined by converting students' cumulative course points to letter grades. Students could earn a maximum of 138 points if they received perfect scores on all 12 assignments. A student received a final grade of $\mathrm{A}$ if he/she earned at least 95 points. Students' scores ranged from 86 to 119 points; the mean was 104.4 points. Three students received B's; the remaining 29 students earned A's.

Cumulative course points for computer use (CCP_computer). In Coun620, there were 12 assignments in all, seven of which required the use of computer tools: participation (7 points), abstracts of journal articles (3 points), group project (15 points), resume (10 points), 
Internet research (10 points), online self-assessment (10 points), and post self-assessment (5 points). "Participation" involved four web-related activities: visiting ONet, Internet search, Leisure scale, and reading bulletin board articles. "Cumulative course points for computer use" (CCP_computer) was calculated by summing points earned on six assignments, excluding the group project. The group project required a group of 4-5 students to plan a three-day career planning workshop for a specific population. Each group had to use PowerPoint to present their projects. Since students were not individually required to use PowerPoint to earn points, the $\mathrm{CCP}_{-}$computer did not include the score of the group project. For detailed information regarding the computer tools used in assignments, see Table 4-7. There were a total of 45 points available in the CCP_computer category, representing about $33 \%$ of the total CCP. Since students were not required to use computer tools, the CCP_computer was assumed to be an index of a student's willingness to use computers. There was a statistically significant correlation between the total CCP and CCP_computer ( $r$ $=.46, p=.008, d f=31)$. This indicates that students who wanted good grades in this course were more likely to learn to use computer tools.

Research question 3-1. There was no relationship between students' motivation to learn and their final grade. The only significant relationship found was that between students' CCP_computer scores and their motivation to use computer tools $(r=.56, p=.004$, $d f=24)$, which indicates that students who were motivated to use computer tools earned more points in the assignments requiring computer tools use. Students did not have to be motivated to use computer tools to have good final grades. Some students who received an "A" for the course seldom used computer tools or the course web site for their assignments. 
Therefore, students could earn high grades regardless of whether or not they were motivated to learn on the course web site. For detailed results see Table 4-8.

Table 4-7

The Computer Tools Use in Assignments of Coun 620

\begin{tabular}{|c|c|c|c|c|}
\hline & Assignments & Type & $\begin{array}{l}\text { Required technology use (but } \\
\text { not limited to) }\end{array}$ & $\begin{array}{l}\text { Course } \\
\text { points }\end{array}$ \\
\hline 1. & Exam (multiple choices) & & Not necessary & 20 \\
\hline \multirow[t]{6}{*}{2.} & Participation & & Some & 10 \\
\hline & Class participation & & No & 3 \\
\hline & ONet & & Browser, hyperlinks & $1 *$ \\
\hline & Internet Search & & Browser, search tools & 3 \\
\hline & Leisure & & Word, Adobe, browser & 2 \\
\hline & Read bulletin board articles & & $\begin{array}{l}\text { Browser, WebCT bulletin } \\
\text { board }\end{array}$ & 1 \\
\hline 3. & Group project & Group & PowerPoint & 15 \\
\hline 4. & Resume & & Browser, search tools & 10 \\
\hline 5 . & Case study & & No & 15 \\
\hline 6. & Abstract journal articles & & Browser, search tools & 3 \\
\hline 7. & Library research paper & & Not necessary & 20 \\
\hline 8. & Holistic Career Plan & & No & 10 \\
\hline 9. & Career Assessment project & Group & Not necessary & 5 \\
\hline
\end{tabular}


Table 4-7

The Computer Tools Use in Assignments of Coun 620 (Continued)

\begin{tabular}{lllc}
\hline & Assignments & $\begin{array}{c}\text { Required technology use (but } \\
\text { not limited to) }\end{array}$ & $\begin{array}{c}\text { Course } \\
\text { points }\end{array}$ \\
\hline 10 & Internet Research & Browser, search tools & $\mathbf{1 0}$ \\
\hline 11 & Online self-assessment & Browser, search tools & $\mathbf{1 0}$ \\
\hline 12 & Post self-assessment on the bulletin & Browser, WebCT & $\mathbf{5}$ \\
\hline
\end{tabular}

\footnotetext{
*: Numbers in bold represent the points included in CCP_computer
}

Table 4-8

The Relationships of Motivation and Academic Achievements

\begin{tabular}{|c|c|c|c|c|}
\hline & \multicolumn{2}{|c|}{$\begin{array}{l}\text { Motivation to use } \\
\text { computer tools }(N=25)\end{array}$} & \multicolumn{2}{|c|}{$\begin{array}{l}\text { Motivation to learn in web- } \\
\text { enhanced Coun } 620(N=32)\end{array}$} \\
\hline & Point biserial $r$ & $p$ & Pearson $r$ & $p$ \\
\hline $\mathrm{CCP}$ & .173 & .408 & .103 & .576 \\
\hline CCP_computer & .559 & .004 & .091 & .662 \\
\hline
\end{tabular}

\section{Motivation and Computer Tools Use (Hypothesis 3-2)}

In order to investigate the relationships of students' motivation with their computer tools use, several indicators of computer tools use were chosen: (1) confidence using computer tools at the end of the course, (2) the frequency of computer tools use at the end of the course, and (3) improvement of computer skills. The data for students' confidence using computer tools and frequency of computer tools use were collected via the post survey of computer competency in Sections I and III. For detailed information refer to RQ I and Tables 4-2 and 4-3. 
Improvement of computer skills. In this course students were required to use computer tools, including Microsoft Word, PowerPoint (for a group project), web browsers, search tools, the bulletin board in WebCT, and Adobe Reader. A chat room was available on WebCT to enable students to communicate with each other, but its use was not required. Nor was it necessary to use multimedia or to participate on the listserv. One open-ended question in the post computer competence survey asked students to compare their ability to use computer tools before and after this course. Nineteen students (59.4\%) reported they felt that either they had improved in the use of some computer tools, or they became more proficient, comfortable, or confident using some computer tools. However, 12 students (37.5\%) felt they had not improved. One said, "No major improvement. I already possessed the abilities required by the tools from past experiences."

Since the evaluation of skills improvement was self-reported, it was hard to determine the actual level of their improvement. Students who felt their computer skills had improved reported a significant change in the number of computer tools they used compared to those who didn't feel they had improved their skills $(t=2.56, p=.016, d f=29)$. Students in these two groups (skills improved and not improved) also showed some differences in their change in confidence frequency of use, but there was not much difference in their final grades and emotions regarding computer use (refer to Table 4-9). Also, a significant relationship was found ( $r=.53, p=.002, d f=30)$ between students' skill improvement and the increased frequency of their computer tools use (refer to Table 4-3). As students improved their computer skills, they increased the frequency with which they used computer tools and also used more computer tools than they had previously. 
Research question 3-2. There was a significant relationship between students' motivation to use computer tools and their computer skill improvement $(r=.49, p=.012, d f$ =24). In addition, there was a statistically significant relationship between students' motivation and their frequency of computer use $(r=.52, p=.002, d f=31)$. This implies that students who were motivated to use computer tools used them with greater frequency. When students improved their computer skills and used more computer tools, they became motivated to learn in this course.

Table 4-9

Comparison of Learning Outcome Between Students Who Had Skill Improvement and Those Who Had No Skill Improvement $(N=31)$

\begin{tabular}{|c|c|c|c|c|c|c|}
\hline & \multicolumn{2}{|c|}{$\begin{array}{l}\text { Skill improvement } \\
\quad(n=20)\end{array}$} & \multicolumn{2}{|c|}{$\begin{array}{l}\text { No improvement } \\
\qquad(n=11)\end{array}$} & \multirow[b]{2}{*}{$t$} & \multirow{2}{*}{$\begin{array}{c}p \\
\text { (2-tailed) }\end{array}$} \\
\hline & $M$ & $S D$ & $M$ & $S D$ & & \\
\hline $\begin{array}{l}\text { Difference in } \\
\text { confidence of computer } \\
\text { use }\end{array}$ & .90 & .81 & .45 & .78 & .98 & .335 \\
\hline $\begin{array}{l}\text { Difference in frequency } \\
\text { of computer use }\end{array}$ & .90 & .77 & .27 & .36 & 1.985 & .057 \\
\hline $\begin{array}{l}\text { Number of changes in } \\
\text { computer tools use }\end{array}$ & 5.80 & 2.19 & 4.18 & 2.14 & 2.56 & .016 \\
\hline $\begin{array}{l}\text { Emotions about } \\
\text { computer use }\left(2^{\text {nd }}\right)\end{array}$ & .61 & .89 & .52 & .92 & .79 & .792 \\
\hline Final grades (CCP) & 105.75 & 7.52 & 103.55 & 7.92 & .77 & .450 \\
\hline CCP_computer & 34.2 & 6.20 & 31.55 & 8.84 & .98 & .151 \\
\hline
\end{tabular}

Note: All data passed Levene's Test for Equality of Variances 
There was no a significant relationship between students' motivation to learn in the web-enhanced environment and their computer skills improvement. This indicates that some students were not interested in computer tool use regardless of whether they were motivated to use the course web site. It appeared that most students were motivated to use computer tools because of course requirements. Students' confidence in the use of computer tools was not related to their motivation to use the computer. This showed that students might feel confident in the use of computers, but still not motivated to use them.

Motivation, Learning Satisfaction, and Performance of the Course Website (Hypothesis 3-3)

This web-enhanced course contained both classroom and web-based settings. In class, students listened to the instructor's lecture, had face-to-face discussions, and engaged in other classroom activities. Some activities took place both in class and on the Web. Learning satisfaction in Coun 620 was related to both classroom and website activities.

Learning satisfaction. Learning satisfaction was determined via the Survey of Course Evaluation (Appendix E, section II), which addressed the richness of lecture notes, supplementary materials, assignments, activities in both class and the web environment, technical support, communication/interaction, and accessibility of the instructor. Students were asked to rate their learning, using a 5-point scale ranging from Very Poor (1) to Excellent (5). Learning satisfaction in web-based and classroom settings were collected separately. A wide range of learning satisfaction was reported, (refer to Table 4-10). Some students were unsatisfied and some very satisfied with web-enhanced learning. Likewise, some preferred the classroom setting, while some were more satisfied with the web-based setting. The reliability of the survey of learning satisfaction was 0.84 , as measured by Cronbach's alpha. 
Table 4-10

Students' Learning Satisfaction in Classroom and Web Settings $(N=32)$

\begin{tabular}{|c|c|c|c|c|}
\hline Item & Learning satisfaction (classroom) & Range & $\bar{M}$ & $\mathrm{SD}$ \\
\hline $1 \mathrm{a}$ & Richness of lecture notes & $1.0-5.0$ & 3.59 & 0.88 \\
\hline $2 \mathrm{a}$ & Supplementary materials & $2.0-5.0$ & 3.63 & 0.79 \\
\hline $3 \mathrm{a}$ & Assignments & $1.0-5.0$ & 3.62 & 0.91 \\
\hline $4 a$ & Activities & $1.0-5.0$ & 3.56 & 0.88 \\
\hline 7 & Accessibility of instructors & $1.0-5.0$ & 3.75 & 1.05 \\
\hline $8 \mathrm{a}$ & Overall learning satisfaction & $2.0-5.0$ & 3.81 & 0.90 \\
\hline \multicolumn{2}{|c|}{ Average of learning satisfaction (classroom) } & $2.17-4.83$ & 3.41 & 0.80 \\
\hline Item & Learning satisfaction (Web) & Range & $\overline{\mathrm{M}}$ & $\mathrm{SD}$ \\
\hline$\overline{1 b}$ & Richness of lecture notes & $1.0-5.0$ & 3.59 & 0.79 \\
\hline $2 \mathrm{~b}$ & Supplementary materials & $2.0-5.0$ & 3.94 & 0.84 \\
\hline $3 b$ & Assignments & $1.0-5.0$ & 3.09 & 1.15 \\
\hline $4 \mathrm{~b}$ & Activities & $1.0-5.0$ & 3.25 & 1.05 \\
\hline 5 & Technical support & $2.0-5.0$ & 3.72 & 0.73 \\
\hline 6 & Communication/Interaction & $2.0-5.0$ & 3.60 & 0.95 \\
\hline $8 \mathrm{~b}$ & Overall learning satisfaction & $1.0-5.0$ & 3.81 & 0.80 \\
\hline Avera & ge of learning satisfaction (Web) & $2.00-4.71$ & 3.59 & 0.60 \\
\hline
\end{tabular}

Performance of the course web site. The performance of the course web site and WebCT site were evaluated in Section I of the Survey of Course Evaluation (Appendix E). Students were asked to evaluate the performance of the course web site, including its 
infrastructure, WBI design, accessibility, speed, reliability, maintenance, ease of use, availability of links, navigation, technical support, and overall performance. An average score for all items was calculated to represent students' overall opinion regarding web site performance. Students expressed a wide range of opinions. The reliability of results for opinions regarding web site was 0.86 , as measured by Cronbach's alpha. Table 4-11 provides data related to the performance of the course web site.

Table 4-11

Evaluation of the Performance of the Course Web Site $(N=32)$

\begin{tabular}{lllll}
\hline \multicolumn{1}{c}{ Items } & \multicolumn{1}{c}{ Function } & Range & $M$ & $S D$ \\
\hline 1. & Easy access & $2.0-5.0$ & 4.03 & 0.82 \\
2. & Speed & $2.0-5.0$ & 3.78 & 0.79 \\
3. & Reliability & $1.0-5.0$ & 3.34 & 0.90 \\
4. & Maintenance & $2.0-5.0$ & 3.59 & 0.80 \\
5. & Easy to use & $1.0-5.0$ & 3.28 & 1.02 \\
6. & Availability of links & $1.0-5.0$ & 3.44 & 1.04 \\
7. & Navigation & $1.0-5.0$ & 3.22 & 1.01 \\
8. & Technical support & $2.0-5.0$ & 3.56 & 0.72 \\
9. & Overall & $2.0-5.0$ & 3.56 & 0.72 \\
\hline Average of performance indicators & $1.89-5.0$ & 3.53 & 0.60 \\
\hline
\end{tabular}

Research question 3-3. A statistically significant correlation was found between students' evaluation of web site performance and learning satisfaction on the web site $\quad(r=$ $.41, p=.021, d f=31)$. Likewise, a significant relationship was found between students' learning satisfaction and their motivation to learn in Coun $620(r=.77, p=.000, d f=32)$. 
Students reported that they were very motivated by certain features of the course web site, such as "the ability to check grades" $(M=6.28)$ and "web-based quizzes" $(M=6.07)$.

The performance of the course web site was significantly related to students' motivation to learn in Coun $620(r=.56, p=.001, d f=31)$. It appears that students were easily discouraged by some factors relating to the course web site, such as "the speed of Internet connection" $(M=5.32)$, "the performance of the computer" $(M=5.81)$, and "access to a computer" $(M=5.88)$. The analysis shows that students' motivation to use computer tools was not related to their learning satisfaction, but related to the performance of the course web site $(r=.51, p=.01, d f=24)$. This indicates that if the web site performs better, motivation will tend to be higher.

Table 4-12

The Relationships of Motivation, Learning Satisfaction, and the Performance of Course Web Site

\begin{tabular}{lccccc}
\hline & $\begin{array}{c}\text { Motivation to use computer } \\
\text { tools }(N=25)\end{array}$ & & \multicolumn{2}{c}{$\begin{array}{c}\text { Motivation to learn in web- } \\
\text { enhanced Coun 620 }(N=32)\end{array}$} \\
\cline { 2 - 3 } & Point biserial $r$ & $p$ & & Pearson $r$ & $p$ \\
Satisfaction (class) & -.16 & .430 & & .20 & .271 \\
Satisfaction (Web) & .37 & .071 & & .77 & .000 \\
Web site performance & .69 & .000 & .56 & .001 \\
\hline
\end{tabular}

Motivation and Feelings While Using Computer Tools (Hypothesis 3-4)

Students had different feelings when using computer tools in this course. Data regarding feelings about computer tools use were collected twice: at the middle and at the end of the semester. For detailed information see Table 4-4 in RQ 1. 
Research question 3-4. A significant relationship was found between students' motivation to learn in Coun620 and their emotions regarding computer tools at the end of the course $(r=.76, p=.001, d f=30)$. Their answers to the survey of emotion levels indicated that students' emotional levels were not limited to computer use, but also reflect their feeling about learning in this web-enhanced course. At the end of the course there were significant differences in both learning satisfaction and motivation between those groups of students who had positive feelings and those who had negative feelings (see Table 4-14). Students who had positive feelings tended to rate the course site performance higher. Still, there was no significant difference in academic achievement, confidence or frequency of computer tools use at the end of the semester between students who had positive feelings, and those who had negative feelings.

Table 4-13.

Differences in Motivation to Learn, Learning Satisfaction, and the Performance of Web Site Between Students Who Had Positive and Negative Feelings While Using Computer Tools (at the End of the Course) $(N=27)$

\begin{tabular}{|c|c|c|c|c|c|c|}
\hline \multirow[b]{2}{*}{ Feelings } & \multicolumn{2}{|c|}{ Positive $(n=18)$} & \multicolumn{2}{|c|}{ Negative $(n=9)$} & \multirow{2}{*}{$\begin{array}{c}t \\
\text { (note) }\end{array}$} & \multirow{2}{*}{$\begin{array}{c}p \\
\text { (2-tailed) }\end{array}$} \\
\hline & $M$ & $S D$ & $M$ & $S D$ & & \\
\hline $\begin{array}{l}\text { Motivation to learn in } \\
\text { Coun } 620\end{array}$ & 5.36 & .64 & 4.49 & .67 & 3.32 & .003 \\
\hline $\begin{array}{l}\text { Learning satisfaction in } \\
\text { the web setting }\end{array}$ & 3.86 & .41 & 3.05 & .51 & 4.43 & .000 \\
\hline $\begin{array}{l}\text { The performance of the } \\
\text { course site }\end{array}$ & 3.69 & .43 & 3.26 & .73 & 1.95 & .063 \\
\hline
\end{tabular}

Note: All three types of data passed Levene's Test for Equality of Variances 


\section{Research Question 4 (RQ 4): Indicators of Changes of the Computer Use}

RQ 4 addresses students' attitudes regarding computer use and indicators of change occurring in students who were motivated to use computer tools.

\section{Attitude Regarding Computer Use in the Future}

At the beginning and end of the course students were given a survey of computer tools competence, in which they were asked to use a 5-point scale, (1: No experience to 5:Very positive) to describe their attitude toward computer use. Average responses to these five questions at the end of the semester revealed that students had positive attitudes about using computers for their professional development, studies, and counseling services $(M=4.40, S D$ $=.52$ ). Students responses toward computer use in the future were not related to their feelings regarding computer use in the course, nor their learning satisfaction with the course site. However, their attitudes were related to their confidence using computer tools $(r=.37$, $p=.021, d f=31)$, their frequency of computer use $(r=.39, p=.028, d f=31)$, and their motivation to use computer tools in the course $(r=.50, p=.011, d f=24)$. This suggested that if students were motivated to learn and gained confidence in the use of computers, they were more likely to be interested in using computer tools in the future.

A significant relationship was found between students' motivation to learn in this course and their attitude toward computer use after taking this course $(r=.64, p=.0001, d f=$ 31), indicating that students who had a more positive attitude about computer use were more motivated to learn in this course. At the end of the course, students who experienced positive feelings about using the computer maintained the same attitude or slightly increased their attitude toward computer use in the future. Students who had negative experiences had less interest in using computers in the future. Specially for question 5, "Do you plan to apply 
computer tools in counseling services, "students who had negative feelings indicated a decrease in their interests to use computers in counseling services. See Table 4-14 below for a summary of these findings.

Table 4-14

Responses of the Question 5 in Students Who Had Positive and Negative Feelings about Using Computer Tools $(N=27)$

\begin{tabular}{|c|c|c|c|c|c|c|c|c|c|}
\hline & & \multicolumn{8}{|c|}{ Feelings regarding computer tools use (rated on a 5-point scale) } \\
\hline & & \multicolumn{4}{|c|}{ Positive $(n=18)$} & \multicolumn{4}{|c|}{ Negative $(n=9)$} \\
\hline & & $M$ & $S D$ & Min & Max & $M$ & $S D$ & Min & $\operatorname{Max}$ \\
\hline \multirow[t]{2}{*}{ Goal 5} & Before & 3.94 & .80 & 3.0 & 5.0 & 4.0 & .84 & 3.0 & 5.0 \\
\hline & After & 4.22 & .97 & 3.0 & 5.0 & 3.67 & 1.32 & 1.0 & 5.0 \\
\hline
\end{tabular}

Most students indicated that they would continue to use computers in the future. According to one open-ended question in Section IV of the course evaluation "Will you continue to use computer tools in the future," 30 students (93.8\%) chose "Yes" while only two students (6.3\%) answered "Undecided." Most students explained that they would use computer tools in their daily lives in the areas of work, study, communication, and professional development. Some were specific about the tools they planned to use. One student who planned to use the computer daily said, "I check my email and search the web for information."

Another student responded that "They are a part of life now. I will use it mostly for communication." 
Index of Changes in Practice in Computer Use

Students were surveyed via section IV of the course evaluation about what kinds of computer tools they were motivated to use. Most students were motivated to use PowerPoint (71.9\%), the bulletin board (68.8\%), web browsers (62.5\%), search tools (65.6\%), and Adobe Reader (50\%). Students reported that they were not motivated to use Microsoft Word, (56.3\%), Email (53.1\%), chat room (71.9\%), multimedia (68.8\%), and listserv (68.8\%). A few students felt that they were discouraged from using PowerPoint, chat room, Adobe Reader, and Listserv. Unfortunately, no questions explored why they were discouraged from using them. For detailed information regarding motivation to use compute tools see Table 4-15.

To examine changes in computer use, data were collected from the surveys of computer tools competence (pre- and post-) and the records of bulletin board use on the WebCT server. Hypotheses 4-1, 4-2, and 4-3 investigated the indicators of changes in bulletin board use; whether there were differences in the purposes of messages (academic, social, or both), the target of communication (general, personal, or both), and the numbers of responses in different time periods as the course progressed. The statistics relating to the frequency and purposes of computer tools use were intended to investigate the changes in computer tools use that occurred during this course. 
Table 4-15.

Motivation to Use Computer Tools $(N=32)$

\begin{tabular}{|c|c|c|c|c|c|c|}
\hline \multirow[b]{2}{*}{ Computer tool } & \multicolumn{2}{|c|}{ Motivated } & \multicolumn{2}{|c|}{ No difference } & \multicolumn{2}{|c|}{ Discouraged } \\
\hline & $n$ & $P(\%)$ & $n$ & $P(\%)$ & $n$ & $P(\%)$ \\
\hline Microsoft Word & 14 & 43.8 & 18 & 56.3 & & \\
\hline Web Browser & 20 & 62.5 & 12 & 37.5 & & \\
\hline PowerPoint & 22 & 71.9 & 8 & 25.0 & & 3.1 \\
\hline Email & 14 & 43.8 & 17 & 53.1 & & \\
\hline Search tools & 21 & 65.6 & 11 & 34.4 & & \\
\hline Bulletin Board & 22 & 68.8 & 10 & 31.3 & & \\
\hline Chat room & 7 & 21.9 & 23 & 71.9 & & 6.3 \\
\hline Multimedia & 10 & 31.3 & 22 & 68.8 & & \\
\hline Adobe Reader & 16 & 50.0 & 15 & 46.9 & & 3.1 \\
\hline Listserv & 6 & 18.8 & 22 & 68.8 & 4 & 12.5 \\
\hline
\end{tabular}

Bulletin board use. Students did not post a significant number of messages on the WebCT bulletin board. In total, 23 students posted 49 messages during the 15 weeks, ranging from one message to five messages. Most of the posted messages were academic in nature $(95 \%)$, while two messages $(3 \%)$ were of a social nature and one $(2 \%)$ was both social and academic. Most students used the bulletin board to ask questions or to post their optional assignments (such as group information or online self-assessment). Some shared good links or resources for their assignments. Students did not usually respond to each other; only five messages were posted to respond to messages posted by others. 
The frequency and purposes of computer use. Students' responses showed that they increased computer use to a daily basis and had new purposes (i.e. communication, shopping, work, entertainment) for using computers beyond the obvious academic application. Students who felt motivated to use computer tools showed significant differences in their confidence in computer use and the frequency with which they used computers before and after taking the course. Their computer use increased to 'daily', and they found new purposes (i.e. communication, shopping, work, entertainment) for using computers beyond the obvious academic application. Students who felt motivated to use computer tools were also more likely to have higher confidence in their ability to use computers, and to use them more frequently. 


\section{Chapter 5: Discussion and Conclusion}

The growth and development of information technology holds great promise for the future of counseling. The field of counseling has, and must continue to evolve as technology offers new ways of teaching, learning, and providing counseling services at a distance. To keep up with the new possibilities, counselors-in-training and professional counselors will have to become competent in the use of computers. This study examined counseling students' motivation to use computer tools in a web-enhanced course. It focused on four research questions that examined

1. how their use of computers changed;

2. the impact of web-based instructional (WBI) features on their motivation to learn;

3. the relationship between their motivation to learn and learning experiences; and

4. indicators of their adoption of computer tools.

In order to understand students' learning in this web-enhanced environment, qualitative and quantitative information were collected and analyzed. The results of this study concluded that students were motivated to learn in this web-enhanced environment. In order to help counselors in training and professional counselors become competent computer users, educational training and programs have to adopt computers into the development of curriculum. This study presented an approach for developing counseling programs that integrate computer tools so that counseling students can become competent using current technologies and be able to provide effective and efficient services in the Information Age. 


\section{Changes in Computer Tool Use}

Research Question 1 looked into changes in computer use by collecting data on students' confidence with computer tools, the frequency with which they used them, their awareness of ACES's technological competencies, and their feelings about computer use.

One objective of Coun 620 was to provide an environment in which students could enhance their computer skills in career guidance and counseling services. Data presented in Chapter 4 showed that the majority of students became more confident in their use of computers by the time they had completed the course. They felt that their computer skills had improved; they felt more comfortable and more proficient with computer tools. They used some new computer tools on a weekly or daily basis by the end of the semester. Students became more familiar with ACES's technological competencies, especially those that were emphasized in the course. The majority of students became more positive toward computer use than they had been before the course began. Also important, they used computers for more than academic purposes; they discovered new applications for computer tools at work, and in their daily activities as well. On the whole, the results of this study supported the conclusion that students' attitudes toward computer use changed when they were exposed to this web-enhanced learning environment.

\section{WBI Features and Learning}

Research Question 2 explored the effects of WBI features on learning. The WBI design of Coun 620 integrated computer tools into activities and assignments with the design of four main WBI features: need-directed supplementary materials, a learner-controlled/learnercentered environment, goal-directed instructions, and a collaborative and communicative environment. 
The results of RQ2 revealed that WBI features affected learning. Over half of the students in Coun 620 were motivated to use computer tools via practicing web-based activities; and their learning was supported by the design of WBI features. They were motivated to use computer tools to implement activities and assignments, were supported by supplementary resources, and felt that they were in charge of their learning. There were some problems along the way, though. Some students were discouraged by inconsistent information, disorganized structure, and difficulties accessing web sites.

To investigate how these WBI features were related to students' learning, we should examine the key elements that supported the performance of these main features. These include the availability and use of computer tools, hyperlinks, the structure of the web site, navigation, related information, communication, and global accessibility. Well developed WBI features can motivate students' learning with the support of these key elements, while poorly developed WBI features may discourage students from learning.

\section{Use of Computer Tools}

Integrating computer use into activities and assignments is essential to building a webenhanced learning environment. The analysis of RQ 2 showed that the majority of students were motivated to use web browsers, PowerPoint, search tools, the bulletin board, and Adobe Reader via implementing activities and assignments. Most had not often used these tools before taking this course. Students had to use web browsers and search tools to find and access career information on the Internet. The bulletin board facilitated collaborative learning and communication. Students were encouraged to learn PowerPoint as they collaborated with others in a group project. Adobe Reader allowed them to get printouts of published documents. 
Integrating computer tools into WBI design but not requiring their use for related activities or assignments does not support learning. For instance, students were neither motivated nor discouraged from using the chat room because it was not required in any activity or assignment. The use of computer tools varied among students if there were not enough extrinsic rewards. While most students were motivated to use the bulletin board, some did not use it very much. They did not appear to be discouraged by using it; they simply were not interested. Students did not need to be motivated to use tools that they had used frequently before taking this course, such as Mircosoft Word and email.

\section{Hyperlinks}

The hyperlink is an important element in a web-based environment. A hyperlink can be linked to a page or a web site to provide extra learning materials. By providing easy access to these ancillary resources through hyperlinks, students can be motivated to learn. However, invalid or broken links can discourage students from learning because they are unable to get support from useful resources.

\section{Structure and Navigation}

Navigation and structure are critical to the future of learner-centered/learner-controlled environment. If this feature is designed well, it motivates students to learn because they are able to take control of their learning. This study showed that a poorly organized structure or difficult navigation will discourage students because they will be confused using the course web site. In this study, some students felt stress when they had to look at several places (e.g. course unit pages and activities page) to make sure they had done the required assignments or activities. They would have preferred a centralized page listing all assignments and activities, and clear navigation to guide them. A few students wanted to have one central site 
instead of two sites (the course web site and the WebCT site) to visit. The diversity of students' backgrounds and needs makes the design of structure and navigation very challenging.

\section{Related Information}

The WBI design of goal-directed instruction involves providing related information, such as clear instructions and guidance. It is crucial that this information be consistent. Clear instructions and guidance help students complete required assignments and reach their learning goals. Consistent information helps students determine what to do and how to do it. In this study, many students were not satisfied with the instructions because of inconsistencies between the course web pages and the classroom handouts. They had to verify information regarding the class schedule, credit points, and the due dates of assignments. As a result, most students felt this course required more time than others because they spent extra time hunting for assignments and verifying the accuracy of information.

\section{Communication and Feedback}

Communication and feedback are important elements of WBI design in a collaborative learning environment. Web-based collaborative learning requires students to use $\mathrm{CMC}$ tools to interact and communicate with each other via the Internet. In this study, students were motivated to learn when they received support from other students and the instructor. Most students, for instance, were motivated to use the bulletin board. They used it to share information with others, ask questions and read announcements from the instructor.

A collaborative learning environment needs to have reasonable expectations regarding communication. A few students felt discouraged because they felt the instructor did not give 
timely feedback. Unfulfilled expectations of feedback can decrease students' motivation to learn. In addition, there should be a connection between students' use of CMC tools and learning outcomes. When the use of CMC tools was not related to collaborative learning, or the rewards (credit points) for using CMC tools were not sufficiently motivating, students were not motivated to learn, even though the WBI design emphasized a collaborative learning environment.

\section{Global Accessibility}

Global accessibility is important to web-based learning, which needs the support of infrastructure to deliver teaching and learning activities. Any WBI feature may perform poorly without infrastructure support. In this study, a few students were frustrated by problems of infrastructure, such as a conflict between AOL and the WebCT server, a slow Internet connection, or computers that did not support required software. Since web-based learning relies heavily on technological support, a WBI course needs to define minimum infrastructure criteria in advance.

\section{Summary of WBI Features and Learning}

It is obvious that WBI features are closely related to students' learning in a web-based environment. Without organized structure, intuitive navigation, and consistent information, students are not able to take control of their learning. Without effective hyperlinks, students cannot access useful resources or pages, which will hinder their learning progress. Without integrating appropriate computer tools and communicative tools, students will not be aware of the benefits of using the computer and collaborative learning via the Internet. Without providing clear instructions and directions, students will be discouraged by confusing information. Without the support of infrastructure, some students will not be able to access 
web sites and interact with others over the Internet. In addition, if it does not consider learning needs and outcomes, the design of WBI features will be ineffective or even counterproductive.

Analysis of the data collected in this study demonstrates that students can be motivated by WBI features, if key elements support WBI performance. Developing organized structure and intuitive navigation is very challenging because it has to consider potential learner's needs, backgrounds, and learning goals. A WBI course may fail if the design does not consider infrastructure criteria, lacks clear navigation, has a poorly organized structure, contains inconsistent information, or lacks an efficient forum for feedback. Students were extremely discouraged when they faced flaws in the WBI design or encountered infrastructure problems that made it more difficult for them to achieve their learning goals. Detailed information regarding these problems is given in Table 5-1.

\section{Motivation and Learning Experiences}

Research Question 3 examined the connections between students' learning experiences and their motivation to learn and to use computer tools in a web-based environment. Specifically, how does motivation relate to academic achievement, computer tools use, learning satisfaction, and feelings about computer use? 
Table 5-1

Potential Problems with Learning in a Web-based Environment

\begin{tabular}{cl}
\hline Features & Potential Problems \\
\hline $\begin{array}{c}\text { Global } \\
\text { accessibility }\end{array}$ & -- Compatibility of software \& hardware \\
(Infrastructure) & -- Capability (speed, stability, maintenance) of the web server \\
& -- Limits of Internet service providers \\
& -- Incompatibility of interface (between network, server, or \\
& computers) \\
& -- Speed of Internet connection \\
& -- Bandwidth required \\
& -- Insufficient instructions or guidance \\
& -- Navigation not intuitive \\
& -- Inconsistent information \\
-- RBI design & -- Modifications made during the semester \\
\hline
\end{tabular}

The results of RQ 3 reinforced the fact that motivation in learning is a complicated matter. In general, students were motivated to learn in order to earn a good grade, to improve their computer skills and to increase their confidence in computer use. Students' motivation to use computer tools was related to several variables, such as credit points given, computer skills, interest in using the computer, WBI features, web site performance, and infrastructure. Students' final grades were not necessarily related to their motivation to learn. A few students were motivated to learn without being interested in using computer tools. 
Computer skills and confidence in computer use had a significant impact on students' motivation to learn in this course. Students' motivation to learn was related to their learning satisfaction, which was influenced by the performance of the course web site. However, students were discouraged from using computer tools if they encountered technical problems, regardless of their confidence level. Students who had positive feelings regarding computer use showed more motivation to learn, felt more satisfied with web-based learning, and gave a more positive evaluation of course performance than students who had negative feelings.

\section{Summary of Motivation and Learning Experiences}

The analysis of RQ3 supported the conclusion that students' learning experiences were related to their motivation to learn. Their motivation to learn involved several variables, including the desire for academic achievement, computer skills, and learning satisfaction. In fact, the results showed that motivation for academic achievement was a driving force regardless of the learning environment. The improvement of skills or confidence in computer use can increase motivation to learn. However, students will be discouraged from learning in an unsupportive web-based environment, even if they have skills or confidence using the computer.

Students demonstrated different extents of intrinsic and extrinsic motivation. Students who had positive feelings about computer use showed higher motivation and satisfaction with their learning than those who had negative feelings. This suggests that students who had positive experiences were likely to experience an internalized and integrated process of intrinsic motivation because they experienced interest, enjoyment, and satisfaction. (Csikszentmihalyi, 1978; Ryan \& Deci, 2000). Motivation theory suggests that students who are more intrinsically motivated, are more likely to continue to use the computer in the future 
(Maehr, 1976; Ryan \& Deci, 2000). All of these factors may have had an impact on students' feelings about computer use and learning in this course.

\section{Indicators of Change in Computer Use}

Research Question 4 investigated students' changes in attitude and practice. In this study, students became aware of the advantages of using computer tools through exposure to them in this web-enhanced course. The analysis of RQ4 indicated that if students were motivated to learn and became confident in the use of computer tools, they were more likely to use them in the future, regardless of how they felt about computer use during the class. Almost all of the students were willing to continue to use computer tools for professional development, study, work, or communication in daily life. Most of them expressed the desire to adopt these computer tools when, through experience, they realized the advantages of using them.

\section{Summary of Indicators of Change}

The results of RQ 4 support the conclusion that the inclusion of motivating factors into instructional design is an effective way to encourage counseling students to use computer tools. Although a few students resisted using some computer tools, all indicators of adoption suggest that students in Coun 620 are likely to adopt computer tools in the future. Students enjoyed taking control of their learning, having a flexible schedule, an environment that was easy to use, and learning collaboratively over the Internet. These benefits motivated them to continue to use computer tools. They will continue to be motivated to use computer tools because they have become capable and confident, and have learned new uses for their new computer skills. 


\section{Implications}

Even though ACES and CACREP have emphasized the importance of technological competencies and computer literacy in counselor education, the curriculum of counseling programs has not changed significantly. Because counseling services emphasize personal contact in face-to-face settings, counselors-in-training and professional counselors resist using computer tools, and do not have adequate computer skills and knowledge. This study, conducted in a web-enhanced counseling course, supports the viewpoint that to enhance students' computer competence will require modification of the curricula of counselor programs (Hines, 2002; McFadden, 2000; Quinn, Hohenshil, \& Fortune, 2000). It implies that when students have a learning environment like that provided in Coun 620, they will improve their computer skills and become aware of ACES's technological competencies. They will be motivated to continue to use computer tools in the future.

\section{Motivation in WBI Design}

An environment geared to motivating counseling students to learn has to incorporate several specific features. The environment must be learner-controlled; it must provide needdirected supplementary materials, clear goal-directed instructions, and the ability to collaborate and communicate. A well-designed WBI that motivates students to learn has to provide active hyperlinks, an organized structure, and intuitive navigation. Perhaps most importantly, it has to provide computer tools to use, and they must be accessible to all students. This study demonstrated that when these elements are present, students will be motivated to learn.

Complicated relationships exist between motivation and learning in a dynamic learning environment. To avoid pitfalls, instructors have to carefully consider all aspects of the 
course design. How will computer tools be used? Are credit points sufficiently motivating? Is information distributed in class consistent with that available on-line? Is communication efficient? Are students aware of the amount of feedback they can expect, and in what period of time? Are learning expectations realistic? Students have to be aware of technical requirements, including minimum memory and processor speed, speed of the Internet connection, and what software and hardware are required. These requirements should be part of the course description so students are aware of them before they register for the course.

\section{Team Work in the WBI Design}

The inclusion of motivating factors into web-based instructional design is an effective way to encourage counseling students to become competent computer users, but it is not an easy task. Designing a course with WBI features requires much effort and teamwork. A review of the literature and experiences in this study, indicate that developing a web-involved course should be a team effort including instructors (who have expertise in content) and instructional designers (who have expertise in web-design). It is unlikely that a single individual will have expertise in both areas. Collaboration between the content-design and web-design experts can lead to a well developed and motivating WBI design.

In the development of a web-based course, the instructor is responsible for determining the course schedule, and for defining learning goals and outcomes. He or she must provide related contents and information for course design, and offer instructions and feedback as the course progress. The role of instructional designers involve appropriately integrating computer tools into the course, designing an organized structure and intuitive navigation, defining the limitations of infrastructure for efficient learning, and providing technical tutorials and instructions to support students. The greatest challenge to developing a 
motivational WBI design is determining how to help students understand the value of computer tools, and motivating them to use those tools for their professional development.

\section{Computer Use in Counselor Education}

The Association for Counselor Education and Supervision (ACES) has developed 12 technological competencies for counselors, though these competencies are not specifically built into counselor programs. In order to help counselors-in-training and professional counselors become aware of and achieve the goals of technological competence, this study suggests that a motivating WBI design integrating the use of computer tools should be added into the curriculum of counselor education, by following ACES's criteria of technological competencies.

In addition, CACREP guidelines state the importance of technological competence and computer literacy, but do not require counseling programs meet these guidelines. CACREP should consider additional requirements for accreditation of counseling programs, and should describe the standards and procedures used to evaluate students' technological skills. In general, expectations regarding computer use have to be discussed in terms of the objectives of counseling programs. Counseling programs that apply for accreditation should be required to demonstrate a plan that integrates computer tools into the curriculum. This plan must involve administrators, teachers, instructional designers, and technical support groups. This study suggests that CACREP has to evaluate how this team will ensure that the learning environment addresses the computer competence of counseling students. Moreover, it must require programs to describe how they will provide guidance that will lead to the application of computer technology in training and services. 


\section{Recommendations for Further Study}

This study was concerned with the enhancement of counseling students' computer skills. It investigated whether exposing students to computer tools in a web-based environment would help them become competent computer users. It assessed changes in computer use, addressed the impacts of WBI features on students' motivation, and evaluated the relationships between students' motivation and their learning experiences.

Many questions were answered, and many more were raised. There is a need for further research to investigate questions that could not be answered in this study. It would, for instance, be interesting to examine what differences exist in students' motivation to learn with various degrees of WBI support. A study using a control group is needed to compare differences in students' motivation to learn with and without a WBI feature.

Since data analysis showed that there were interrelationships among some learning variables, it would be interesting to look into the impact of these interrelated learning variables on motivation. Applying multi-regression analysis in future studies will be helpful in understanding the impact of learning variables on motivation in a web-based environment.

Learning in a traditional face-to-face environment is different than learning in a webbased environment that relies heavily on the use of information technologies. Learners need more help and support when they learn via the Internet because of its inherent limitations. Future studies should consider the impact of individual learning characteristics on motivation in a web-based environment.

\section{Summary of the Study}

Computers have become an integral part of every day life. Today, they are omnipresent in homes, schools and offices. It is time for the field of counseling to fully adopt computers. 
Computers offer tremendous possibilities for the field of counseling. They offer counseling students and educators the ability to communicate with each other, perform research more thoroughly and efficiently, and provide counseling services without being limited by distance and time. The first step in promoting the use of computers must be to help counselor educators develop courses that integrate a web-based environment. Then, counseling students must be taught how to use computer tools in a motivating environment constructed by the WBI developing team. The integration of computer tools into WBI design-from conception, through implementation, and evaluation - encourages counseling students to learn about computer tools and persuades them to use computer tools to interact with people in various settings. The challenge now is to overcome the concern that counseling must always be held in a face-to face setting, and how to explore new ways in which the technology can be exploited. We must examine carefully the obstacles that discourage counselor educators and students to take advantage of the incredible potential of the computer. As a small start, further studies should seek to understand how counseling students can be convinced to become competent computer users through the use of a WBI environment. 


\section{References:}

American Counseling Association (ACA). (1999). The ethical standards for Internet online counseling. Retrieved April 20, 2002, from the World Wide Web, http://www.counseling.org/gc/cybertx.htm

American Psychology Association (APA). (1997). APA ethics office. Retrieved June 25, 2002, from the World Wide Web, http://www.apa.org/ethics/homepage.html

Ancis, J. R. (1998, Spring). Cultural competency training at a distance: Challenges and strategies. Journal of Counseling \& Development, 76, 134-143.

Association for Counselor Education and Supervision (ACES). (1999a). Technical competencies for counselor education students: Recommended guidelines for program development. Retrieved July 02, 2002, from the World Wide Web, http://filebox.vt.edu/users/thohen/competencies.htm

Association for Counselor Education and Supervision (ACES). (1999b). ACES guidelines for online instruction in counselor education. Retrieved July 08, 2002, from the World Wide Web, http://filebox.vt.edu/users/thohen/acesweb/

Atkinson, J. W. (1964). An introduction to motivation. Princeton, NJ: D. Van Nostrand Company, Inc.

Atkinson, J. W., \& Raynor, J. O. (1978). Personality, motivation, and achievement. Washington: Hemisphere Publishing Corporation.

Archer, J., \& Scevak, J. J. (1998). Enhancing students' motivation to learn: Achievement goals in university classrooms. Educational Psychology, 18(2), 205-223. Bandura, A. (1977). Social learning theory. Englewood Cliffs, NJ: Prentice-Hall. 
Berry, T. (2002). A survey of counselor trainee preferred learning style and its relationship to computer skills and technology use. Unpublished manuscript. Counseling Department. Morgantown, WV, WVU.

Brown, A. (1997). Designing for learning: What are the essential features of an effective online course? Australian Journal of Educational Technology, 13(2), 115-126. Retrieved Feb. 02, 2001, from the World Wide Web: http://cleo.murdoch.au/ajet/ajet13/su97p115.html

Brown, J.S., Collins, A., \& Duguid, S. (1989). Situated cognition and the culture of learning. Educational Researcher, 18(1), 32-42.

Cabaniss, K. (2002). Computer-related technology use by counselors in the new millennium: A delphi study. Journal of Technology in Counseling 2(2), Retrieved July 12, 2002, from the World Wide Web, http://jtc.colstate.edu/vol2_2/

Campus Computing Project (2001). The 2001 campus computing survey. Retrieved July 01, 2001, from the World Wide Web: http://www.campuscomputing.net/

Cecez-Kemanovic, D. W., C. (2000). “Towards a communicative model of collaborative web-mediated learning." Australian Journal of Educational Technology 16(1): $73-85$.

Chandras, K. V. (2000). Technology-enhanced counselor training: essential technical competencies. Journal of Instructional Psychology, 27(4), 224-227.

Council for Accreditation of Counseling and Related Educational Programs (CACREP) (2001). The 2001 Standards. Retrieved April 20, 2002, from the World Wide Web http://www.counseling.org/cacrep/2001standards700.htm. 
Cole, J. (2000). Surveying the digital future: The UCLA Internet report. Retrieved June 14, 2002, from the World Wide Web, Available:

http://WWW.CCP.UCLA.EDU/pages/internet-report.asp

Csikszentmihalyi, M. (1978). Intrinsic rewards and emergent motivation. In M. Lepper \& D. Green (Eds.), The hidden costs of reward: New perspectives on the psychology of motivation. (pp.205-216). Hillsdale, NJ: Lawrence Erlbaum Associates.

Csikszentmihalyi, M. (1988). The flow experience and its significance for human psychology. In M. Csikszentmihalyi \& I. Csikszentmihalyi (Eds.), Optimal experience: Psychological studies of flow in consciousness (pp. 15-35). NY: Cambridge University Press.

Deci, E. L. (1975). Intrinsic motivation. New York: Plenum.

Deci, E.L. \& Ryan, R.M. (1985). Intrinsic motivation and self-determination in human behavior. New York: Plenum Press.

Department of Labor (DOL). (2001). Overview of Report on the American Workforce. U.S. Department of Labor. Retrieved May 10, 2002, from the World Wide Web wysiwyg://62/http:/www.bls.gov/opub/rtaw/rtawhome.htm

Dewey, J. (1938). Experience and education. New York: Collier Books.

Driscoll, M. (2002). Web-based Training: Creating e-learning experiences, $2^{\text {nd }}$ ed. SanFransisco, CA: Jossey-Bass/Pfeiffer Inc.

Duchastel, P. (1997). A motivational framework for Web-based instruction. In B. H. Khan (Ed.). Web-based Instruction, Englewood Cliffs, NJ: Educational Technology Publications, Inc.

Getz, H. G., \& Schnuman-Crook, A. (2001). Utilizing of online training for on-site clinical supervisors: One university's approach. Journal of Technology in Counseling, 2(1), 
Retrieved Dec. 12, 2001, from the World Wide Web, http://jtc.colstate.edu/vol2 1/Supervisors.htm

Hayes, B.G., \& Robinson, E. H. III. (2000). Assessing counselor education students attitudes toward computers and multimedia instruction. Journal of Humanistic Education and Development,38(3), 132-141.

Hines, P. L. (2002). Student technology competencies for school counseling programs. Journal of Technology in Counseling 2(2), Retrieved July 12, 2002, from the World Wide Web, http://jtc.colstate.edu/vol2_2/

Jones, K. D., \& Karper, C. (2000). How to develop an online course in counseling techniques? Journal of Technology in Counseling, 1(2). Retrieved Dec. 12, 2001, from the World Wide Web, http://jtc.colstate.edu/voll 2/online.htm

Jonassen, D. (1993). Conceptual frontiers in hypermedia environments for learning. Journal of Educational Multimedia and Hypermedia, 2, 331-335.

Keller, J. M. (1983). Motivational design of instruction. In C.M. Reigeluth (Ed.). Instructional design theories and models: An overview of their current status. Hillsdale, NJ: Erlbaum.

Khan, B. H. (1997). Web-based Instruction. Educational Technology Publications, Inc.: Englewood Cliffs, NJ.

Kinzie, M. B. (1986). Requirements and benefits of effective interactive instruction: Learner control, self-regulation, and continuing motivation. ETR\&D, 38(1), 1-21.

Kraut, R., Lundmark, V., Patterson, M., Kiesler, S., Mukopadhyay, T., \& Scherlis, W. (1998). Internet paradox: A social technology that reduces social involvement and psychological well-being? American Psychologist, 53(9), 1017-1031. 
Kraut, R., Kiesler, S., Boneva, B., Cummings, J., Helgeson, V., \& Crawford, A. (2002). Internet paradox revisited. Journal of Social Issues, 58(1), 49-74.

Lundberg, D. J. (2000). Integrating online technology into counseling curricula: Emerging humanistic factors. Journal of Humanistic Counseling, Education, and Development, 83(3). 142-151.

McKenna, K. Y. A., Green, A. S., \& Gleason, M. E. (2002). Relationship formation on the Internet: What's the big attraction? Journal of Social Issues, 58(1), 9-31.

Maehr, M. L. (1976). Continuing motivation: An analysis of a seldom considered educational outcome. Review of Educational Research, 46(3), 443-462.

Maehr, M. L, \& Midgle, C. (1991). Enhancing student motivation: A schoolwide approach. Educational Psychologist, 26 (3\&4), 399-427.

McFadden, J. (2000). Computer-mediated technology and transcultural counselor education. Journal of Technology in Counseling, 1(2), Retrieved Dec. 12, 2001, from the World Wide Web, http://jtc.colstate.edu/vol1_2/transcult.htm

McCombs, B. L. (1991). Motivation and lifelong learning. Educational Psychologist, 26(2), 117-127 (\#454).

Myers, J.E., Gibson, D. M. (1999). Technology competence in counselor education: Results of a national survey. Retrieved Dec. 10, 2001, from the World Wide Web: http://cybercounsel.uncg.edu/book/manuscripts/techcomp.htm

Myrick, R. D., \& Sabella, R. A. (1995). Cyberspace: New place for counselor supervision. Elementary School Guidance \& Counseling, 30, 35-44. 
National Board for Certified Counselors (NBCC). (1998). Standards for the ethical practice of Web counseling. Retrieved April 20, 2002, from the World Wide Web, http://www.nbcc.org/ethics/webethics.htm

National Board for Certified Counselors (NBCC). (1997). Definitions of counselors. Retrieved April 20, 2002, from the World Wide Web, http://www.nbcc.org/ethics/webethics.htm

National Career Development Association (NCDA). (2000). Career connecting in a changing context: A summary of the key findings of the 1999 national survey of working America. Columbus, OH: National Career Development Association.

National Center for Education Statistics (NCES). (1999). The condition of education 1999. NCES. Retrieved June 21, 2001, from the World Wide Web, http://nces.ed.gov/ National Center for Education Statistics (NCES). (2001). The condition of education 2001. NCES. Retrieved May 10, 2002, from the World Wide Web, http://nces.ed.gov/ National Science Foundation (NSF). (2000). Chapter 9: Science \& engineering Indicators 2000. NSF.

Owen, Jr., D. W., \& Dean, (1999). Computer utilization by school counselors. Professional School Counseling, 2, 3, 179-187.

Parks, M. R., Roberts, L. D. (1998). 'Making MOOsic': The Development of Personal Relationships on Line and a Comparison to their Off-Line Counterparts. Journal of Social \& Personal Relationships, 15(4), 517-537.

Pintrich, P. R., \& Schunk, D. H. (2002). Motivation in education: Theory, research, and applications, Upper Saddle River, NJ: Merrill Prentice Hall. 
The Pew Internet \& American Life Project (2000, May). Tracking online life: How women use the Internet to cultivate relationships with family and friends. Retrieved June 12, 2002, from the World Wide Web, http://www.pewinternet.org/reports/index.asp

Powell, T. (1998). Online counseling: A profile and descriptive analysis. Retrieved Apr. 18, 2002, from the World Wide Web, http://netpsych.com/Powell.htm

Ryan, R., \& Deci, E. (2000). Self-determination theory and the facilitation of intrinsic motivation, social development, and well being. American Psychologist, 55, 68-78.

Quinn, A.C., Hohenshil, T., \& Fortune, J. (2002) Utilization of technology in CACREP approved counselor education programs. Journal of Technology in Counseling 2(2), Retrieved July 12, 2002, from the World Wide Web, http://jtc.colstate.edu/vol2 2/quinn/quinn.htm

Reigeluth C.M. (1983). (Ed.). Instructional design theories and models: An overview of their current status. Hillsdale, NJ: Erlbaum.

Rogers, E. M. (1995). Diffusion of innovations, $4^{\text {th }}$ ed. New York, NY: The Free Press.

Sampson, Jr. J. P., Carr, D. L., Panke, J., Arkin, S., Minvielle, M., \& Vernick, S. H. (2002). Design Strategies for Need-Based Internet Web Sites in Counseling and Career Services: Technical Report Number 28. Retrieved June 18, 2002, from the World Wide Web, http://www.career.fsu.edu/documents/technical\%20reports/Technical\%20Report $\% 2028 /$ TR$\underline{28 . h t m l}$

Sampson, J.P., Kolodinsky, R.W., \& Greeno, B.P. (1997). Counseling on the information highway: Future possibilities and potential problems. Journal of Counseling and Development, 75, 203-212. 
Schrum, L., \& Berefeld, B. (1996). Teaching and learning in the information age: A guide to educational telecommunications. Boston, MA: Allyn and Bacon.

Shambaugh, R. N., \& Magliaro, S. G. (1997). Mastering the possibilities: A process approach to instructional design. Boston: Allyn \& Bacon.

Skinner, B. F. (1953). Science and human behavior. New York: Free Press.

Stipek, D. (2002). Motivation to learn: Integrating theory and practice. Boston, Massachusetts: Allyn and Bacon.

Swindle, R. Jr., Heller, K., Pescosolido, B., \& Kikuzawa, S. (2000). Responses to nervous breakdowns in America over a 40-year period: Mental health policy implications. American Psychologist, 55(7), 740-749.

Super, D. E. (1990). A life-span, life-space approach to career development. In D. Brown, L. Brooks \& Associates (Eds.), Career choice and development: Applying contemporary theories to practice, (2nd ed.). San Francisco, CA: Jossey-Bass.

Sussman, R. J. (2002). Counseling over the Internet: Benefits and challenges in the use of new technologies. Retrieved June 18, 2002, from the World Wide Web, http://cybercounsel.uncg.edu/book/manuscrips/internetcounseling.htm

Woodford, M. S., Rokutani, L., Gressard, C., \& Berg, L. B. (2000). Sharing the course: An experience with collaborative distance learning in counselor education. Journal of Technology in Counseling, 2(1). Retrieved Dec. 10, 2001, from the World Wide Web, http://jtc.colstate.edu/vol2 1/Sharing.htm

Verduin, J.R. \& Clark, T.A. (1991). Distance education: The foundations of effective practice. San Francisco, CA: Jossey-Bass Publishers. 
Visser, L., Plomp, T., \& Kuiper, W. (1999). Development research applied to improve motivation in distance education, ED436169.

Vygotsky, L. (1978). Mind in society: The development of higher psychological process. Cambridge, MA: Harvard University Press. 
Appendixes 


\section{Appendix A}

Web-based Instructional Design:

The Development of a Counseling Course

Developing a web-based instructional design (WBI) for a teaching and learning

environment is a complex and detailed process. The goal of the web-based instructional design is to develop a web site that can achieve the instructional purposes of the instructor and accommodate the needs of diverse learners. This is a systematic process that includes identifying instructional problems, determining the instructional sequence, implementing a prototype and modules, revising, and evaluating. The result of these activities will be the creation of a WBI design that delivers necessary information and provides activities for a specific audience with specific learning purposes (Driscoll, 2002; Shambaugh \& Magliaro, 1997).

\section{The Model of Web-based Instructional Design: Building a House}

As the instructional designer of this course, my role was to develop a web site that could meet the instructor's teaching goals and the learners' needs. Constructing a WBI design can be compared to building a house (see figure 1). To build a house, one has first to consider its purpose, then the lot on which the house will be built, the structure of the house, the budget, all the effort that will be required, and its features and appearance. Before building, a blueprint must be drawn. To finalize the blueprint, more detailed decisions have to be made, including the layout of each story, the use of each room, the electric and water plans, etc. When the blueprint is ready, construction can begin. The process of building a house is a team effort that includes the owner, the builder, and a variety of technicians. The house plan will be evaluated frequently and revised if necessary. The stages of building a house occur in a specific order, and are interrelated and overlapping. Any design modifications may influence and require a revision of other areas of 
design.

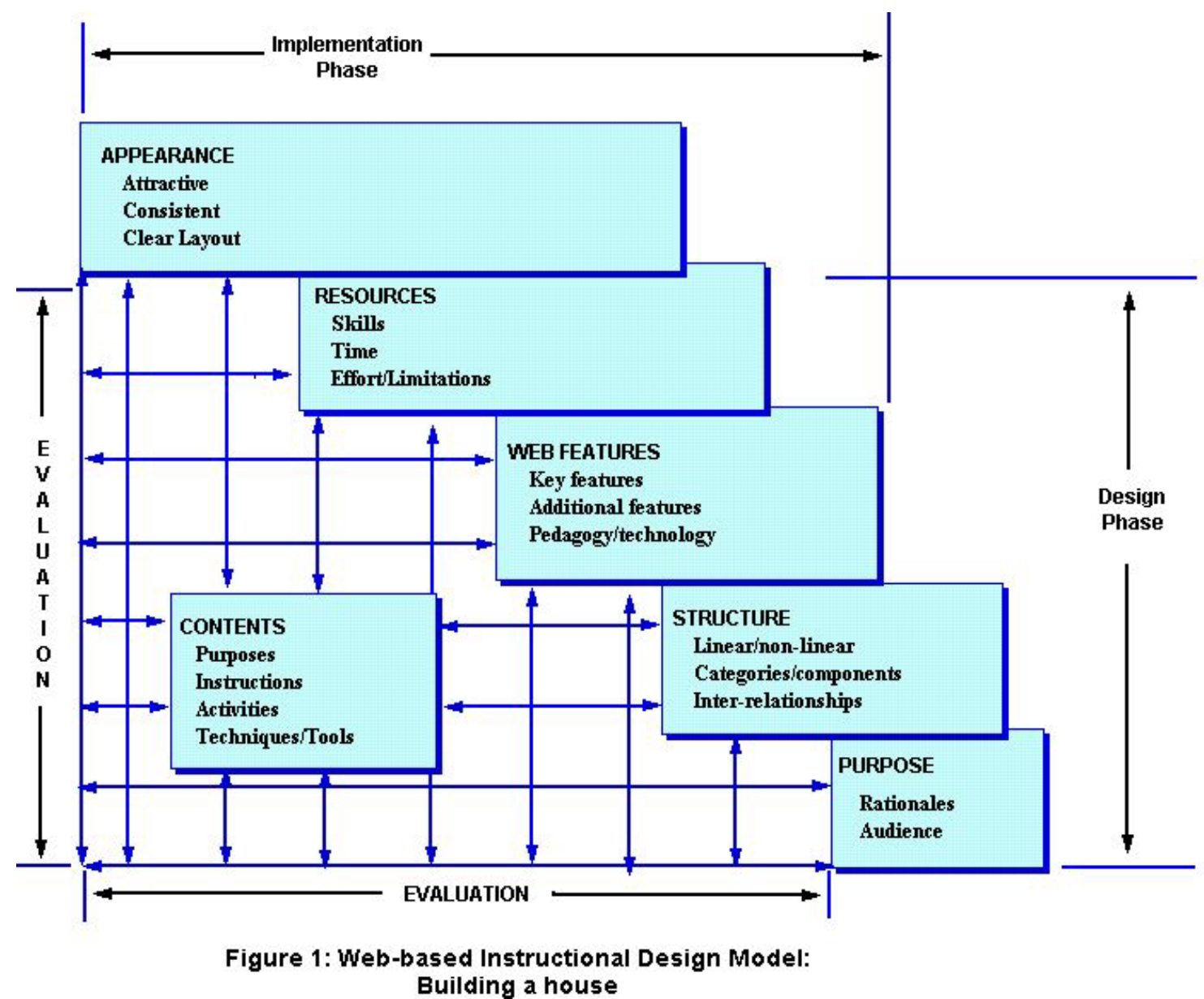

My WBI design model includes six stages and the task of evaluation. The six stages are concerned with (1) the purposes of the web course, (2) the structure of the web site, (3) the features that will be provided, (4) supporting resources, (5) the appearance of the web pages, and (6) the contents of each page. The WBI design groups these stages into two phases: design and implementation (see Table A-1). The design phase, like drawing a blueprint for the house, includes determining the purpose, structure, features, and resources of the web course. In the implementation phase, like the construction of a house, the features and the appearance are developed, and the contents of the web course and the resources necessary for the WBI design are determined. The design phase obviously occurs before implementation, but during the $3^{\text {rd }}$ and $4^{\text {th }}$ stages (where features and resources are determined) these two phases overlap. Developers 
make decisions regarding the features of a web course in the design phase, and they implement these features in the implementation phase. Also, in the design phase they will determine what resources will be available, but they will apply, and be limited by these resources in the implementation phase.

Although the stages of building a WBI design must occur in a certain order, they are related to each other and overlap in the design and implementation phases (see Table A-1).

Table A-1: Two Phases and six Stages of a Web-based Instructional Design Model

\begin{tabular}{|c|c|c|c|}
\hline Phase 1 & Stage & Concern & Phase2 \\
\hline \multirow{6}{*}{ 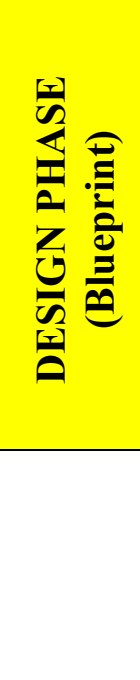 } & $1^{\text {st }}$ Stage: Purpose & What is the purpose of the web course? & \\
\hline & $2^{\text {nd }}$ Stage: Structure & $\begin{array}{l}\text { How should the course's web site be } \\
\text { structured? }\end{array}$ & \\
\hline & $3^{\text {rd }}$ Stage: Features & What web features are provided? & \multirow{4}{*}{ 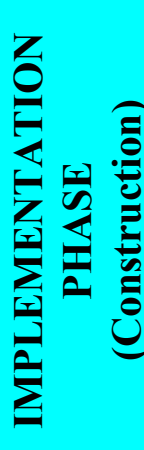 } \\
\hline & $4^{\text {th }}$ Stage: Resources & $\begin{array}{l}\text { What resources can the developers devote } \\
\text { to the site? }\end{array}$ & \\
\hline & $5^{\text {th }}$ Stage: Appearance & What does the web site look like? & \\
\hline & $\begin{array}{l}6^{\text {th }} \text { (centered) Stage: } \\
\text { Contents }\end{array}$ & What are the contents of each page? & \\
\hline
\end{tabular}

The evaluation model I used includes formative and summative evaluation, which is used to ensure consistent design among stages and that the goals of each stage are reached. The task of evaluation determines the input and output of each stage and is independent of the two phases of WBI design. However, the formative evaluation focuses more on the details of instructional design, while the summative evaluation has a more global focus on performance. 


\section{The WBI Development of Coun 620: Lifespan Career Counseling}

Dr. Srebalus, a professor of the Department of Counseling, Rehabilitation Counseling, and Counseling Psychology (CRCP) at West Virginia University (WVU), recognizes the benefits of applying Internet technology to education. He believes that teaching in both traditional and Internet environments can help students become efficient counselors. Career Development and Counseling is one of a few counseling courses benefiting from the integration of computer technology. Career counseling is one of the areas in which the Internet has proven useful. The contemporary meaning of career is not limited to jobs and occupations, but also includes family roles and leisure time (Super, 1990). In today's society an individual seldom stays with a job for his or her whole life. The Internet has become an important resource for people who are seeking career guidance and job information (NCDA, 2000).

Coun620: Lifespan Career Development, a three credit hour course, is required at the Masters level in the CRCP program at WVU. The course is also required by the Council for Accreditation of Counseling and Related Educational Programs (CACREP). Many people can benefit from lifespan career planning, which involves career exploration, assessment, readiness, and work adjustment. Career guidance and counseling is challenging because of the diverse needs for career development and the uncertainty of the job market.

Counselors-in-training are expected to master counseling skills so they can provide effective service to individuals who require guidance in finding suitable jobs. Dr. Srebalus had devoted a great deal of time to developing a web site as a supplement to Coun 620 in 2001. The purposes of this Web-supplement were to provide supplementary handouts to offer activities integrating Internet use in order to enhance students' learning. As he planned to teach a course for a cohort program of the Counseling Master's Degree in the spring semester of 2002, he considered adding some computer mediated communication (CMC) tools. The cohort program is 
offered to students who commute to school rather than living on campus. Dr. Srebalus recognized that these students would benefit from CMC tools. The students who participated in this program were mainly non-traditional students. Most of them had full time jobs and took continuing education courses on weekends. In September 2001, I chose to work on Coun 620 as a project for a course I was taking in Web-based Instructional Design.

\section{My Mission}

To develop a web-based course, an instructional designer has to be aware of the content and context. My background in counseling training prepared me for my role as an instructional designer for counselor education. Counseling educators train counselors-in-training to provide efficient and effective counseling services. My WBI design was intended to create a motivating environment for counseling students in which they could learn alternative methods of helping people and use available information on the Internet to get the benefits of information technology. I do not believe that integrating information technology into counselor education can replace face-to-face counseling services, but it can enable counselors to provide more effective and efficient counseling service for diverse populations.

\section{Needs Analysis}

Before beginning the web design, I met with Dr. Srebalus to understand his expectations for the revision of Coun 620 . He asked me to develop it separately from the course held in Fall, 2001. He wanted the future WBI design to include web-based practice quizzes to help students learn career development theories and prepare for the National Counselors Examination (NCE). Also, because the students were commuters, he wanted a web-based bulletin board and a chat room to give students a way to communicate with each other over the Internet. He did not plan to integrate multi-media into the course at that point because he was concerned about low bandwidth and the limitations of the course server. 
By applying the WBI Design Model described above (Fig. 1), I modified the supplementary web site into the enhanced web site that supported learning in Coun 620 . First Stage: "What is the purpose of the web course?"

The web-enhanced environment for Coun 620 was developed with three goals in mind: (1) to facilitate students' learning at a distance, (2) to help them improve their computer competence, and (3) to enable them to communicate with each other. Since the course would be taught in both a traditional classroom and a web environment, the pedagogical design had to include face-to-face and web-based activities. Students were expected to become comfortable using computer tools as supportive career counseling tools, so I wanted to develop additional activities related to enhancing their computer competence.

Student profiles. Most students in the cohort program were non-traditional students. We expected that they may not be as familiar with computer tools as traditional students. They were professionals working in different fields, so they had different backgrounds and various types of experience helping people.

Context. Coun 620 would be offered off campus during the weekend. Computers and Internet support were not available in the classroom. Students had to have access to a computer to participate in this course, either in their office, local library, or at home. The course would be offered intensively during a 5-week period, so students would have to become familiar with the web site and activities in a short time.

Second Stage: "How should the course's web site be structured?"

In order to offer a web-enhanced learning environment for Coun 620 , the web site had to be designed in a hierarchical structure with webbed interlinks. 
Hierarchical structure. A hierarchical structure was chosen to provide clear guidance for students so they could work independently. Six main categories with links were included on the homepage of the course web site. These are displayed graphically in Figure 2, below.

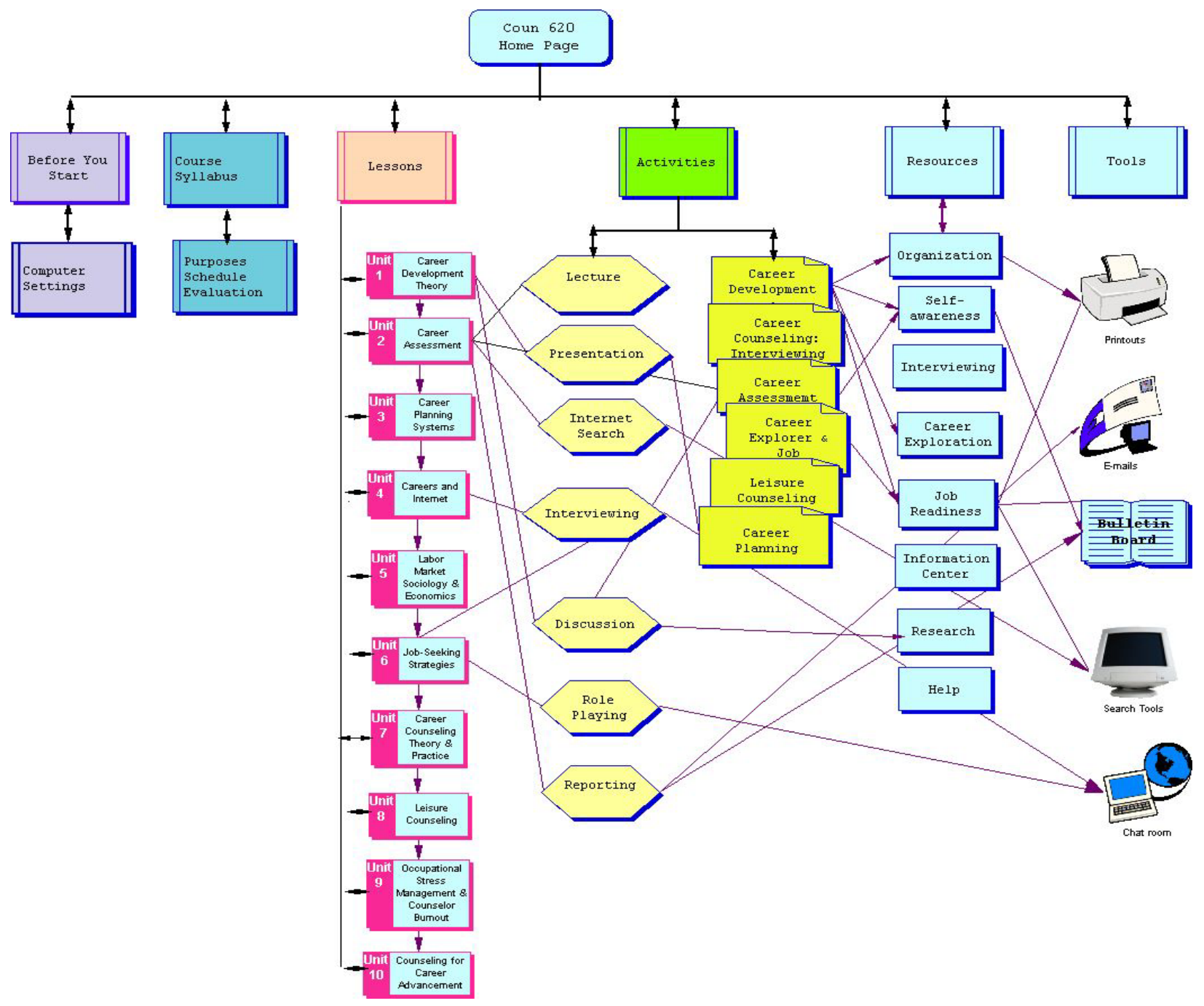

Figure 2. The Site Structure for the Revision of Coun 620

The hierarchical structure linked six categories of function in the home page, explained below:

- Before You Start: This link provided all information students needed before they began the course, such as minimum computer requirements, required software and where it could be accessed for download, and the notations used in the course. 
- Course Syllabus: This included course information: objectives and materials, the schedule, and evaluation.

- Course Units: This linked to the current course web site. Students were able to access materials and handouts for ten units of Coun 620.

- Activities: This provided course lessons and activities for both classroom and Internet settings. It consisted of six sections of activities; each section could be taught in one or two class sessions.

- Communication: This linked to the WebCT page, which housed the bulletin board and chat room that enable students to communicate with each other.

- Resources: This link provided supplementary web-based resources.

Webbed interlinks. The design used webbed interlinks which allowed students to link one page to any other page, based on their interests and needs. This was accomplished by providing a navigation bar on each page. In order to help students use the web site without getting lost, a site map with a draw-down menu was designed. When the user moved the mouse over the box of activities, a draw-down menu appeared. Then, the user could select an item on the drawn-down menu (see figure 3).

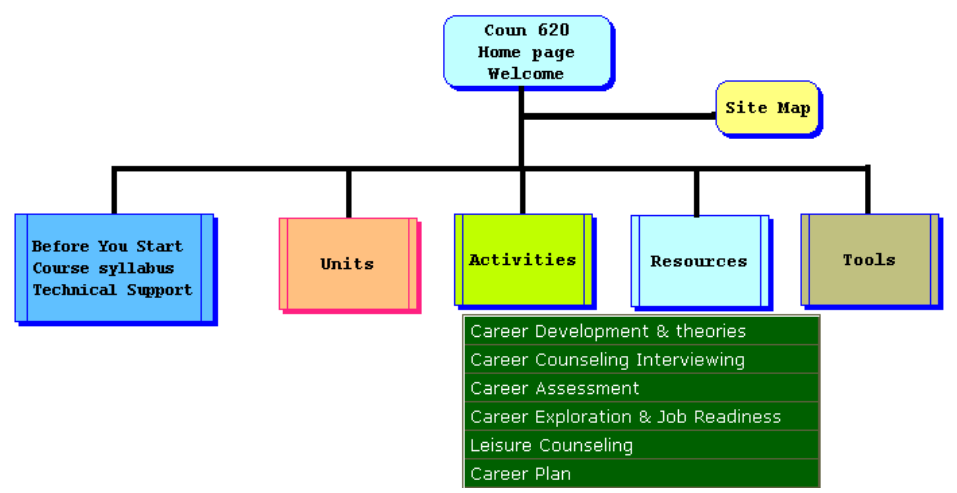

Figure 3: The Site Map of Coun 620 


\section{Third Stage: Web features}

Counselor education focuses on the development of cognitive learning, which teaches students to construct their knowledge from both theoretical and practical perspectives. Counseling programs emphasize personal contact and communication, which are usually taught in a classroom setting. The web-enhanced environment of Coun 620 was designed to enhance students' learning about career information available on the Internet and enable them to access remote resources. It included several key features, such as an open system, webbed links, intuitive navigation, and flexibility that allowed students to learn at their own pace in an environment they controlled. In order to encourage students to use the course web site, four additional features were included: Learner-centered/learner-controlled environment, goaldirected instructions, collaborative learning and communicative environment, and need-directed supplementary resources.

Learner-centered/learner-controlled environment. In the development of a learner-centered environment the designer must consider the diversity of learners' needs, beliefs, backgrounds, prior knowledge and experiences, and preferences (Johnson, 1993). The "learner-centered" feature allows people to interact with pages, based on their personal learning strategies and choices. Several key features supported this feature, such as intuitive navigation, organized structure, tutorials, rich resources, etc.

Goal-directed instructions. Clear goal-directed instructions are important when students have several options in learning activities. They can access any page from any other page via the links in each page. The directions for activities in Coun 620 included task-focused and abilityfocused instructions. For task-focused instructions, there were four kinds of design:

1. The design of categories (Before you start, Syllabus, Units, Activities, Communication, and Resources) in a navigation bar on each page. 
2. The image of action (lecture, discussion, printout, reading assignment, etc.) was given to a specific action as an icon. On the syllabus page (see Fig 4) and other activity pages, students could visualize an action and determine the work required for them to complete it.

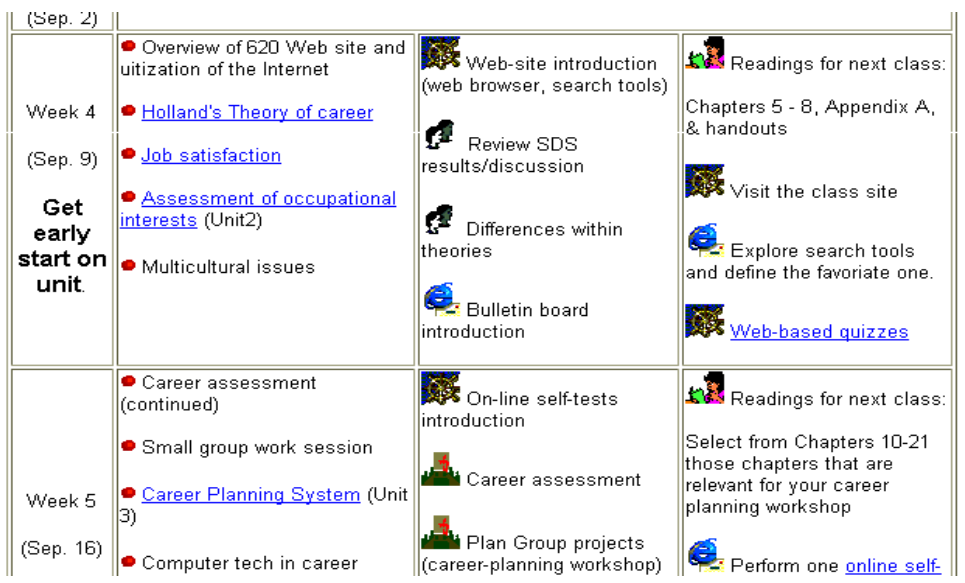

Fig 4: The Web Page of Syllabus in Coun 620

3. On the "Activities" page, six sections of activities were listed with related subactivities and assignments (see figure 5). Each section included related sub-activities and assignments.

4. On the "Resources" page, seven categories of resources were listed with annotations, which gave directions for use.

For ability-focused instructions, two types of instructions were provided.

1. Students had many options to choose from, based on their ability. Students did not have to follow the same path to work on their activity or assignment. For example, a student could click on the activity of "Career Development and Counseling Theories" (Figure 5) to view the whole activity or just click on one of its activities (e.g. Case study) or assignments (Web-based quiz practices) to study. Each activity section also gave clear instructions, including its purpose, time required, sub-activities, assignments, and evaluation. Students could then make their selections, based on their need and ability. 


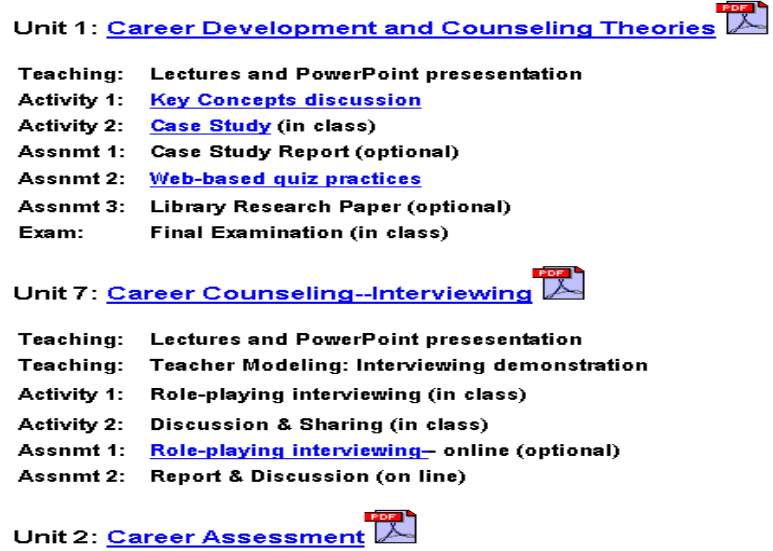

Fig 5: The Activity Page

2. The "Before you start" page provided students all the information they needed to prepare for this course. Students who were not familiar with computer settings could download necessary software through links on this page (Figure 6).

3. A multiple-choice web-based practice served as a study guide. Students could click on a box to indicate their answer. If the answer was right, "Congratulations!" appeared at the top of the quiz. If the answer was wrong, the top of the quiz indicated what students should study again (see Figure 7).

Browser is a sofware application that allows you to access the
World Wide Web. There are many browsers available, which
work in very similar ways, but you still can tell some
differences. Netscape or Microsoft Internet Explorer $4.0 x$ and up
are suggested to introduced to download and install in your
computer. You can free download from their sites.

Figure 6: The Downloading Links Provided on the "Before You Start" Page 


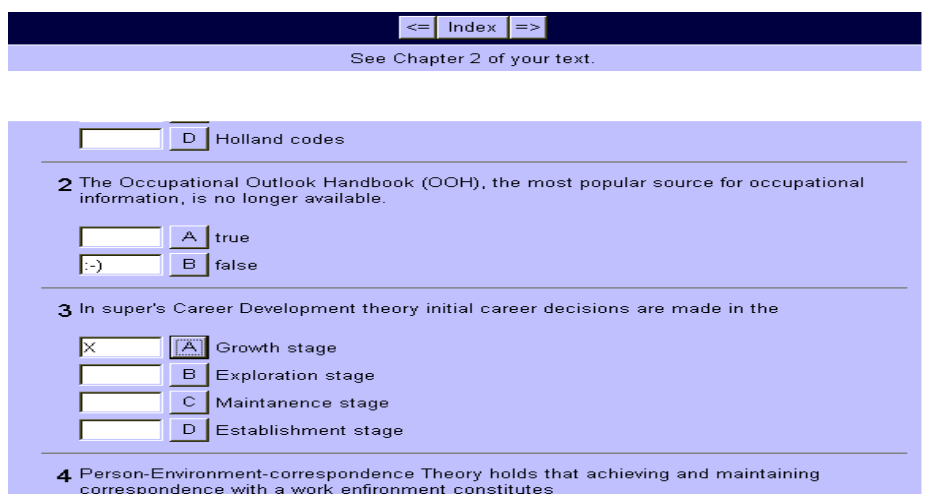

Fig 7. Web-based Practice Quiz for Guided Study

4. Tutorial in the use of CMC tools were provided. Since students might not be familiar with using the bulletin board and chat room, tutorials in PowerPoint format, which included images and instructions, were designed to demonstrate their use (See Figure 8).

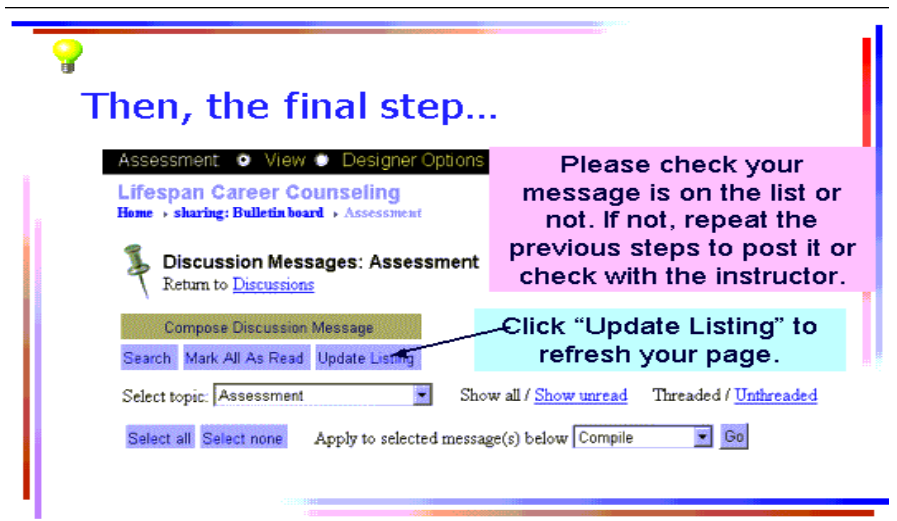

Figure 8. Tutorials for the WebCT Bulletin Board

Collaborative learning and communicative environment. Collaborative learning is important in both the classroom and on the Web. The availability of CMC tools in Coun 620 encouraged students to discuss, communicate and work together as well as get support via the instructor's feedback. The WBI design for collaborative learning is based on learning theories (behavior, cognitive, constructive, suited theory and more) and uses the support of CMC tools. Learning counseling skills and knowledge requires communication among students and between teachers and students. Web-based collaborative activities in this course included taking an online assessment, visiting an online job database, participating in discussions via the bulletin board or 
chat room, and a group project and presentation. These activities could be conducted either individually or in groups. Students were required to use CMC tools to implement these activities or assignments and share them with the class by posting messages on the bulletin board, by emailing each other, or via the chat room.

Need-supportive resources. It is important to provide rich information and resources to students in a web-based environment. Many counseling students do not feel comfortable using computer technology; novice computer users could become frustrated when they first work on web-based activities that require them to search for resources on the Internet (Sampson, et. al., 2002). For beginning users, searching and using web resources requires a long period of practice and training. The Resources page on the Coun 620 web site provided seven different types of resources: Organizations, Self-awareness, Interviewing, Career exploration, Job readiness, Information center, Research, and Help. Over 140 web-resources with hyperlinks were provided for students to use as they worked on their course activity or assignment. Some annotations were provided to introduce the web sites (see figure $9 \& 10$ ).
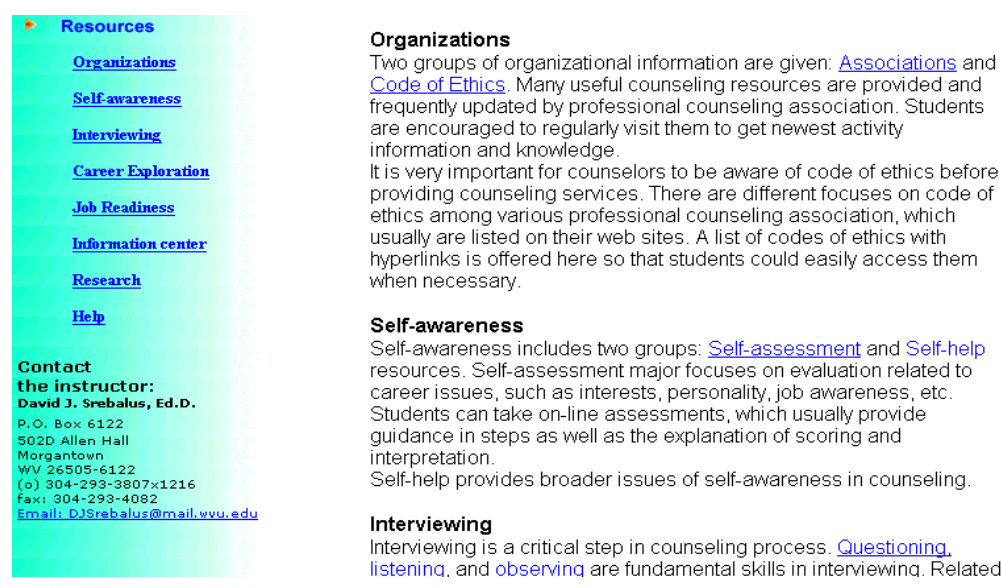

Figure 9: The Web Page of Resources in Coun 620 

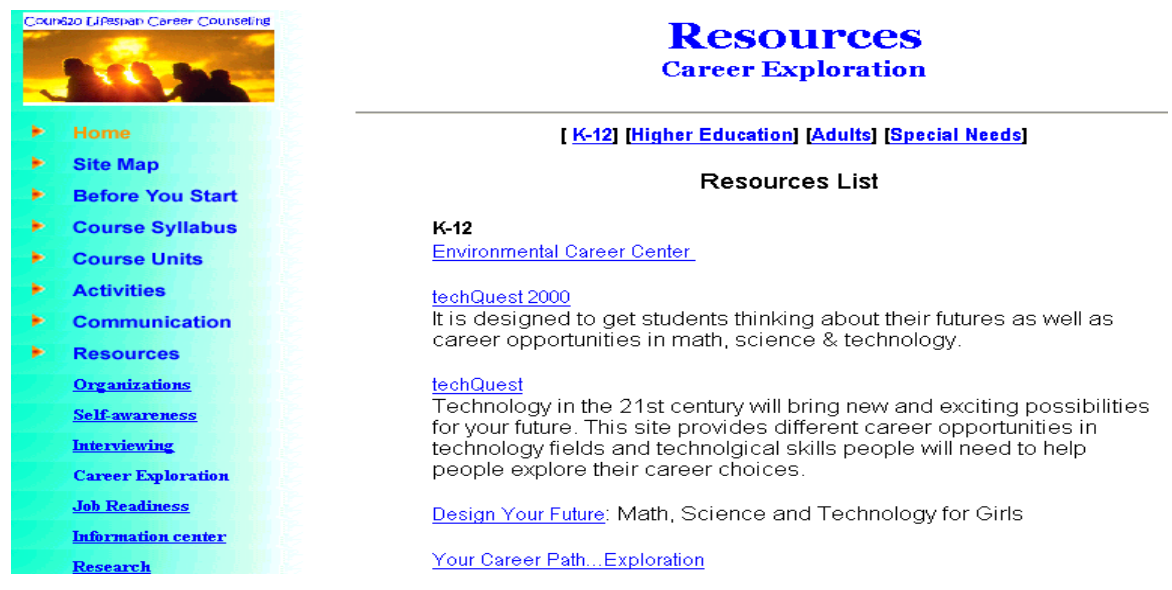

Figure 10: The Resources Web Page for Career Exploration

Fourth Stage: "What resources can the developers devote to the site?"

The resources needed to develop the Coun 620 website included time, people, developing tools, and CMC tools. The developing team included the course instructor, Dr. Srebalus, and an instructional designer, me. Budget was not a consideration because most of work was voluntary. Time, though, was a great concern. Dr. Srebalus and I were both very busy with other responsibilities, but I had to finish the prototype of Coun 620 for my course project, and the WBI design had to be complete and ready to teach for the cohort program in April, 2002. My responsibility was to implement the course web site; the instructor's responsibility was to provide related content and to contact other technical or administrative personnel. We worked together and made several critical decisions.

Work on WBI design. Based on the additional features I chose, we decided to include:

1. CMC tools: We chose the bulletin board and chat rooms supported by WebCT ( Webbased set of Course Tools), which was provided by the Instructional Technology Resource Center (ITRC) at WVU. WebCT was chosen because it was available, and because it was supported by WVU. The availability of technical support for the CMC tools from the ITRC made the WBI development of Coun 620 much simpler than putting them under the Coun 620 server. Another benefit was that we would not have to worry about the maintenance of these tools. 
2. We developed an on-line practice quiz for students. I used a software package called 'Hotpotato' to develop an on-line practice quiz. The instructor was responsible for providing questions, answers, and study guidance.

3. We collected online resources (web sites, database, articles, professional institutions, etc.) and classified them into different categories.

4. We chose three activity pages: "Career development and counseling theories," "Career counseling - interviewing," and "Career Assessment" to develop first: these would be our prototypes. Several web-based activities were developed under them, including an on-line practice quiz, taking online assessments, and online interviewing. Detailed information, including the purpose, approximate time required, steps, assignments, and evaluation, accompanied each activity.

5. We developed a "Before You Start" page: Because students might have different levels of computer literacy, we provided detailed information about how to use the website on the Before You Start page, including information related to the minimum computer specifications, software needs (web browser, Adobe Reader, email, audio/video players) and where to download software (Figure 6). The icons used in this course were also explained to help students visualize their work (see Figure $5 \& 11$ ).

6. Tutorials: Tutorials were provided to accommodate different levels of learners. Since the use of the bulletin board and chat room would be new to some students, two PowerPoint tutorials were developed to explain their use (see figure 8). A site map, developed by Macromedia Fireworks, was included to help students learn to use the web site in a short time (see figure 4). 


\begin{tabular}{|c|c|c|c|c|c|c|c|c|c|}
\hline$\Rightarrow$ & 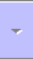 & $\underset{\text { Stop }}{\otimes}$ & Refresh & $\frac{\text { Ầ }}{\text { Home }}$ & Search & Favorites & $\begin{array}{c}\text { Media } \\
\text { Media }\end{array}$ & $\begin{array}{l}\in 3 \\
\text { History }\end{array}$ & Mail \\
\hline$/ / 157.1$ & 82. I & $43 / c$ & $s / 620 / b$ & $\mathrm{htm}$ & & & & & $\overline{7}$ \\
\hline
\end{tabular}

Notations of activities in this course:

In course schedule, you will notice many icons with explanations
in activities and assignments. In order to help you understand
their meanings, here is the explanation.
Word Document for assignments

Figure 11: Icons Used in Coun 620

Development tools. The WBI design of Coun 620 required the use of numerous tools in its development. These included: Macromedia Dreamweaver and Fireworks; Microsoft Word and PowerPoint; Adobe Acrobat PDF (Portable Document Format) Writer, WebCT, and Hotpotato. We also used web browsers and web-based search tools. The web site of Coun620 included dynamic HTML, JavaScript and some graphics which were developed by using Macromedia Dreamweaver and Fireworks. Microsoft Word and PowerPoint were used for developing assignment pages, lecture presentations, and tutorials. Most handouts were developed in PDF format, using Adobe's Acrobat software.

Learning tools. Computer tools used in this course included email, bulletin board, chat room, search engine, web browser, Microsoft software, and Acrobat Reader. The Email system was available via the WVU server, or students could use a web-based email system, such as Hotmail or Yahoo. A link to the WebCT page under the ICRT server provided students access to its web page, the bulletin board, chat rooms, and the grading book. Students had to download a web browser (Netscape or Internet Explorer) to use the course web site. A search engineGoogle - was embedded in the course web site to help students surf the Internet. Multimedia was not required in this course, but if students wanted to view audio or video clips, they could 
download related audio/video players such as Quick Time, Real Player, or Windows Media. Students could print out handouts and other materials available on the web pages in Word, PDF or HTML format. They had to download Acrobat Reader if they want to print the handouts in PDF format.

The Coun 620 website enabled students to access resources and activities at their own pace and based on their own needs. Technical support was provided, including guidance regarding minimum computer specifications, software download links, and some helpful tips for using the bulletin board and chat room. The instructor would provide in-class and web-based activities, enriched resources, and CMC technical support. By following the course schedule, students studied, practiced, observed, and collaborated by using CMC tools.

Fifth Stage: Appearance of the web site

I wanted the Coun 620 website to have a consistent appearance and a clear layout. All pages included a navigation bar on the left, and used the same background and text fonts. A picture with links allowed users to access the instructor's home page, the CRCP department, the WVU School of Education, and the main WVU website. The navigation bar located on the left had links to each main category. Clicking on the navigation bar, users could access a category (Sitemap, Before You Start, Course Syllabus, Course Units, Activities, Communication, and Resources) in a new window. In addition, a shortcut to WebCT was provided on the homepage to provide easy access. The homepage provided a brief introduction about Coun 620 (See figure 12). The background was designed in light green behind the navigation bar and white in the content area. The text font chosen for the contents was Arial Narrow; Arial Black was used for the titles. We chose not to use frames in the design in order to simplify maintenance and to achieve a clear appearance. Main content areas always used a white background and used two thirds of the screen to ensure readability. 


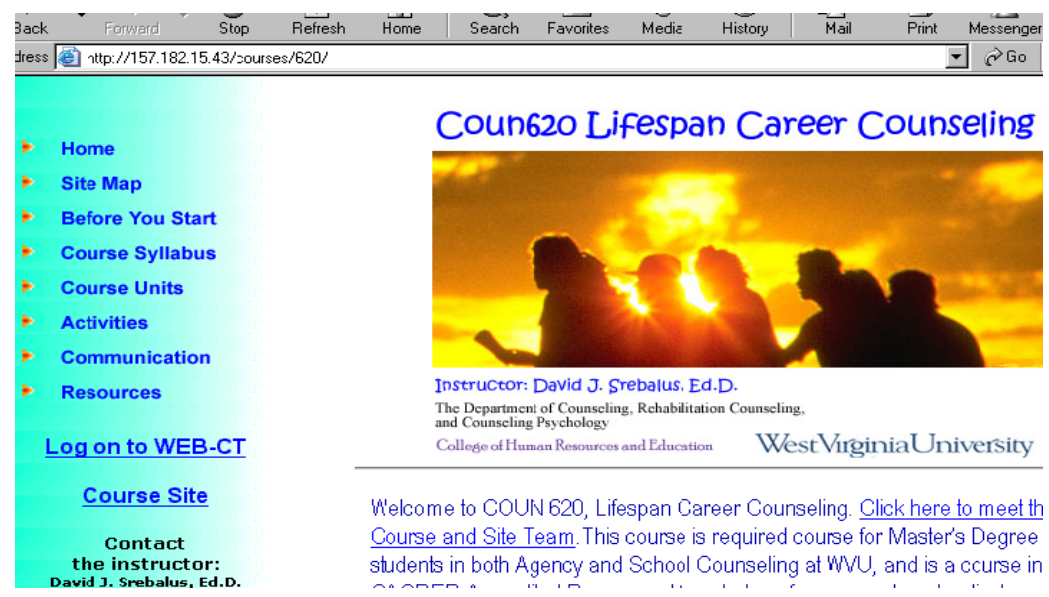

Figure 12: The Home Page of Coun 620

The layout of each page was similar to the homepage, but included an additional miniature picture of the homepage above the navigation bar (See figure 13). When users moved the cursor to the link, the text changed from blue to yellow, so they could verify their choice. For example, when users wanted to access an activity page, they would move their mouse over "Activity," and the color of "Activity" would change from blue to yellow so they would know where they were going (see figure 13).

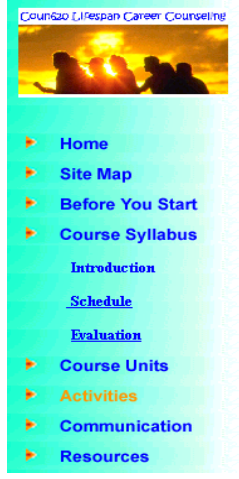

\section{Course Syllabus \\ Introduction \\ Course Objectives:}

1. To overview popular career and lifestyle development theories. See how integrate with other important life choices and changes.

2. To study decision-making and how the process applies to career plannir

3. To overview both traditional and emerging career development and care theories.

4. To study and practice effective job-seeking strategies, including placem education and recruitment programs in business and industry.

5. To be able to use the O-NET, DOT, OOH, and GOE with clients.

6. To study the relationships among work, family, and leisure.

Figure 13: An Example of the Page Layout (Syllabus Page) of the Coun 620 Website 


\section{Sixth Stage: Contents}

The contents of the course addressed career counseling in both traditional and Internetbased environments. The course was designed to help students learn about career development and counseling. Effective learning requires that students have an opportunity to construct knowledge about career guidance and counseling on their own. The contents of each page provided information to facilitate this goal.

- Before You Start: This category included "Requirements" and "Computer settings." The "Requirements" page provided course expectations, activity notations, and suggestions for taking the course. The "Computer settings" page gave information regarding minimum suggested system requirements and resources for downloading software.

- Course Syllabus: This category included "Introduction," "Schedule," and "Evaluation." The "Introduction" stated the course objectives, the text book used, and related information. The "Schedule" page provided the course schedule arranged by week, including the topics, class activities, and assignments with notations and links to handouts, PowerPoint lectures, online quizzes, etc. The "Evaluation" page explained information about assignments (options, credits, due date).

- Course Unit: Ten units of career development topics were included under this page: career development theory, career assessment, career planning systems, careers and the Internet, labor market sociology and economics, job seeking strategies, career counseling theory and practice, leisure counseling, occupational stress management and counselor burnout, and counseling for career advancement. Each page provided supplementary materials in HTML and PDF format, resources with hyperlinks, PowerPoint lectures, etc. 
- Activities: Six groups of activities were provided: career development and counseling theories, career counseling-interviewing, career assessment, career exploration $\&$ job readiness, leisure counseling, and career planning. These activities were incorporated into the pedagogical design. The main "Activities" page linked to each group of activities and the related teaching activities, student activities, and sequential assignments in the activity (See figure 6). Each activity section took from 3 to 6 hours to teach, depending on its contents. Each group of lesson pages provided detailed information about the purpose of the lesson, time one should expect to spend, procedures, activities, assignments, and evaluation. Tutorials and tools were provided to help students with assignment pages, learning outcomes, steps, time spent, credits, technologies needed, evaluation, and some links to resources (see Figure 14).
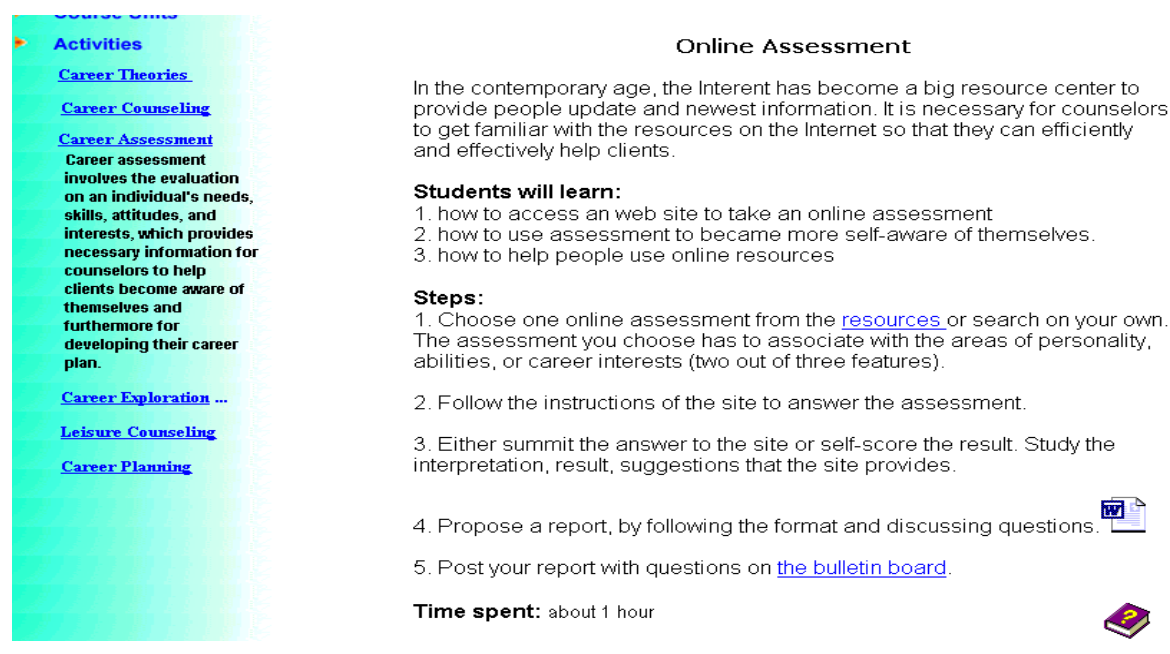

Figure 14: The "Online Assessment" Assignment Page

- Communication: This page provided links to the bulletin board and chat rooms in WebCT, which enabled students to share their learning and communicate with each other. To get into the WebCT site, students needed to provide their username and password. The WebCT page also allowed students to view their grades. Another chat 
room linked to a commercial server that did not require a username and password was also available to students for communication and sharing.

- Resources: The resources page consisted of eight types of recourses: Organizations, Self-awareness, Interviewing, Career exploration, Job readiness, Information center, Research, and Help. Over 130 web-resources with hyperlinks were provided for students to use as they worked on their course activity or assignment.

The learning theories support the contents used in this course. Lessons and activities were developed in goal-oriented, self-regulated, constructive, and collaborative directions, based on behavioral, cognitive, constructive, situated, social cognitive, or collaborative learning theories (Bandura, 1986; Brown, Collins, \& Duguid, 1989; Vygotsky, 1978; Skinner, 1953). The contents of activities and assignments in Coun 620 were based on cognitive learning theories; rich resources were provided based on situated learning theory and constructive learning theories; the online assessment followed cognitive and constructive learning theories; the career workshop project was based on collaborative, cognitive and social cognitive learning theories. The content of each group of activities was arranged in a sequence. For example, in the "Career Assessment" page, three teaching instructions, two learning activities, and four assignments were listed. A handout on "Career Assessment" was available in PDF format. Students could choose to access either the main page of career assessment, links to materials (GATB, SDS Interpretation), or assignment pages (Taking on-line assessment, Career Assessment Library). The learning theories supporting the career assessment activity involved cognitive, social cognitive, collaborative, and constructive learning theories. Technology applied in this activity included Microsoft Word and PowerPoint software, a web browser, web search tools, the bulletin board, Acrobat Reader, and web sites. 
Coun 620 provided hands-on activities in both real and virtual environments so students could 'learn by doing'. The course provided them an opportunity to develop both their traditional and virtual counseling skills. The contents were intended to help students improve their knowledge of career development and counseling, build counseling skills, and become confident in helping people in real environments. Rich resources provided on the web site allowed students to learn based on their learning styles, interests, and needs. The Internet-based technologies provided in this course helped students become familiar with their functions and feel comfortable using them as efficient counseling tools.

\section{Evaluation}

The evaluation of the Coun 620 web site involved formative evaluation on its prototype and the whole course web site, a summative evaluation of the project, and an evaluation of the pilot study.

Formative evaluation. During the design and implementation phases, we frequently checked the consistency of each page, including its appearance, navigation, and layout, the availability of links, the appropriateness of content chunks, and purposes. The most common mistakes we discovered through formative evaluation were inconsistent font type and font size, page layout spelling errors, and broken links in the navigation bar or between pages. The appropriateness of content chunks was evaluated based on the chosen features of the WBI design. We examined whether a chunk of information on a page would be overwhelming (too much information) or boring (too simple).

Formative evaluation was also conducted after the course web site was posted on the Internet. We were surprised to find that the appearance of the web site varied on different computers, even though we had carefully defined the font type, size, color, and layout of texts during implementation. We had to re-design the pages to accommodate the WBI design to 
different computers as much as possible. The speed of loading information had been one of our main concerns; we were pleased to see it was not a problem because we had not used many pictures or multimedia. For the use of CMC tools, we just ensured that the links to the WebCT page on the server of ITRC were available. The ITRC provided technical and administrative support to ensure that the bulletin board and chat rooms were available and healthy.

Summative evaluation of the prototype. Summative evaluation of the prototype was mainly conducted by the instructor, Dr. Srebalus, and an outside expert, Dr. Wells. Dr. Wells, the director of TREK 21, taught a course called "Web-based instructional design" in the program of Technology Education at WVU. The prototype focused on the performance of the course web site and three activities: Career development and counseling theories, career counselinginterviewing, and career assessment. Drs. Wells and Srebalus asked these questions: "Will it help students achieve the learning goals of the course?" "Does it encourage people to learn?" "Does it efficiently facilitate learning?" "Do its structure, features, and navigation provide a user-friendly learning environment?" They concluded that students would get more learning support with the use of this enhanced web site.

Summative evaluation of the pilot run. After finishing the development of the prototype, a web-enhanced Coun 620 was ready to deliver to students in a cohort program by April 2002. The main change was to add the prototype into the original course web site. The course units in the prototype were accessed via hyperlinks to the original course web site, while the new course web site integrated all course units as an individual category.

The cohort program, a Master's Degree in Counseling program, was held during four weekends from April 19 to May 18, 2002. It consisted of eight sessions in the classroom and four sessions on the Internet. In order to evaluate students' learning outcomes, I conducted a 
pilot study by using both qualitative and quantitative methods to evaluate the performance of the web site and the impact of the web site on learning.

Most students were satisfied with the performance (speed of interaction, stability, accessibility, and maintenance) of the course and WebCT websites. They were able to learn by taking web-based activities and exploring the Internet. However, several problems were discovered via the pilot run:

1. Some students reported that they needed more help in computer use, while some students felt satisfied with the WBI design. Developing a WBI design that worked for different levels and needs of learners was not an easy work. The WBI design of Coun 620 had to provide different levels of instruction for diverse learners, who had different background, technical skills, and experience.

2. Some students were confused by inconsistencies between the syllabus on the web and that distributed in the classroom. The syllabus provided included all sections in the classroom and on the web. However, the syllabus on the Web did not match the schedule in classroom, because the instructor had to modify the schedule because of teaching progress and chosen activities. In addition, several students indicated that they needed clearer instructions about assignment due dates because the instructor had not specified due dates for assignments.

3. Students felt frustrated by technical problems, such as slow Internet connections, broken links, trouble accessing CMC tools. This was especially true for novice computer users. Several students who used American Online (AOL) as their Internet Service Provider had trouble accessing the bulletin board and chat room on the WebCT site. In addition, they were upset and did not know what to work on when they faced a computer or Internet connection failure. Some broken links in course unit pages also caused confusion and frustration. 
4. Students were discouraged by the extra time and effort required to learn to use new technology (the web site and computer tools) in such a short period of time (four weeks). Summary of Evaluation

My WBI design model consisted of two phases and evaluation. The success or failure of a WBI design is determined by the design and implementation phases; however, evaluation is applied to ensure the efficacy of the WBI design and to supply feedback on both the design and implementation phases. Formative evaluation can take place any time in any stage of development as developers add materials (contents, images, or activities) or modify pages (appearance, layout, or links), which can influence the function or performance of other pages. Summative evaluation, which is concerned with infrastructure and use, is conducted when a developed web site is implemented; it supplies information about the function of the website when it is being used by students.

As the formative evaluation of Coun 620 focused more on the instructional design of the web site, its summative evaluation was more concerned with its effectiveness and efficiency for a specific group of learners. The process of WBI is never-ending. More revisions of the Coun 620 web site are needed, including the maintenance of links, the addition of more contents and instructions, and ensuring consistent information in learning activities and assignments. In addition, infrastructure limitations have to be considered. Perhaps a different bulletin board than that available on WebCT would prevent the unknown conflict between AOL and WebCT. It might be necessary to provide different design options (e.g. text-only) to accommodate some computers. Revision and enhancement of Coun 620 will be ongoing as students encounter different problems. 
Appendix B

\section{Computer Tools Competence - Pre Survey}

I. Demographic Information: (Please check the appropriate box)

\section{Gender:}

Age:

Ethnicity:

Main Interest in Counseling Services (check only one)

Years employed in counseling related field

Level of computer use

Have you ever taken a web-based course (section) before?

Last four digits of your Social Security Number:

Female

$18-25$

26-35

$36-45$

$>45$

African American Asian Hispanic Other:

\begin{tabular}{lcccc} 
Caucasian & African American & Asian & Hispanic & \multicolumn{2}{l}{ Other: } \\
Career development & Parenting & Relationships & Marriage & Undecided \\
Mental health & School & Drug \& alcohol & Other: & \\
None & $6-10$ & $11-15$ & $16-20$ & $>20$ \\
No experience & Beginner & Intermediate & Advanced & \\
None & Once & More than once & & \\
& & & & \\
\end{tabular}

II. Please evaluate how confident you feel using the following computer tools, BEFORE YOU STARTED THIS COURSE, by placing a check on the scale from 1 to 7.

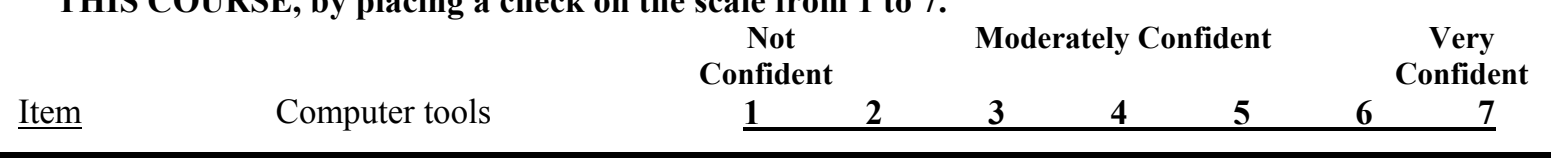

1. Microsoft Word (type, print, modify, save, etc.)

2. Web Browser (access, bookmark, retrieve information, save, etc.)

3. PowerPoint (develop slides, show, modify, save, links, etc.).

4. Electronic Mail (send, reply, forward, attach file, etc.)

5. Web-based Search Tools (keyword search, access, etc.)

6. Web-based Bulletin Board (type, post, read, reply)

7. Web-based Chat room (access, chat, send message)

8. Multimedia (download, install, play)

9. Adobe Reader (downloading, installing, print, save)

10. Listserv (subscribe, post, reply, unsubscribe)

\section{- Over-}


III. Please provide more detailed information about the frequency and purposes for your use of computer tools, BEFORE YOU STARTED THIS COURSE, by placing a check in the box.

\section{Explanation:}

\begin{tabular}{|c|c|c|}
\hline \begin{tabular}{|l} 
Frequency of use: (choose the best description) \\
- None: Never use \\
- Seldom: less than once a month \\
- Monthly: at least once a month \\
- Daily: at least once a day \\
- Frequently: a few hours a day \\
- Always: most of time a day
\end{tabular} & $\begin{array}{l}\text { Purpose for use: } \\
\text { (You may select more than } 1 \text { category.) } \\
\text { - Academic: any work related to a } \\
\text { course } \\
\text { - Social: for communication, making } \\
\text { friends } \\
\text { - Shopping } \\
\text { - Other }\end{array}$ & $\begin{array}{l}\text { Note: If you never used a } \\
\text { computer tool, please check } \\
\text { 'None' in the 'Frequency of use' } \\
\text { column and do not answer the } \\
\text { section for 'Purpose for use'. }\end{array}$ \\
\hline
\end{tabular}

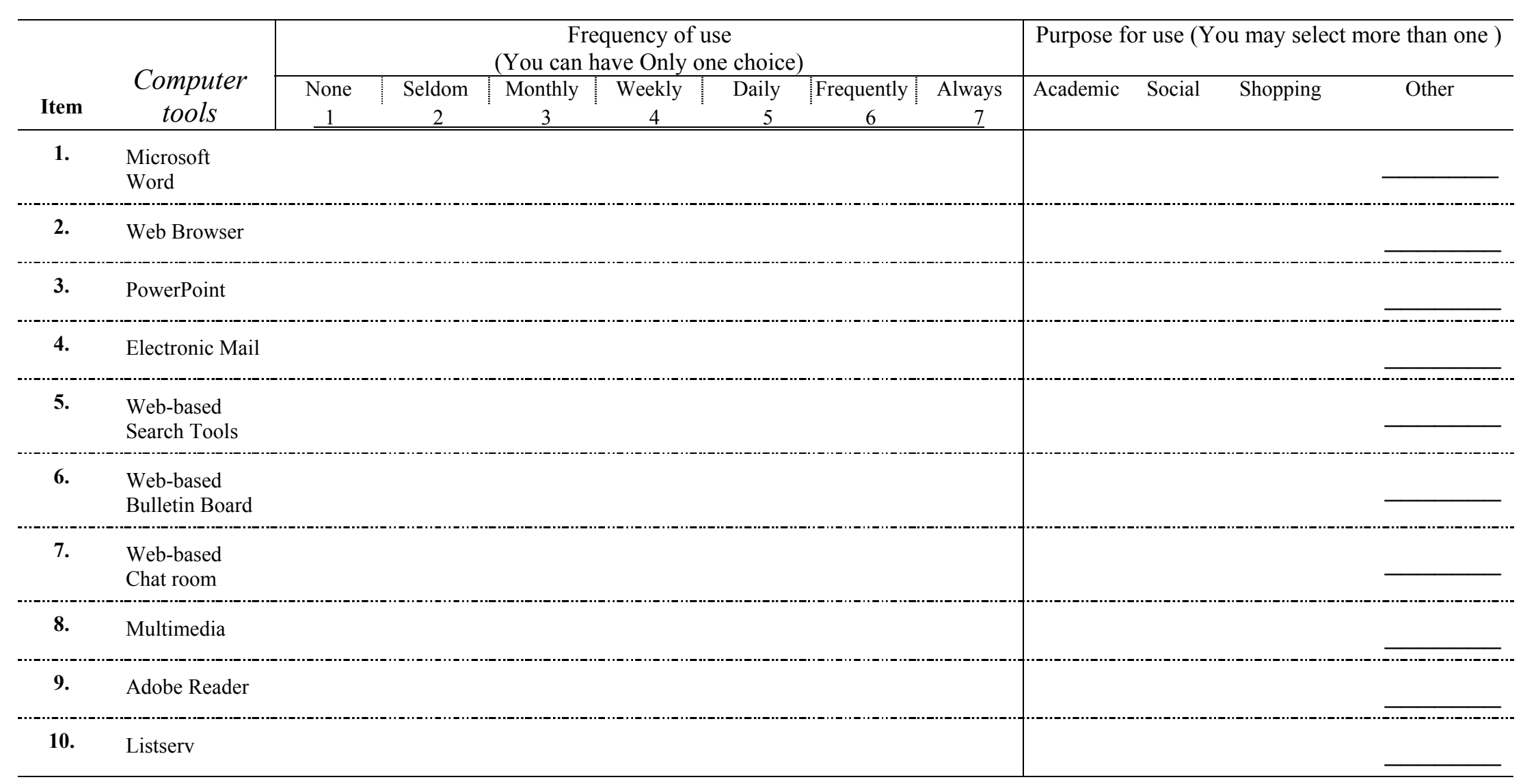

- Over - 


\section{Please answer the following question by checking the box.}

\begin{tabular}{llllll} 
Item & Learning goals of computer tools use & No & Somewhat & Very \\
Interest & Positively \\
Interest & & 1 & 2 & 3 & 4 \\
\hline
\end{tabular}

1. Do you expect to use any Internet related software, like email, browser, search tools, etc., in your development as a professional?

2. Do you expect to use computer software in your studies?

3. Do you plan to develop your ability to use computer tools?

4. Do you expect counseling services get the help from computer tools?

5. Do you plan to apply computer tools in counseling services?

\section{Please evaluate your technical competencies in the following areas, according to the technical competence developed by the Association for Counselor Education and Supervision (ACES, 1999)}

\section{Item Description of technological competency}

\section{Very Poor}

Fair

\section{3}

\section{4}

Excellent

1. Be able to use productivity software to develop web pages, presentations, letters, reports, etc.

2. Be able to use audiovisual equipment such as video recorders, audio recorders, projection equipment, and playback units.

3. Be able to subscribe, participate in, and sign off counseling-related listservs.

4. Be able to access and use counseling-related CD-ROM databases.

5. Be able to use email.

6. Be able to use computerized statistical packages.

7. Be able to use computerized testing, diagnostic, and career-decisionmaking programs with clients.

8. Be able to help clients search for various types of counseling-related information about careers, employment opportunities, education and training opportunities, financial assistance/scholarships, treatment procedures, and social and personal information.

9. Be aware of the legal and ethical codes which relate to counseling services via the Internet.

10. Understand the strengths and weaknesses of counseling services provided via the Internet.

11. Be able to use the internet for finding and using continuing education opportunities in counseling.

12. Be able to evaluate the quality of internet information 
Appendix C

\section{Computer Tools Competency -Post Survey}

Last four digits of your Social Security Number:

\section{Please self-evaluate your ability in using the following computer tools by placing a check on the} scale from 1 to 7.

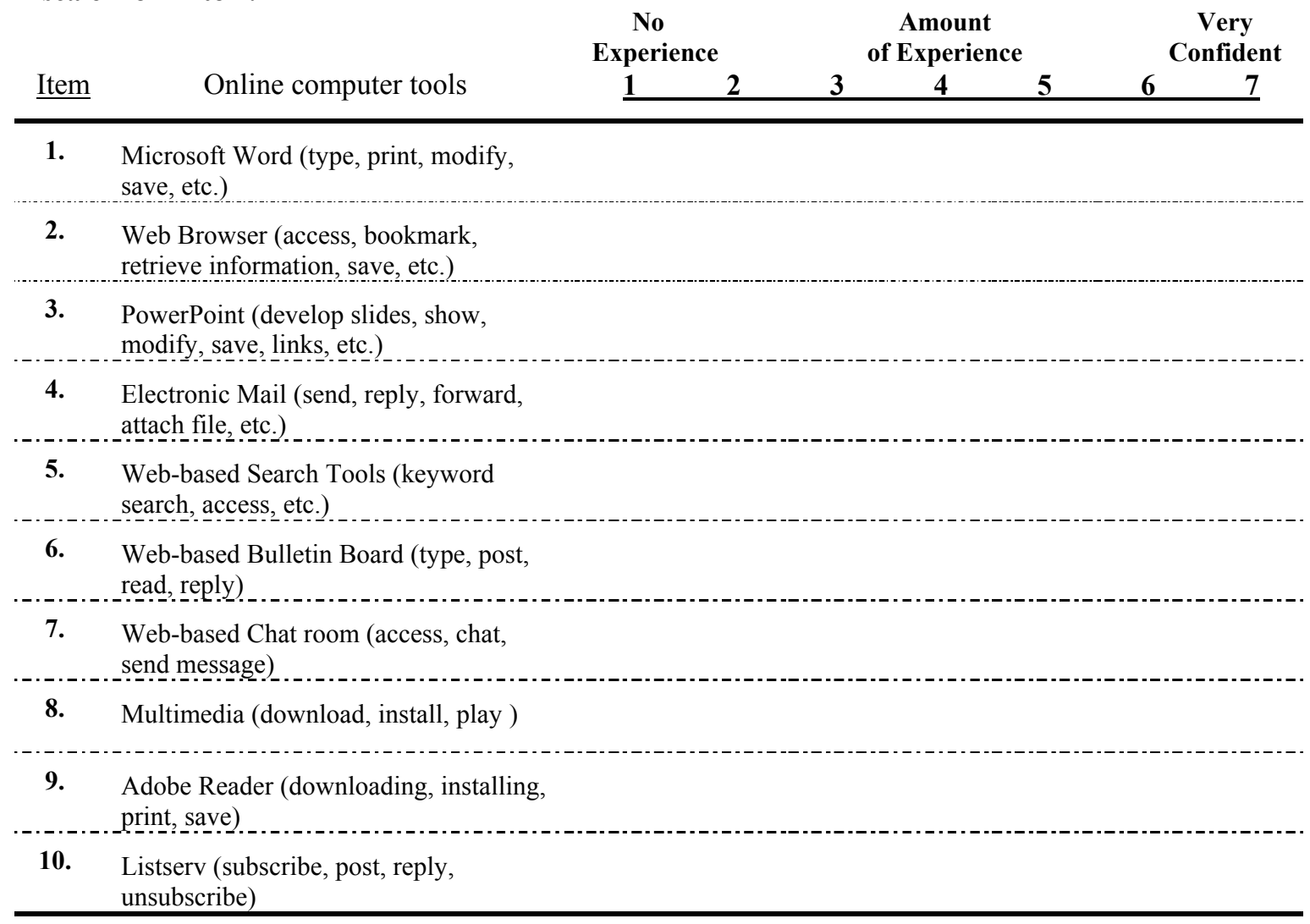

\section{Please answer the following question by checking the box.}

\begin{tabular}{lllll} 
& No & & Somewhat \\
Intem & Interest & & $\begin{array}{c}\text { Very } \\
\text { Positively }\end{array}$ \\
\hline
\end{tabular}

1. Do you expect to use any Internet related software, like email, browser, search tools, etc., in your development as a professional?

2. Do you expect to use computer software in your studies?

3. Do you plan to develop your ability to use computer tools?

4. Do you expect counseling services get the help from computer tools?

5. Do you plan to apply computer tools in counseling services?

\section{- Over -}


III. Please provide more detailed information about the frequency and purposes for your use of computer tools DURING THIS COURSE, by placing a check in the box.

\section{Explanation:}

\begin{tabular}{|c|c|c|}
\hline $\begin{array}{l}\text { Frequency of use: (choose the best description) } \\
\text { - None: Never use } \\
\text { - Seldom: less than once a month } \\
\text { - Monthly: at least once a month } \\
\text { - Weekly: at least once a week } \\
\text { - Daily: at least once a day } \\
\text { - Frequently: a few hours a day } \\
\text { - Always: most of time a day }\end{array}$ & $\begin{array}{l}\text { Purpose for use: } \\
\text { (You may select more than } 1 \text { category.) } \\
\text { - Academic: any work related to a } \\
\text { course } \\
\text { - Social: for communication, making } \\
\text { friends } \\
\text { - Shopping } \\
\text { - Other }\end{array}$ & $\begin{array}{l}\text { Note: If you never used a } \\
\text { computer tool, please check } \\
\text { 'None' in the 'Frequency of use' } \\
\text { column and do not answer the } \\
\text { section for 'Purpose for use'. }\end{array}$ \\
\hline
\end{tabular}

\begin{tabular}{|c|c|c|c|c|c|c|c|c|c|c|}
\hline \multirow{3}{*}{ Item } & \multirow{3}{*}{$\begin{array}{l}\text { Computer } \\
\text { tools }\end{array}$} & \multicolumn{7}{|c|}{$\begin{array}{c}\text { Frequency of use } \\
\text { (You can have Only one choice) }\end{array}$} & \multirow{3}{*}{\multicolumn{2}{|c|}{ 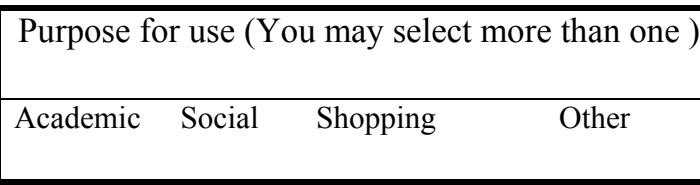 }} \\
\hline & & \multirow{2}{*}{$\begin{array}{c}\text { None } \\
\frac{1}{1} \\
\end{array}$} & \multirow{2}{*}{$\begin{array}{c}\text { Seldom } \\
2 \\
\end{array}$} & \multirow{2}{*}{$\begin{array}{c}\text { Monthly } \\
\text { M } \\
\end{array}$} & \multirow{2}{*}{$\begin{array}{c}\text { Weekly } \\
4 \\
\end{array}$} & \multirow{2}{*}{$\begin{array}{r}\text { Daily } \\
5 \\
\end{array}$} & \multirow{2}{*}{\multicolumn{2}{|c|}{\begin{tabular}{c|c} 
Frequently & Always \\
6 & 7 \\
\end{tabular}}} & & \\
\hline & & & & & & & & & & \\
\hline 1. & $\begin{array}{l}\text { Microsoft } \\
\text { Word }\end{array}$ & & & & & & & & & \\
\hline 2. & Web Browser & & & & & & & & & \\
\hline 3. & PowerPoint & & & & & & & & & \\
\hline 4. & Electronic Mail & & & & & & & & & \\
\hline 5. & $\begin{array}{l}\text { Web-based } \\
\text { Search Tools }\end{array}$ & & & & & & & & & \\
\hline 6. & $\begin{array}{l}\text { Web-based } \\
\text { Bulletin Board }\end{array}$ & & & & & & & & & \\
\hline 7. & $\begin{array}{l}\text { Web-based } \\
\text { Chat room }\end{array}$ & & & & & & & & & \\
\hline 8. & Multimedia & & & & & & & & & \\
\hline 9. & Adobe Reader & & & & & & & & & \\
\hline 10. & Listserv & & & & & & & & & \\
\hline
\end{tabular}


IV. Please evaluate your technical competencies in the following areas, according to the technical competence developed by the Association for Counselor Education and Supervision (ACES, 1999).

\begin{tabular}{|c|c|c|c|c|c|c|}
\hline & & Very Poor & & & & Excellent \\
\hline Item & Description of technological competency & 1 & 2 & 3 & 4 & 5 \\
\hline
\end{tabular}

1. Be able to use productivity software to develop web pages, presentations, letters, reports, etc.

2. Be able to use audiovisual equipment such as video recorders, audio recorders, projection equipment, and playback units.

3. Be able to subscribe, participate in, and sign off counseling-related listservs.

4. Be able to access and use counseling-related CD-ROM databases.

5. Be able to use email.

6. Be able to use computerized statistical packages.

7. Be able to use computerized testing, diagnostic, and career-decisionmaking programs with clients.

8. Be able to help clients search for various types of counseling-related information about careers, employment opportunities, education and training opportunities, financial assistance/scholarships, treatment procedures, and social and personal information.

9. Be aware of the legal and ethical codes which relate to counseling services via the Internet.

10. Understand the strengths and weaknesses of counseling services provided via the Internet.

11. Be able to use the internet for finding and using continuing education opportunities in counseling.

12. Be able to evaluate the quality of internet information

\section{Please feel free to provide your experiences in using online computer tools in this course.}

1. Please describe the impact for you to use computer tools offered in this course. 
2. Describe your motivation to use computer tools in this course. Please describe what motivated your use.

3. Please compare your ability to use computer tools before and after this course.

4. Please use this space to make comments or suggestions about either the course or this survey.

Thank You 
Appendix D

\section{Evaluation of Emotion Level}

Your last four digits of Social Security Numbers:

Purpose: This survey is to evaluate your feelings regarding the use of computer tools throughout this course.

\begin{tabular}{|c|c|c|c|c|c|c|c|}
\hline \multirow[b]{2}{*}{$\underline{\text { Item }}$} & Not & & \multicolumn{2}{|c|}{ Sometimes } & & \multicolumn{2}{|c|}{ All the time } \\
\hline & 1 & 2 & 3 & 4 & 5 & 6 & 7 \\
\hline
\end{tabular}

(1) I felt anxious using them.

(2) I felt satisfied using them.

(3) I felt stressed using them.

(4) I felt happy using them.

(5) I felt worried using them.

(6) I felt I was creative when I used them.

(7) I felt concentrated using them.

(8) I felt alone when I used them.

(9) I felt pleased using them.

(10) I felt confused when I used them.

(11) I felt bored using them.

(12) I felt confident of using them.

(13) I felt uncertain when I used them.

(14) I was interested in using them.

(15) Overall, I felt __ when I used them. 
Last four digits of Social Security Number:

Demographic Information:

\begin{tabular}{llll}
\hline Student Status: & Full time student & Part time student & \\
\hline Job status: & Full time job & Part time job & None \\
\hline
\end{tabular}

\section{Please rate the performance of the COUN 620 web site}

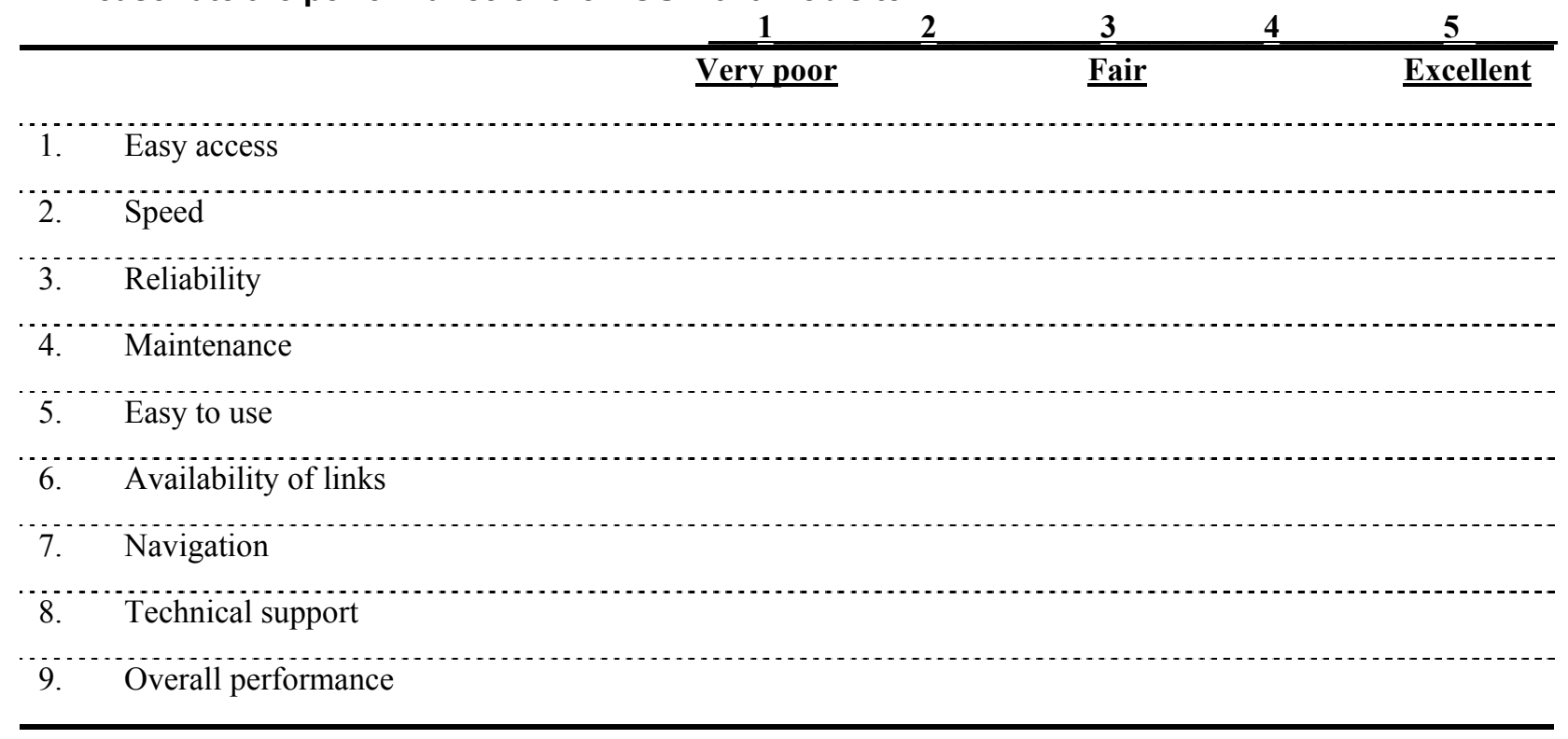

II. Please rate the following in terms of their contribution to your learning satisfaction

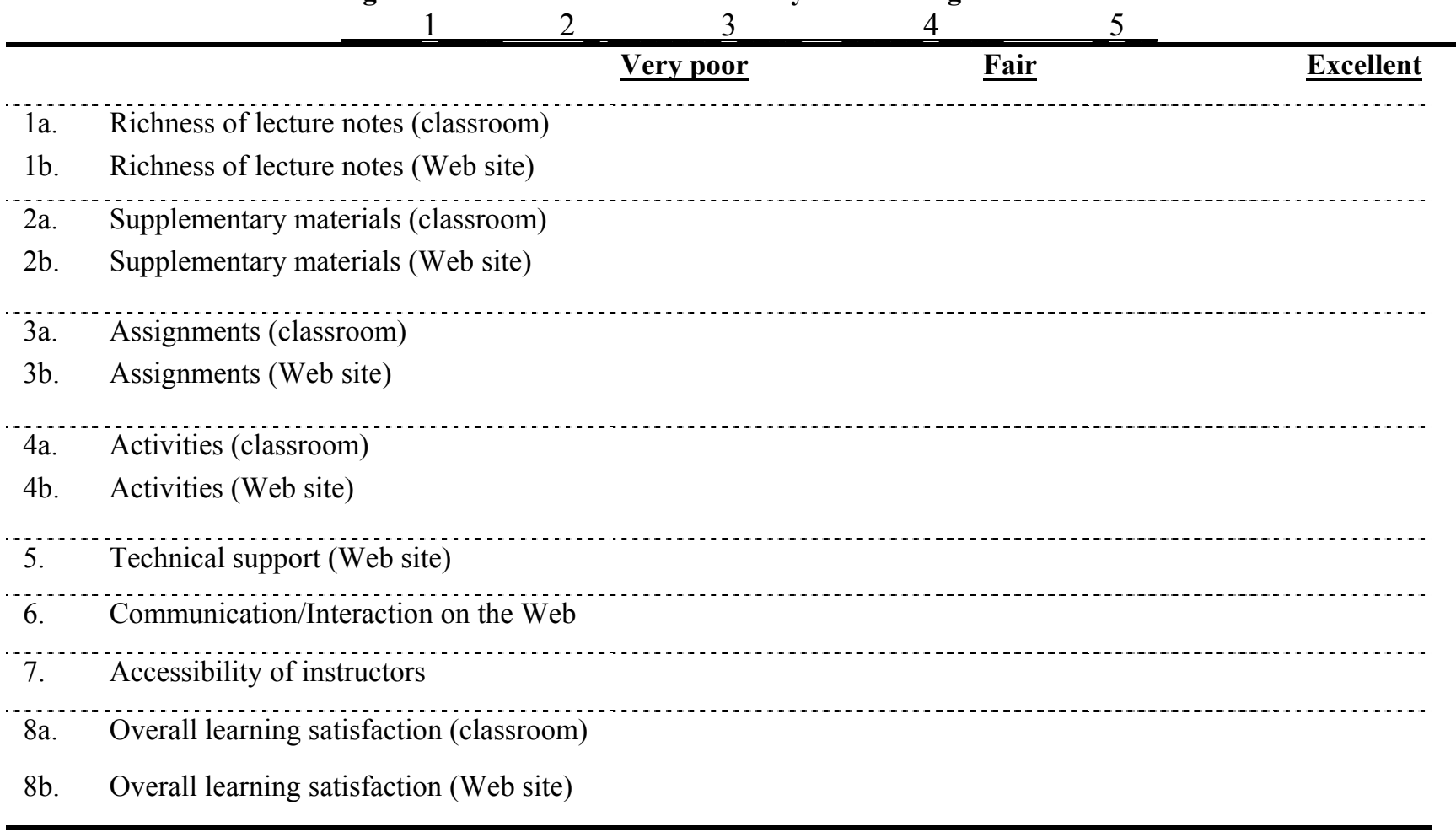


III. Please indicate how the following affected your learning experience in Coun 620 .

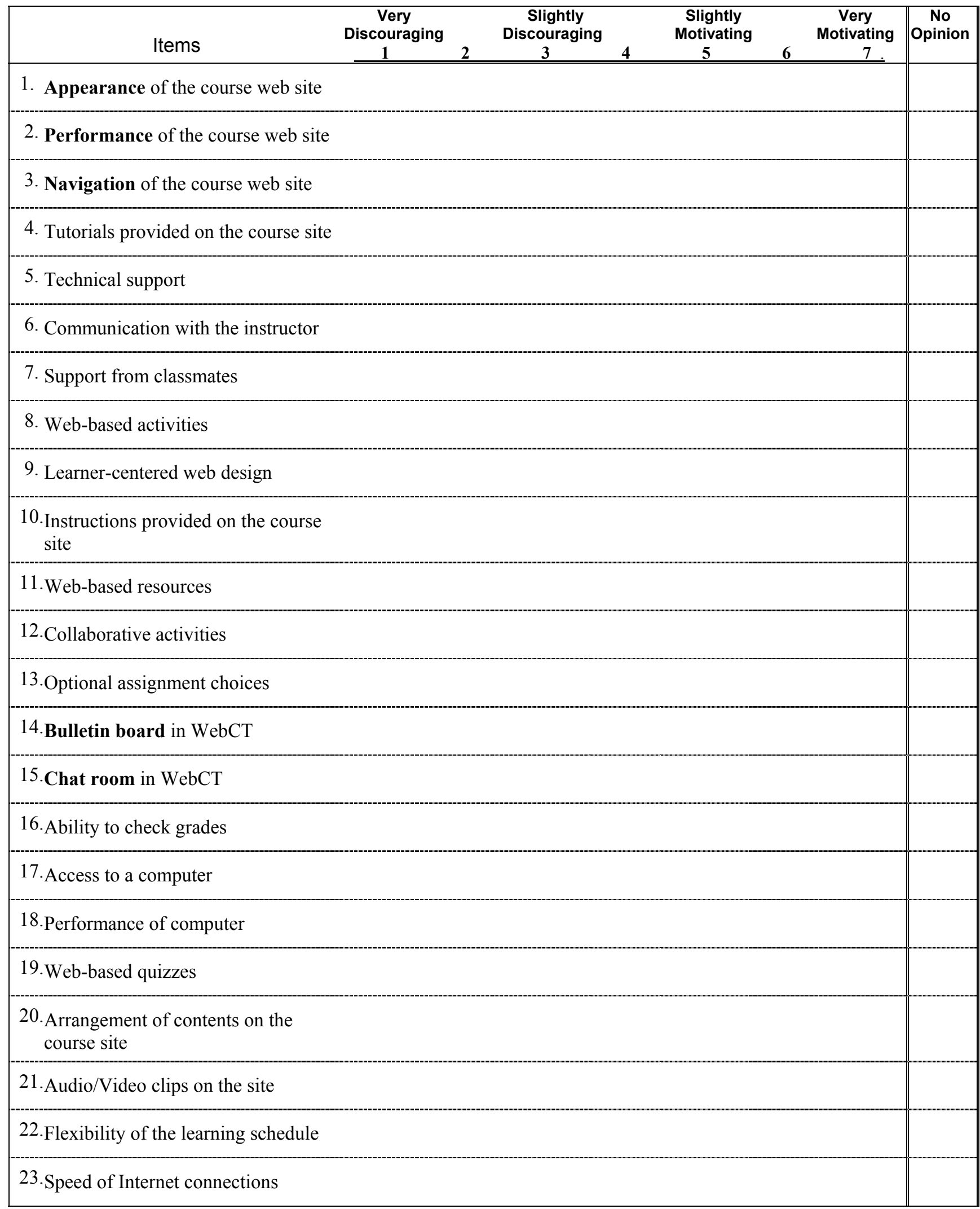




\section{Please provide your feedback by answering the following:}

1a. We are interested in whether taking this course motivated you to learn to use computer tools. Please indicate whether you were discouraged or motivated to use the following computer tools. If you feel there was no change in your use of the computer tool, please check "no opinion."

\begin{tabular}{l}
\multicolumn{1}{c}{ Items } \\
\hline 1. Microsoft Word \\
2. Web browser \\
3. PowerPoint \\
4. Electronic mail \\
5. Web-based search tools \\
6. Web-based bulletin board \\
7. Web-based chat room \\
8. Audio/Video player \\
9. Adobe Reader \\
10. Listserv \\
11.
\end{tabular}

1b. Please check all statements which are true for you:

\begin{tabular}{|c|c|}
\hline I was motivated to use computer tools because... & $\begin{array}{l}\text { I was discouraged from using computer tools } \\
\text { because... }\end{array}$ \\
\hline I practiced using them via web-based activities. & I didn't get enough technical support \\
\hline $\begin{array}{l}\text { the web site provided clear goal-directed } \\
\text { instructions. }\end{array}$ & I didn't need them. \\
\hline $\begin{array}{l}\text { the course provided plenty of supplementary } \\
\text { materials. }\end{array}$ & the Internet connection was slow. \\
\hline I felt confident using them. & it was hard to find a computer available \\
\hline I got support from tutorials provided on the web site. & $\begin{array}{l}\text { the quality of electronic communication is not } \\
\text { as good as face-to-face }\end{array}$ \\
\hline it was convenient to communicate with others. & the course workload was too heavy. \\
\hline I was in charge of my learning. & the performance of the website was poor. \\
\hline computer tools were easy to use. & the computer tools were not easy to use. \\
\hline it will be helpful for my professional development. & using the Internet is too time-consuming \\
\hline
\end{tabular}


2a. Did the design of the Coun 620 web site enhance your learning? $\quad \underline{\text { Yes, }}, \underline{\text { Noo, }} \quad$ No opinion 2b. Please discuss your answer.

3a. How often did you use the WebCT site in this course? times/week

3b. How often did you use the Coun 620 web site? times/week

3c. What did you use them for?

4a. Will you continue to use computer tools in the future? Yes, №, $\underline{\text { Undecided }}$

4b. If you answered 'Yes,' Please discuss how you plan to use computer tools in the future (e.g. in daily life, work place, or study).

5. Did you spend more time on this course than most other courses? $\underline{\text { Yes, }} \underline{\text { Noo, }} \quad \underline{\text { Undecided }}$ Please explain why.

6. Please provide any suggestions for improving the web-based instructional design of this course. 


\section{Curriculum Vita}

\section{Ying-Ying Kuo}

\section{HIGHLIGHTS OF QULIFICATIONS}

- Self-motivated, creative and intuitive problem solver

- Capable of both quantitative and qualitative methods of research

- $\quad$ Accustomed to work independently and collaboratively and handle multiple projects simultaneously

- $\quad$ Proficient in web-based instructional design, computer software, questionnaire design, and statistical evaluation

\section{SUMMARY OF SKILLS}

- Research design

- Survey development

- Interpersonal communication
- Data collection and analysis

- Web page development

- Database design and management
- Computer Skills

- Web-based instructional design

- Project management

\section{EDUCATIONAL BACKGROUND}

Technology Education (August, 1999 - May, 2003), West Virginia University, WV

Degree: Ed.D., Major: Technology Education , Minor: Counseling

Dissertation: Assessment of Students' Motivation to use Computer Tools in a Web-enhanced Counseling Course

Counseling (September, 1995 - May, 1998), University of Alabama at Birmingham, AL

Degree: M.A., Counseling

Intern: provided services for Chinese community in Birmingham, AL

Industrial Engineering (September, 1981 - June, 1983), National Tsing Hua Univ., Taiwan, ROC

\section{Degree: M. S., Major: Operation Research}

Thesis: Resources Allocation on the Higher Education with Multi-level Programming

Industrial Engineering (September, 1976 - June, 1980), National Tsing Hua Univ., Taiwan, $\mathrm{ROC}$

\section{Degree: B. S., Major: Manufacturing/Time study}




\section{WORK HISTORY}

- Graduate Assistant (July 2001 - Present), Teaching and Learning Technologies Center, College of Human Resources and Education, West Virginia University, Morgantown, WV

- Volunteer (June 1998 - January 1999), Employee Assistance Service (EAS), Birmingham, AL

- Volunteer (September 1998 - December 1998), Amelia Center, Birmingham, AL

- Counseling Internship (September 1997 - April 1998), Student Counseling Center, School of Education, University of Alabama at Birmingham, AL

- Reliability \& Quality Assurance Engineer (October 1985 - June 1993), Section of Quality Assurance Planning, Quality Assurance Center, Chung Shan Institute of Science \& Technology (CSIST), Taiwan, ROC

- Planning Specialist (August 1983 - September 1985), Planning Section of the Administration at Science Based Industrial Park (SBIP), Science Based Industrial Park, Taiwan, ROC

- Industrial Engineer (July 1980 - June 1981), Industrial Engineering Section of the TV Plant, General Instrument of Taiwan Limited, Taiwan, ROC

\section{PUBLICATIONS}

Kuo, Y. Y. (2003). Assessment of Students' Motivation to Use Computer Tools in a Web-Enhanced Counseling Course. Unpublished dissertation. Morgantown, WV: West Virginia University.

Pedersen, P., Ivey, A.E., Ivey, M.B., \& Kuo, Y.Y. (July, 2000). Instructors Manual for Intentional Group Counseling: A Microskills approach, Belmont, CA: Brooks/Cole.

Kuo, Y. Y. (1983). Resources Allocation in Higher Education with Multi-level Programming. Thesis. Taiwan, ROC: National Tsing Hua University.

Kuo, Y. Y. (1998). Living in Birmingham: A Resource Book for Chinese Newcomers (in Chinese). Birmingham, AL: Chinese Scholars and Students Association. 


\section{RESEARCH PROJECTS AT WEST VIRGINIA UNIVERSITY}

- April 2003. Assessment of students' motivation to use computers tools in a webenhanced counseling course (Amendment). Investigation of motivation and learners' characteristics in a web-based environment.

- April 2003. Validation of Learning Traits Questionnaire. Data collection via web-surveys

- November 2002. Validity and reliability of Learning Traits Questionnaire. Data collection in paper-and pencil surveys.

- August 2002. Assessment of students' motivation to use computers tools in a webenhanced counseling course. Investigation of motivation and learning experiences in a webbased environment. (Dissertation)

- April 2002. The effect on achievement and learning satisfaction when students are motivated to use communicative mediated communication (CMC) tools.

Investigation of learning and web-based instructional design features.

- April 2001. Learning on the Web: The relationship of learning traits and course delivery. Investigation of learning satisfaction in a fully web-based course.

- September 2000. The impact of taking a virtual class. Exploration of the roles of students and teachers in a fully web-based course.

\section{WEB PAGE DEVELOPMENT}

- Maintenance of the Technology Integration Center, TLTC (January, 2002 - Present) URL: http://www.hre.wvu.edu/ tltcl Rresponsible to maintain and update the information weekly, which included revising room schedules, creating forms, and links.

- Coun 620: Lifespan Career Counseling (September, 2001 - Present) URL: http://157.182.15.43/courses/620/ I acted as an instructional developer for this web-enhanced course.

- Intentional group counseling (August, 2000 - January, 2001) URL: http://norm.dpo.uab.edu/ youngsh/ It was a project of a course, Instructional Design. I developed this site as if it was a web-based supplement for a counseling course, which used Intentional Group Counseling as a textbook.

- Dr. Pedersen's homepage revision \& maintenance (September, 1998 - October, 2001) URL: http://www.ed.uab.edu/ppedersen/ ; http://soeweb.syr.edu/chs/pedersen/

- Chinese Counseling Services (November, 1997- September, 1998) URL: http://www.dpo.uab.edu/ yingkuo/ The web site introduced counseling concepts, knowledge and services for the Chinese when I was intern student at UAB. 